\title{
Lieder und Liederzyklen
}

\author{
Eine Passage
}

Die Lieder und Liederzyklen sind die Hauptgattung der musikalischen WalserRezeption. Sie werden hier in chronologischer Abfolge kommentiert, sofern sie nicht schon in den anderen Kapiteln behandelt wurden. Nach Möglichkeit wurde für jedes Werk und jede Werkgruppe eine eigene Herangehensweise gewählt, um eine katalogartige Darstellungsweise zu vermeiden. Im Gesamten ergibt sich eine kleine Geschichte der musikalischen Walser-Rezeption.

\subsection{Einleitung}

Ursprünglich war vorgesehen, die knapp 300 auf Texte von Robert Walser entstandenen Lieder nach Besetzung, ästhetischer Ausrichtung und geografischer Herkunft der Komponistinnen und Komponisten zu gliedern. Darauf wurde schließlich verzichtet, obwohl eine Einordnung in übergreifenden Typologien, wie sie Martin Zenck im Falle der Paul-Celan-Vertonungen mit zehn Kategorien vorgenommen hat, auch anregend gewesen wäre. ${ }^{1}$ Der Bestand der WalserLieder ist allerdings dermaßen bunt, inhomogen und disparat, dass bereits die Frage, wie ein Werk einzuordnen wäre, schwierig zu beantworten ist. Zudem birgt eine solche Kategorisierung auch die Gefahr, die spezifischen Qualitäten eines Werks zu übersehen. Für diese in der Walser-Forschung erstmalige Darstellung des Repertoires wurde deshalb in der Regel der chronologische Ansatz gewählt, wobei den frühen, noch während Walsers Lebzeiten komponierten Liedern die Kapitel 1 und 2 dieses Buches gewidmet sind. Mehrere Werke der gleichen Person werden in der Regel zusammen behandelt, um ein Gesamtbild zu ermöglichen und die Darstellung übersichtlich zu halten. Dabei ist jeweils die erste Walser-Komposition für die chronologische Position entscheidend.

In diesem Kapitel tauchen besonders viele Namen auf, die kaum bekannt sind oder deren musikalische Beschäftigung mit Walser überrascht. Wer würde zum Beispiel vermuten, dass Frank Bodin (*1962) Robert Walser vertont hätte? Bodin, heute mit Preisen überhäuft, gefragter Gast auf roten Teppichen und seit

1 Vgl. Zenck: Musikalische Rezeption, S. 405. 
drei Jahrzehnten ein ständiger Innovator der Werbe- und Kommunikationsbranche, komponierte mit 23 Jahren drei Klavierlieder auf Mikrogramm-Texte. Bodin hatte die Nase schon damals im Wind, denn er ist der erste, der kurze Zeit nach der Veröffentlichung der beiden ersten Bände Aus dem Bleistiftgebiet im Frühjahr 1985 auf diese Mikrogramme reagierte und drei Lieder komponierte, in denen Walsers Texte klar im Vordergrund stehen: Unter Verzicht auf alles Illustrative orientiert sich der Gesang an der deklamierenden Sprechstimme, meist im engen Ambitus einer Quinte. Das Klavier begleitet mit ostinaten Laufbewegungen und Akkordbrechungen durchaus unprätentiös und belebt die Deklamation subtil mit dissonierenden Zwischentönen.

Bodin ist nur einer von vielen, die sich in ihren kompositorischen Anfängen mit Walser beschäftigten und später andere Wege einschlugen. Für einige war die Auseinandersetzung mit Walser auch eine Form der Befreiung und zugleich ein Anstoß für Neues. So bemerkte der in Indien geborene, in Deutschland aufgewachsene und heute als Komponist und Forscher an der Concordia University in Montreal lehrende Sandeep Bhagwati ( $\left.{ }^{*} 1963\right)$ zu seiner Serenade (1986) für Sopran und Streichtrio nach Walser und zur Cellosonate (1990), deren dritter Satz ein »Walzer für Walser« ist:

Beides sind Jugendwerke, die ich so ohne weiteres heute vielleicht nicht mehr
aufführen lassen würde. Aber ich weiss, dass Walser damals extrem wichtig
für mich war, um in einem kompositorisch-ästhetischen Umfeld, das sich in
einer immer langweiliger werdenden post-avantgardistischen Epigonalität
festzufahren drohte, neue Luft zum Atmen zu bekommen. Mich interessierte
nicht - wie andere Komponisten - seine Psychologie, sondern geradezu seine
anti-psychologischen Aspekte: Höflichkeit ohne Dank und Gegenliebe, die
unironische Unterstellung guter Absichten gegen alle Evidenz, die lockere
Spaziergangs-Form ohne formalen Legitimationszwang, die freundliche aber
bestimmte Nicht-Anerkennung banaler Denk- und Gefühls-Klischees und der
grossen hohlen Worte der Moderne (Extreme! Wahnsinn! Demaskierung! Sub-
version! Avantgarde! Rebellion! Neurasthenie! Effizienz! Kohärenz! etc). Mich
reizte die Doppelbödigkeit, die im Harmlosen und Hübschen nicht Abgründe
des Bösen entlarvte, sondern darin schlicht Unbestimmtheit und Absichts-
losigkeit sah. All das baute mich damals sehr auf - und meine beiden Stücke
waren wohl eher unbeholfene Danksagungen für diesen Freiraum von Walser als
wirklich ihm gerecht werdende Musik. ${ }^{2}$

Dieser von Bhagwati formulierte Aufstand gegen die »post-avantgardistisch[e] Epigonalität« lässt sich in vielen Walser-Liedern beobachten. Stilgebundene Vertonungen sind eine Seltenheit, ganz egal ob es sich um klassische

2 E-Mail von Sandeep Bhagwati an Roman Brotbeck vom 12.10.2016 und o7.11.2020. 
Avantgarde, Neoklassik, Neoromantik, Minimal Music, traditionellen Jazz, Folk oder Rock handelt, so als wäre Walsers Schreiben einfach nicht beizukommen mit Musikstilen, die zu ernst genommen werden und keine selbstironische Position einnehmen können. Einige stilistisch gebundene Kompositionen seien hier kurz erwähnt; letztlich entziehen auch sie sich mehr oder weniger stark der Stilistik, der sie verpflichtet sind.

Selbst ein Komponist wie der ehemalige dramatische Tenor Gary Bachlund ( $\left.{ }^{*} 1948\right)$, der in einer traditionellen tonalen Musiksprache komponiert, wählte bei der Vertonung von Overly philosophic (2012), der englischen Version von Walsers Gedicht Zu philosophisch (SW 13, 23), eine oktophone Skala, bei der sich Halb- und Ganztöne abwechseln, was eine auffällige Verfremdung der Diatonik bewirkt und harmonisch entfernt an Wagners Chromatik erinnert. ${ }^{3}$

Ein weiteres Beispiel für eine stilgebundene Walser-Vertonung findet man beim Genfer Musiker, Chansonier und Performer Christophe Balleys (alias Jerrycan), der Walser ungebrochen in die Ästhetik des französischen Chansons einbrachte. 2009 schuf er zu Aus Rücksicht (SW 13, 215) bzw. französisch Par égard ${ }^{4}$ ein feinfühliges Chanson, nuancenreich instrumentiert und poetisch. Die beklemmende Ironie, mit der Walser im 1929 publizierten Gedicht seine Jugendlichkeit beschreibt (»Aus Rücksicht auf das Weltgemüt / hielt ich das Altern für verfrüht. [...] Ich gab mich jung und blieb es«), wird in Balleys Vertonung besänftigt. Zudem lässt er den Schluss des Gedichts weg, bei dem das lyrische Ich verschwindet und mit einer schiefen, an Wilhelm Busch erinnernden Sentenz ersetzt wird (»Gewiß ist der, der liebt, ein Tor, / doch geht hieraus etwas hervor «). Auch noch in der gemäßigteren französischen Fassung (»Fou bien sur, qui ose / aimer, mais il en sort toujours quelque chose «) hätte dieser Schluss den das lyrische Ich singenden und repräsentierenden Balleys in einen kommentierenden Modus gezwungen, der die wehmütig-sentimentale Stimmung des Chansons irritiert hätte. 2013 komponierte Balleys noch ein

3 Gary Bachlund nahm als Vorlage eine Übersetzung von Bertram Kottmann ( ${ }^{*} 1947$ ), der seine Texte und Übersetzungen online veröffentlicht, so auch die Übersetzung von Robert Walsers Gedicht Zu philosophisch (SW 13, 23), vgl. Kottmann: Overly philosophic. Auch Gary Bachlund stellt seine Kompositionen frei zur Verfügung, vgl. Bachlund: Overly philosophic. Der Komponist verliert dadurch die Kontrolle über die Rezeption und weiß nicht, ob seine Walser-Vertonung bisher aufgeführt wurde: »Placing them online, for the most part as free to download, I rarely hear from people who later I learn have performed something of mine. Nor have I had concern about this, for my >business model is no business model at all. [...] Therefore I cannot tell you whether this setting of Bertram's translation has been performed or not.« E-Mail von Gary Bachlund an Roman Brotbeck vom 30.11.2020.

4

Walser: l'écriture miniature, S. 5 . 
zweites Chanson, in dem er ein Satzfragment aus Walsers Prosastück Neueste Nachricht verwendet:

[D]a bin ich wieder der, der ich von jeher war, und bin glücklich und mache allerlei nette kleine Bekanntschaften, gehöre der Welt, wie auch sie mir gehört, und die Welt ist weit, und mein Herz ist's auch, obschon es gar nicht mehr so jung ist. (SW 17, 7 f.)

Daraus bildet Balleys den Refrain des Chansons »J'appartiens au monde / Et le monde m'appartient «, der dann als Ausgangspunkt zu selbst verfassten Versen wie »Il [le monde] entre tous les étés / Et de tous les côtés « dient. ${ }^{5}$ Balleys Chansons sind stark an die Kunstfigur und das Pseudonym von Jerrycan gebunden und wohl auch nur von ihm selbst interpretierbar.

Dies verhält sich beim Tübinger Singer-Songwriter Bernhard Mohl ( $\left.{ }^{*} 1962\right)$ ähnlich. Er interpretiert Walser in der Liedermacher-Tradition eines Wolf Biermann, Mani Matter oder Reinhard Mey und reduziert seine einfachen Strophenlieder auf die Hauptharmonien. Oft schreibt Mohl die Lieder gar nicht auf Papier: »Sobald ich das Gefühl habe, >jetzt stimmt's!<, erstelle ich - als Erinnerungshilfe - eine Aufnahme mit dem Handy. «6 Auch bei Der Schnee (SW 13, 147) geht Mohl vom poetischen Hauptgerüst des Gedichts aus und komponiert es als Strophenlied. In der Liedermacher-Tradition spielt er mit den >Unpässlichkeiten<, die entstehen, wenn die Diktion des Gedichts nicht zur stur durchgehaltenen Struktur des Strophenlieds passt. Zu dieser Liedermacher-Tradition gehört ebenfalls, dass Mohl seine Lieder mit einer als Pointe gesetzten Schlusskadenz beendet.

Ebenfalls in die Singer-Songwriter-Haltung begibt sich bei seiner WalserVertonung Ernst Huber ( $\left.{ }^{*} 1957\right)$, der führende Sänger der 1982 gegründeten österreichischen Band Broadlahn (steiermärkisch für >breite Lawine<), die Volksmusik, Jazz und Weltmusik mit sehr viel Steiermärkischem vereinigt. Huber übersetzte die letzte Strophe des Gedichtes Im Bureau (SW 13, 7) ins Steiermärkische. Wenn man den Text liest, ${ }^{7}$ versteht man ihn; wenn Ernst Huber ihn aber auf dem Album Am Rand der Welt singt, wird Walser für >Außer-Steiermärkische< zur reinen Sprachmusik. ${ }^{8}$ Die Band schweigt bei

5 Vgl. Jerrycan: Vaste Monde.

6 Vgl. E-Mail von Bernhard Mohl an Roman Brotbeck vom 15.11.2020.

7 »Da Mond is die Wundn von da Nåcht / Bluatstropfn san ålle Stern / ob i dem blühenden Glück a fern / i bin dafür bescheidn gmåcht //: da Mond is die Wundn von da Nåcht ://«. Broadlahn: $\underline{\text { Da Mond. }}$.

8 Vgl. Broadlahn: Vom Rand der Welt (2007). 
diesem Lied, das Huber - nur von der Gitarre begleitet - in einfachem Sprechgesang vorträgt.

2013 widmete sich auch der in Montreal geborene Genfer Musiker Alain Croubalian (1964-2021), Kopf der legendären Rock'n'Roll-, Folk- und Bluesband The Dead Brothers, Robert Walser mit der Vertonung des Gedichtes Angst (I) (SW 13, 15f.).

Interessanterweise habe ich den Text von Robert Walser, den ich schon immer schätzte, aber nie mit meinen Tätigkeiten in der Musikbranche bzw. der Rock'n'roll-Welt zusammengebracht hatte, in Deutschland entdeckt. Es ist die Dramaturgin Judith Gerstenberg, die mich nach Hannover geholt und das Gedicht für mich ausgesucht hat. Für das Wirtshaus im Spessart sollte ich der Erzähler sein und die Musik komponieren. Angst ist so eine Kabarett-artige

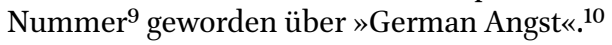

Angst erschien 2018 auf dem gleichnamigen Album der Dead Brothers. Dieses Album - und insbesondere der Song Angst - sprengt so ziemlich alle GenreGrenzen. Im Walser-Lied klingt deutlich Klezmer-Musik ${ }^{11}$ an, die sich zum Schluss in einen rasenden, abgründig verschepperten Totentanz steigert. Nach einer ersten Version für Gesang, Banjo und Schlagzeug für das Hannoveraner Schauspiel erweiterte Croubalian die Instrumentalbegleitung mit zumindest in der traditionellen Rockmusik exotischen Instrumenten wie Violine, Emmentaler Halszither, Helikon und Pauke. ${ }^{12}$ Auch Alain Croubalian beweist, was in diesem Kapitel zu sehr unterschiedlichen Walser-Liedern oft zu beobachten ist: Wer den »auf den Rändern «13 tanzenden Walser vertonen will, wird von ihm geradezu gezwungen, stilistische Zäune zu überspringen und zuweilen auch einzureissen.

9 Wegen des kabarettistisch angelegten Konzepts wurde auch der Text minimal verändert: »sie fuhren los auf mich« statt »sie kämen auf mich los«, und »Ich möchte« wird durchwegs mit »Ich wünschte« ersetzt.

10 E-Mail von Alain Croubalian an Roman Brotbeck vom 28.12.2020.

11 Das jiddische Arrangement geht auf den Kontext der Hannoveraner Produktion zurück, in der die Ängste der deutschen Seele thematisiert wurden, zu denen auch das Judentum gehört. Vgl. Beyer: Premiere: »Das Wirtshaus im Spessart« sowie Kohlmann: Eine Höhle der Angst.

12 Diese Version brachten die Dead Brothers am 14. September 2013 im legendären Musiklokal Китайский летчик Джао Да (Chinesischer Pilot Jao Da) in Moskau zur Uraufführung.

13 Vgl. Utz: Tanz auf den Rändern. 


\subsection{Anna Renfer: 44 Lieder für Singstimme mit Klavierbegleitung (ohne Jahreszahl)}

Nur wenige Spuren haben sich von Anna Renfer ${ }^{14}$ erhalten: Partituren mit geistlicher oder religiös beeinflusster Musik, ein Streichquartett, Klavierstudien für die linke Hand op. 37 und die Sammlung von 44 Liedern, in denen sich die Vertonung von Walsers Langezeit (SW 13, 7f.) befindet, dazu eine Vertonung des Gedichtes Unser Weg von Carl Seelig. Schon allein deswegen ist der Liederzyklus hervorzuheben, denn einzig Anna Renfer bringt in einer Komposition Carl Seelig als Lyriker mit Robert Walser zusammen..$^{15}$ Der ausführlichste Eintrag zu Anna Renfer findet sich bei Aaron I. Cohen:

Swiss pianist composer, b. Biel-Bienne, Canton Bern, 1896. She began her piano studies at the age of 11 . She studied theory at the Bern Conservatory from 1918 to 1920 and at the University of Bern in 1935. She continued her studies at the Conservatory of Bienne and studied theory, the piano and singing in Gstaad. Her piano teachers included E[dwin]. Fis[c]her, Cherbulier [recte: Antoine-Elisée Cherbuliez], E. Levi [recte: Ernst Levy], A[drian]. Aeschbacher, R[udolf]. Serkin, H.[?] Pembauer ${ }^{16}$ and $H[$ ermann] Scherchen. She is a member of the Swiss Tonkuenstler. ${ }^{17}$

Nur schon diese wenigen Stichworte zeigen, dass Anna Renfer bei vielen großen Musikern ihrer Zeit studiert hat. Weitere Recherchen ergaben: Anna

14 Sie schreibt sich auch als Anna Margaretha Spoerri-Renfer, als Anna Spoerri-Renfer oder Anna M. Spoerri-Renfer. Die Kompositionen zeichnet sie in der Regel mit Anna Renfer, weshalb hier diese Version gewählt wird.

15 Die meisten Kompositionen von Anna Renfer befinden sich im Bestand des Forum MusikDiversität in der Musikbibliothek der Hochschule der Künste Bern, sie weisen kaum Datierungen noch Editionsangaben auf. In der Vera Oeri Bibliothek der MusikAkademie Basel gibt es größer besetzte geistliche Werke. Teilweise tragen die Partituren Jahreszahlen und Opusnummern (bis zur Opuszahl 41), die auf einen umfangreichen Nachlass hinweisen, über dessen Aufenthaltsort ich keine Informationen finden konnte.

16 Vermutlich Josef Pembaur der Jüngere, österreichischer Pianist (1875-1950).

17 Cohen: International Encyclopedia of Women Composers, Bd. 2, S. 663. Der Vermerk »Ref. composer« zeigt an, dass Cohen diese Angaben von der Komponistin selbst bekommen hatte. Sie hat ihm auch ein fotografisches Porträt zur Verfügung gestellt. Über die in Schweizer Bibliotheken vorhandenen Kompositionen hinaus erwähnte Anna Renfer gegenüber Cohen noch folgende, nicht nachweisbare Werke: »Sonata in C-Minor (vlc and pf) (1968)«, »Small variations [pf] «; »Eight songs (J. Reinhart) (S and pf) (1924)« / »Magnificat (5-part ch a-cap)«. 
Spoerri-Renfer wurde am 17.11.1896 geboren ${ }^{18}$ und verstarb am 24.06.1984. ${ }^{19}$ In den Schweizerischen Tonkünstlerverein (STV) ist sie 1968 im Alter von 72 Jahren eingetreten. Weil die meisten Partituren mit Jahreszahlen zwischen 1969 und 1971 versehen sind, muss Anna Renfer auch im Alter als Komponistin noch sehr aktiv gewesen sein. Mit über 80 Jahren reichte sie für die Tonkünstlerfeste 1977 in Biel und 1978 in Luzern je zwei Kompositionen ein (1977: Klavierstudien für die linke Hand op. 37 und »Skizzen« für Klavier; 1978: ein Magnificat für fünfstimmigen Chor und den Psalm 23 für Sopran, Bass und Orgel), wurde jedoch beide Male von sämtlichen Jury-Mitgliedern abgelehnt. Vermutlich waren die tonale Musiksprache und die schlichte Faktur der Partituren Grund für die Absage. Dass sie eine unbekannte Komponistin war, dürfte auch nicht geholfen haben.

Mit 85 Jahren schickte Anna Renfer aus dem Engeried-Spital Bern Wladimir Vogel ihre Klavierstudien für die linke Hand zu.

Gestatten Sie mir, sehr geehrter Herr, Ihnen die Klavierstudien für die linke Hand zu übermitteln.

Ich bin Mitglied des schweiz. Tonkünstlervereins

Anna Spoerri-Renfer ${ }^{20}$

Eine Woche später schreibt Vogel der Komponistin zurück, wahrscheinlich ohne zu ahnen, dass sie gleich alt ist wie er selbst.

Sehr geehrte Frau Spoerri,

Ihre Klavierübungen für die linke Hand habe ich mit Interesse gelesen und finde sie zwar ziemlich schwierig, aber dem Zweck entsprechend.

Was mir auffiel ist, dass Sie das Klavier nur in der engen Lage benützen und die großen Möglichkeiten ausladender weiterer Lagen ausser Acht lassen. Da wären viele harmonische und strukturelle Möglichkeiten auf verschiedenen Ebenen zu erreichen bei vollem Klavierklang (Pedal). Dabei wären auch rhythmische Verlagerungen auf verschiedenen Ebenen möglich. Es wäre eine klangliche Bereicherung.

18 Dank an Martina Hotz von der SUISA. Die Nachkommen von Anna Renfer haben die Mitgliedschaft bei der SUISA am o1.11.1984 gelöscht; deshalb verfügt die Urheberrechtsgesellschaft über keine Namen von Erben oder Rechtsnachfolgern.

19 Vgl. die Rubrik zum Hinschied von Mitgliedern im STV-Jahresbericht 1984, S. 65. Dort ist auch das Aufnahmedatum als Mitglied aufgeführt: 1968. Dank an Doris Lanz für diese Recherche im Archiv des Schweizerischen Tonkünstlervereins sowie die Hinweise auf den späten Briefwechsel mit Wladimir Vogel und die identischen Lebensdaten von Vogel und Renfer. Ein weiterer Dank gilt auch hier Walter Labhart für die Unterstützung mit seiner Dokumentationsbibliothek. 
Gestatten Sie mir die Noten zu behalten zwecks ev. Vorschlägen zu Aufführungen. Sind diese Stücke auch im Heinrichshofen's Verlag ${ }^{21}$ selbst erschienen und in Deutschland selbst beziehbar?

Mit freundlichem Gruss ${ }^{22}$

Vogel gibt gute, wenn auch relativ allgemeine Ratschläge. Dass er die Noten behalten und zur Aufführung empfehlen will, zeigt aber doch seine Wertschätzung.

Leider fehlen Dokumente zum früheren Leben und Schaffen von Anna Renfer; das macht auch die Datierung des Entstehungszeitraums der 44 Lieder sehr schwierig. Die 44 Lieder des Zyklus sind eine eher seltene Mischung aus regionaler, nationaler und internationaler Literatur. Die Texte stammen von 28 Autorinnen und Autoren sowie aus dem Hohelied. ${ }^{23}$ Zwar kommen auch Goethe und Storm vor, aber das Hauptgewicht liegt auf Deutschschweizer Lyrik aus der ersten Hälfte des 20. Jahrhunderts, Lyrikerinnen und Lyriker, die in den fünfzig Jahren zwischen 1867 (Alfred Huggenberger) und 1917 (Erwin Schneiter) zur Welt kamen. Die Gedichte sind von unterschiedlicher Qualität; Texte von höchstem Rang befinden sich neben Heimat- und >Röseligarten $<-$ Lyrik in unterschiedlichen Schweizer Dialekten sowie religiös verbrämten Sinngedichten. Der Pflug und Scholle lobende Heimatdichter Alfred Huggenberger wird von Anna Renfer neunmal vertont; sie berücksichtigt aber auch Autorinnen und Autoren mit ganz anderem ideellem Hintergrund wie Carl Albert Loosli oder Olga Brand.

Dass Erwin Schneiter, der erst in den frühen 1940er-Jahren religiöse Gedichte zu publizieren begann, im Zyklus vertreten ist, legt eine Entstehung nicht vor 1940 nahe. Möglich ist allerdings auch, dass es sich bei 44 Lieder um

21 Diese Bemerkung könnte sich darauf beziehen, dass die Klavierstudien für die linke Hand von Hug \& Co in Kommission verkauft wurden. Heinrichshofen übernahm ähnliche Kommissionen in Deutschland.

22 Vogel: Brief [Durchschlag] vom o6.o6.1981.

23 Folgende Autorinnen und Autoren - neben Walser - wurden von Anna Renfer in den 44 Liedern vertont: Anton Auckle [als Autor nicht nachweisbar], Richard Avenarius (18431896), Werner Bergengruen (1892-1964), Olga Brand (1905-1973), Walter Dietiker (18751948), Gustav Falke (1853-1916), Ida Frohmeyer (1882-1968), Johann Wolfgang Goethe (1749-1832), Rudolf Hägni (1888-1956), Peter Halter (1856-1922), Gerhart Hauptmann (1862-1946), Alfred Huggenberger (1867-196o), Gottfried Keller (1819-189o), Meinrad Lienert (1865-1933), Carl Albert Loosli (1877-1959), Conrad Ferdinand Meyer (1825-1898), Josef Reinhart (1875-1957), Anna Renfer (1896-1984), Hans Rhyn (1888-1967), Emil Schibli (1891-1958), Erwin Schneiter (1917-1990), Walter Schweizer [Lebensdaten nicht nachweisbar], Carl Seelig (1894-1962), Carl Spitteler (1845-1924), Theodor Storm (1817-1888), Georg Thürer (1908-2000), Rudolf Weckerle [Lebensdaten nicht nachweisbar] sowie Bibeltext (Hohelied Salomos 8,6-7). 
einen Sammelzyklus handelt, in dem Anna Renfer die Lieder zusammenfasste, die sie während ihres langen Lebens komponiert hat. In diesem Fall wäre die Datierung noch viel offener: Einzelne der Lieder könnten dann schon aus den 1920er-Jahren stammen. ${ }^{24}$ Die wenigen Daten zu Renfers Leben verweisen auf eine Jugendzeit in Biel und ab 1918 auf einen Lebensmittelpunkt in Bern. In beiden Städten könnte sie Robert Walser auch persönlich begegnet sein.

Es gibt einen Abschnitt in Renfers Leben, in dem ihre Lehrer sie sowohl auf Walser als auch auf Seelig aufmerksam gemacht haben könnten: Als Anna Renfer im Alter von 39 Jahren am 1934 gegründeten, kleinen Konservatorium Biel studierte, kannte sie bestimmt Wilhelm Arbenz, den Gründer dieser Schule und ersten Schweizer Vertoner von Robert Walser (vgl. Kap. 2). Ihr Lehrer, der Schweizer Komponist und Pianist Ernst Levy, der in den 193oer-Jahren aus Paris zurück in die Schweiz kam und von Arbenz als Klavierlehrer nach Biel geholt wurde, war gut bekannt mit Carl Seelig, dem Vormund und Freund von Robert Walser. Seelig und Levy standen in Briefkontakt, der besonders 1918/19 intensiv und ab den 3oer-Jahren eher sporadisch war. ${ }^{25}$ Levy hat zahlreiche von Seeligs Gedichten vertont. ${ }^{26}$ Der Antisemitismus, der sich auch gegen Schweizer Juden richtete, zwang den heute weitgehend vergessenen Levy, 1941 in die USA zu emigrieren (vgl. Kap. 2). Es ist naheliegend, dass die Lieder komponierende Anna Renfer in Biel auf Seelig aufmerksam gemacht worden ist und dass Renfers Lieder und somit die Walser-Vertonung eher in den 1940er- und 195oer-Jahren als später anzusiedeln sind. Dann wäre Anna Renfer nach James Simon und Wilhelm Arbenz die dritte, die Walser noch zu dessen Lebzeiten vertont hat.

Anna Renfer komponiert eine einfache, ins Modale zurückgenommene tonale Musik: Kaum Leittöne, dafür leere Quinten und Oktaven, Penta- und Hexatonik, fast keine Chromatik, einfache Rhythmik, schlichte Melodien. Bei diesen Stilmerkmalen erstaunt der tonartliche Reichtum der Lieder. Die Komponistin scheint sich mit Tonartensymbolik beschäftigt und Gedichte

24 In ihren biografischen Angaben an Aaron I. Cohen erwähnt sie explizit die verschollenen »Eight songs (J. Reinhart) (S and pf) (1924)«.

25 Im Nachlass Levys liegen 81 Briefe Seeligs, in demjenigen Seeligs 14 (Universitätsbibliothek Basel, Handschriften-Abteilung, Signatur NL 300: A 114, 1-81; Robert Walser-Archiv Bern, Nachlass Carl Seelig).

26 1936, als Anna Renfer wohl bei ihm studierte, komponierte Ernst Levy auf Texte Carl Seeligs die Klavierlieder Wie der Blitz und Er hielt in seiner Hand ... sowie den Hymnus symphonicus für Orgel, 2 Trompeten, Horn, 2 Posaunen, Tuba, Pauken und Vokalquartett (oder Chor ad libitum). Und noch 1977 schrieb er - fünfzehn Jahre nach Seeligs Tod - die Cantate IX (Liedercantate) für Tenor und Streichorchester auf ein Gedicht von Carl Seelig. Dazu kommen rund ein Dutzend weitere Vertonungen, die auch auf Übersetzungen Seeligs zurückgreifen. 
auf diese Symbolik ausgerichtet zu haben. So ist zum Beispiel das einzige Lied in C-Dur die Vertonung des Hohelieds, das zudem den Abschluss des Zyklus bildet. In der gegenüberliegenden Tonart Fis-Dur finden wir Unser Weg von Carl Seelig (vgl. Abb. 66). Ein kurzer Vergleich der Kompositionen zu Seelig und Walser zeigt allerdings, dass Anna Renfer mit den Tonarten sehr unterschiedlich umgeht. Bei Unser Weg gibt es mit einer Ausnahme zu Beginn des Liedes als Harmonik nur die Tonika, die zwischen Dur und Moll wechselt, gleichförmig angeschlagen und nur auf »Sterne« und »Frieden« arpeggiert. Die Schlichtheit bekommt hier schon fast einen >konzeptuellen< Aspekt.

Walsers Langezeit ist das einzige Lied in cis-Moll (vgl. Abb. 67); hier dominiert ebenfalls die Tonika mit der leeren Quinte $c i s$ - gis; der Terzton $e$, der diese Quinte zum cis-Moll-Dreiklang bestätigen würde, kommt nur sporadisch vor. Im Gegensatz zur Seelig-Vertonung wird dieses Lied im weiteren Verlauf deutlich komplexer, da die einfache Anfangsstruktur zunehmend aufgelöst wird.

$\mathrm{Zu}$ Beginn dominieren leere Quinten und Oktaven, das Tonhöhenmaterial beschränkt sich auf ein Hexachord. Das gibt der Klaviermelodie, die mit Akzenten und Marcatozeichen belebt wird, einen modalen Charakter, da die siebte Stufe von cis-Moll ausgelassen wird; weder $h$ (melodisch Moll) noch his (harmonisch Moll) kommen vor.

Anna Renfer differenziert nun dieses einfache Ausgangsmaterial - zum ersten Mal bei »zu lachen« mit dem Wechsel in die Oktave in der linken Hand und dem höchsten Ton des Liedes in der Gesangsstimme. Bemerkenswert ist der Akzent im Klavier auf der unbetonten Silbe von »lachen«. Je stärker nun die Komponistin Walsers Text musikalisch interpretiert, desto mehr zerfällt die klare Anfangssituation. Anna Renfer setzt in diese >unschuldige< diatonische Welt plötzlich Töne hinein, die in der cis-Moll Skala gar nicht vorkommen, und zwar nicht irgendwelche, sondern ausgerechnet das $c^{1}$, das im Querstand zum dominierenden cis in der Klavierbegleitung steht (auf »machen«, »Gang«, »Herzen«). Bei »müden « singt die Sängerin das bisher ausgesparte $h$, zusätzlich betont in der linken Hand. Ab »alte Schmerzen« verschwinden auch die leeren Quinten; sie werden von verminderten Quinten abgelöst, die mit den Terzen zu verminderten Dreiklängen ergänzt werden. Vieles erscheint nun verändert: Die munteren Akzente werden zu Sforzatoschlägen, die Chromatik nimmt zu, die Singstimme wechselt für den ganzen Schlussteil ins tiefe Register und sinkt hinab bis zum as auf »nebst«. Renfer verlangt von der Sängerin in diesem Lied also eine Tessitura von fast zwei Oktaven. Vor allem aber wird der Schlussteil von der Ambivalenz zwischen der Grundtonart cis-Moll und dem >Gegenton< $c$ bestimmt, der bei »weinen « mit Doppeloktaven prägend in den Vordergrund tritt. Dieses $c$ ist in eine einfache aufsteigende Linie eingebettet, die bei »Ich« mit cis beginnt und auf einem Seufzer mit der auffallenden Notenfolge $a-c-h$ 

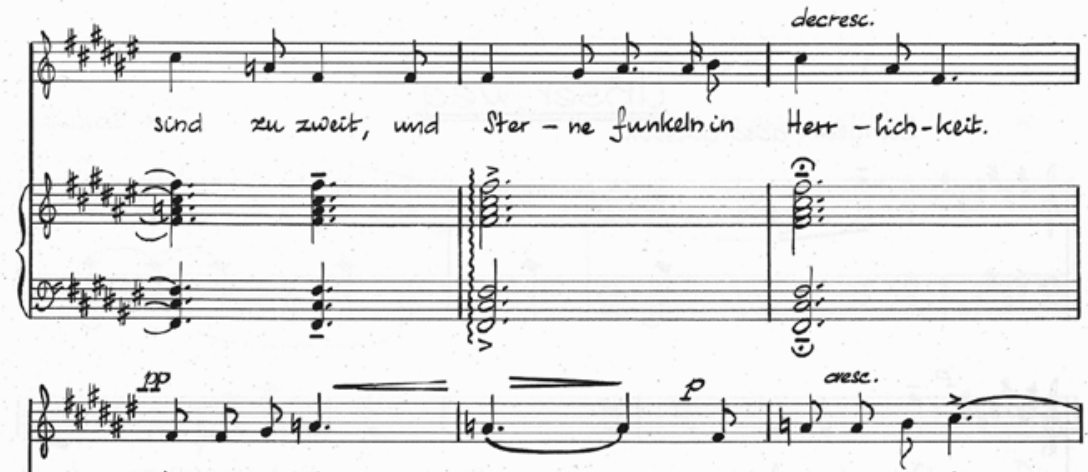

Wennwirauch lei - den, es hat ei -nen Sinn:
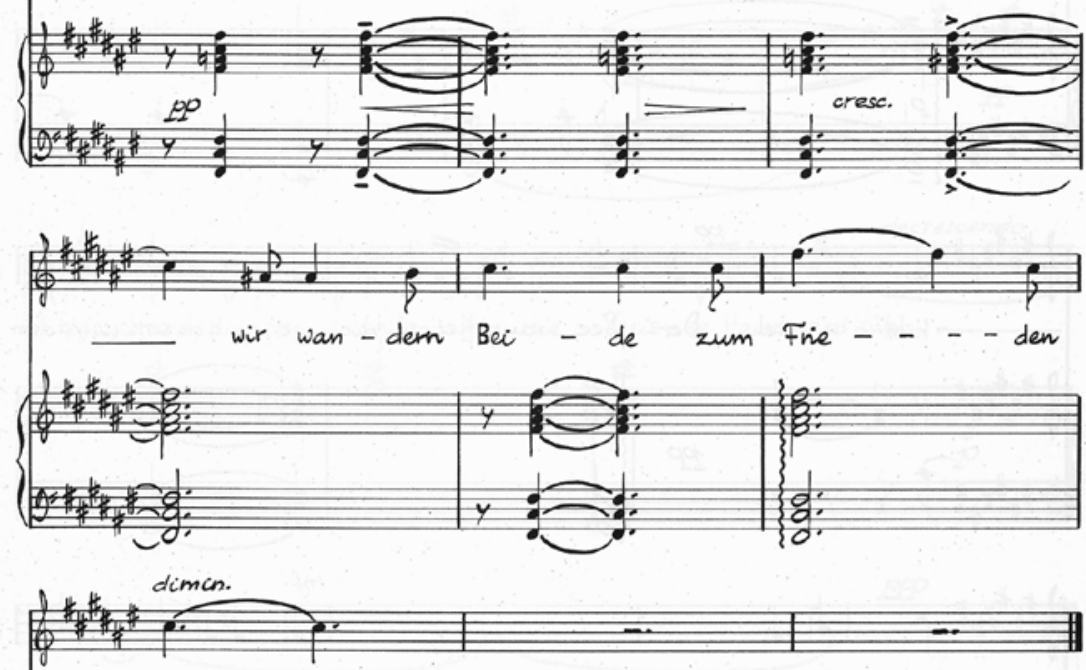

hin.

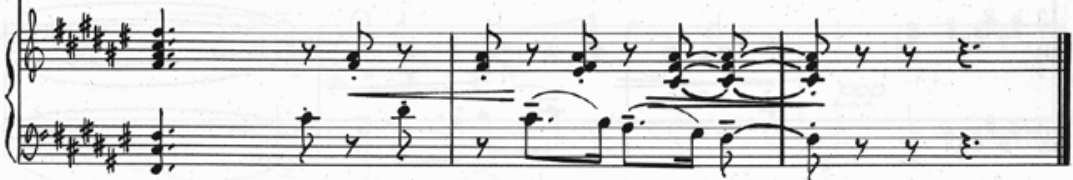

Abb. 66 Anna Renfer: Unser Weg (Carl Seelig), S. 2

endet. ${ }^{27}$ Bei »nebst andern« wiederholt Renfer diese Stelle eine Oktave tiefer, und man erwartet eigentlich erneut ein $h$ als Auflösung, aber sie dreht bei »Dingen« erneut zum cis und damit zum Anfang zurück. Diese eher wie eine

27 Die Folge der Notennamen A-C-H, Teil des legendären B-A-C-H-Motivs, könnte Renfer durchaus bewusst gewählt haben. 

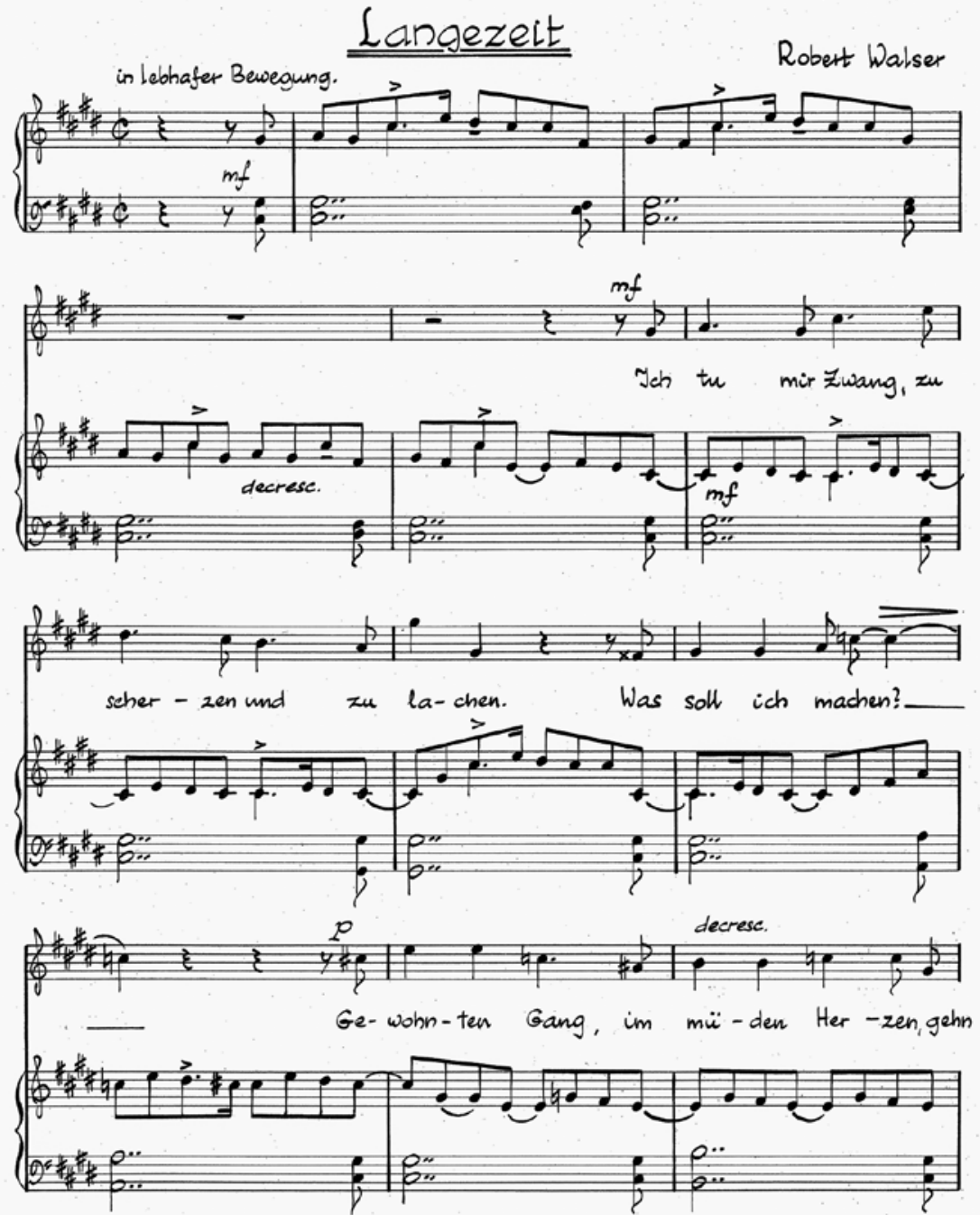

Abb. 67 Anna Renfer: Langezeit 

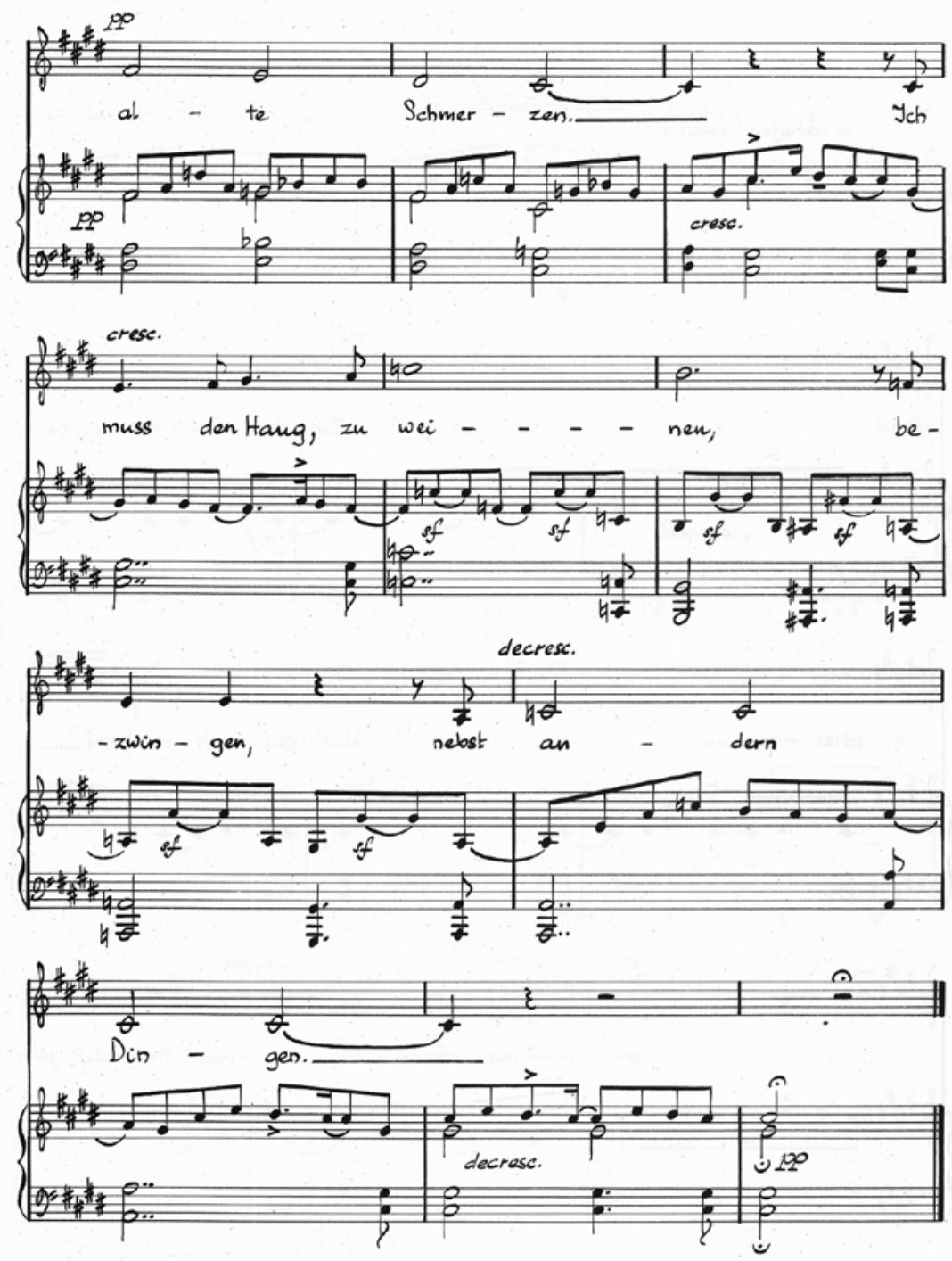
Erinnerung denn als Lösung wirkende Reprise zeigt, dass Renfer Walsers Schlusswendung sehr genau versteht. Sie relativiert alle vorherigen >großen< Worte mit der Anfügung »nebst andern Dingen « und führt in den prosaischen Alltag der Lebensdinge zurück.

Anna Renfer ist eine Komponistin mit wenigen kompositorischen Mitteln zu deren Erweiterung ihr Wladimir Vogel denn auch geraten hat -, aus denen sie jedoch das Maximum herausholt. Viel Zeit zur Umsetzung des Ratschlags blieb ihr nicht, Renfer verstarb drei Jahre nach dem kurzen Briefwechsel und vierzehn Tage vor Wladimir Vogel.

\subsection{Daniel Glaus: Sechs Lieder nach frühen Gedichten von Robert Walser (1977)}

Daniel Glaus (*1957) zählt zu den führenden Schweizer Komponisten und komponiert für alle Gattungen. Als Organist der Stadtkirche Biel (1985-2006) und seit 2007 des Berner Münsters gehört er zu den radikalen Reformern der Orgelmusik und mit der Idee einer winddynamischen Orgel (mit modulierbarem Winddruck auf den Tasten) auch des Orgelbaus. ${ }^{28}$ Er setzt sich für die Erneuerung der Kirchenmusik ein und initiierte den 4. und 5. Kirchenmusikkongress (1997 in der Kartause Ittingen und 2015 in Bern). Daniel Glaus unterrichtete von 1984 bis 2019 an der Zürcher Hochschule der Künste Komposition und Musiktheorie und ist seit 1988 Dozent für Orgel und Komposition an der Hochschule der Künste Bern. Als Komponist interessiert er sich nicht nur für Musik, sondern für Philosophie, Ökologie, die Weltreligionen sowie insbesondere für die jüdische, arabische und die mittelalterliche Mystik.

Drei Jahre vor Beiseit (vgl. Kap. 10.5) und noch vor Beginn seiner Studien am Konservatorium Bern vertonte Daniel Glaus mit knapp zwanzig Jahren sechs frühe Gedichte von Robert Walser. Er zählt damit nach Wladimir Vogel und Urs Peter Schneider zu den ersten, die sich nach Walsers Tod 1956 kompositorisch mit dem Schriftsteller auseinandergesetzt haben.

Vielleicht ist noch anzumerken, dass ich bewusst Gedichte gewählt habe, die Walser in etwa meinem damaligen Alter geschrieben hatte. Ich habe mich während meiner Semer-Zeit ${ }^{29}$ entgegen dem Willen des Deutschlehrers intensiv

28 Eidenbenz/Glaus/Kraut: Frischer Wind.

29 »Semer« ist Schweizerdeutsch für das kantonale Lehrerseminar mit Patentabschluss zum Volksschullehrer, heute von der Pädagogischen Hochschule Bern abgelöst. Dieser zugleich als Mittelschule fungierende Ausbildungsweg, der viel Instrumental- und 
mit Walser beschäftigt, durfte als Patentlektüre den »Jakob von Gunten« nur zusammen und im Vergleich mit »Unterm Rad « von Hesse wählen. ${ }^{30}$

Diese frühen Lieder sind ohne Verfremdungen der Stimme und ohne Spezialeffekte im Klavier komponiert. Die späteren großformal wirksamen Proportionen und Zahlenkonzepte von Glaus sind noch nicht nachweisbar, aber innerhalb der traditionellen Disposition von Melodie und Begleitung zeigen sich Differenzierungen und Raffinessen, die auf die späteren Werke vorausweisen. In jedem der sechs Lieder übernimmt die Klavierbegleitung eine andere Rolle, mal akkordisch-statisch, mal polyphon, mal ein anderes Instrument nachbildend, wie zum Beispiel das Akkordeon beim vierten Lied Im Mondschein (SW 13, 19f.). Glaus imitiert das Akkordeon allerdings nicht in der transzendierten Weise, wie Holliger das in seiner Vertonung desselben Gedichts (vgl. Kap. 6.4) tut, sondern durchaus volkstümlich und 〉ländlerisch〈; auch die getrennten Tastaturen des Akkordeons werden in der Klavierbegleitung imitiert. Das Volksmusikalische wird wie mit einer Registerwalze der Orgel dosiert. Bei »Es war aber eine Handharfe, die durch die Räume drang « steigert Glaus diesen Volkston ins Schubert'sche. Diese »zitierende Nachkomposition $\aleph^{31}$ Schuberts ist in der musikalischen Walser-Rezeption der erste von zahlreichen Bezügen zu Franz Schubert.

Am deutlichsten spürt man den späteren Glaus, der beim Komponieren eigentlich immer auf der Suche nach der Nicht-Musik, nach dem NichtGott, ${ }^{32}$ nach dem Nicht-Klang und dem >Verklang ist, im fünften Lied Stille (vgl. Abb. 68). Glaus gliedert das Lied in zwei Strophen von sechs Takten, die melodisch und harmonisch analog verlaufen. Innerhalb der Strophe wird die Versstruktur zwar umgesetzt, aber mit dem Enjambement des ersten Verspaars zu einem Elfsilbler leicht durchgeschüttelt, sodass der strikte Wechsel von Achtsilblern und Siebensilblern in Walsers Gedicht (SW 13, 17f.) erst am Schluss der Strophen deutlich wird.

Wie wär' ich froh, (4)

wenn irgendwo / nur still ich ruhen könnte (11) /

Zufriedenheit, (4)

als warmes Kleid, (4) /

mir innre Stille gönnte. (7)

anderen musischen Unterricht ermöglichte, wurde oft von diesbezüglich interessierten Studierenden gewählt.

30 E-Mail von Daniel Glaus an Roman Brotbeck vom 21.10.2020.

31 Ebd.

32 Vgl. Brotbeck: Musik und/oder Nit-Musik sowie ders.: Gott im Kindbett wie eine Frau. 


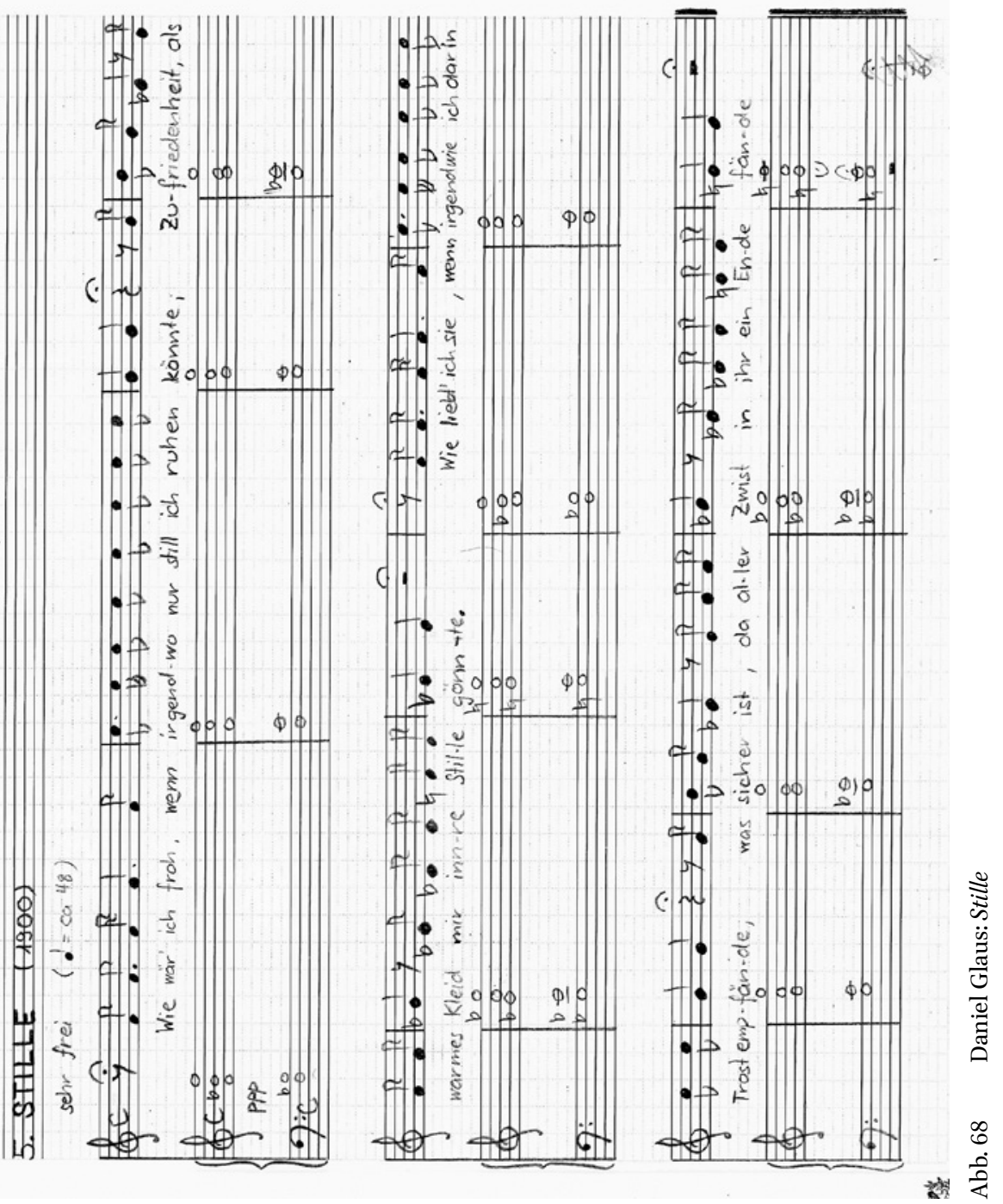


Die fünfstimmigen Klavier-Akkorde sind streng gebaut: Der unterste, mittlere und oberste Ton der Akkorde bilden ein Raster aus Doppeloktaven. Nur der zweite und vierte Ton verändern die Harmonik zwischen den Akkorden. Die ersten drei Akkorde bestehen aus Quinten und Quarten in wechselndem Aufbau, zuerst Quarte-Quinte, dann Quinte-Quarte. ${ }^{33}$ Glaus vermeidet damit dem strengen Kontrapunkt verpflichtet - Quintparallelen. Der dritte Akkord ist - verschoben nach $g$ - gleich gebaut wie der erste. Glaus könnte nun beim vierten Akkord dieses Muster (mit $g-d^{1}-g^{1}-d^{2}-g^{2}$ ) weiterführen. Aber ausgerechnet bei den Stellen »Zufriedenheit« (und analog in der zweiten Strophe »was sicher ist«) verschiebt Glaus die Töne zu einem übermäßigen Dreiklang, den die Singstimme in der Melodie übernimmt. Beim fünften Akkord verengt Glaus zum verminderten Dreiklang (auf »Kleid« respektive »Zwist«). Der sechste Akkord ist wieder in der >Grundstellung « und identisch mit dem dritten Akkord, wenn da nicht die Singstimme wäre. Diese singt bei »innre Stille gönnte « zum ersten Mal Töne, die im Klavierakkord nicht enthalten sind, und bei »gönnte« macht sie den leeren Quart-Quint-Klang mit dem es ${ }^{1}$ zum c-Moll-Akkord (in Quartsextstellung). Glaus >gönnt< sich hier gewissermaßen die traditionelle Marke für Trauer und Melancholie. Im Repertoire der Standard-Dreiklänge fehlt jetzt nach dem übermäßigen, verminderten und Moll-Dreiklang nur noch die Dur-Variante. Und diese kommt - fast!

Beim letzten Akkord steht in Analogie zum $e s^{1}$ auf »gönnte « in der Singstimme ein $e^{1}$ auf »fände«, was die Duraufhellung ergäbe, die zum Schluss des Gedichts durchaus passen könnte - aber ausgerechnet hier durchbricht Glaus bei den Klavierakkorden die sture Umrahmung durch die Doppeloktave und setzt als obersten Ton ein $a^{2}$, was zu einem Mollseptakkord (in Sekundstellung) führt.

Mit diesem Schluss sucht Glaus schon in jungen Jahren nach ambivalenten Lösungen, die nicht aufgehen: Den Konjunktiv, der Walsers Gedicht - wohl auch gewählt wegen der klangfarblich verwandten Umlaute (ö und ä) in den Reimwörtern - durchzieht, will er nicht in reines Dur auflösen; das hätte auch der Autoreflexivität des Gedichts widersprochen, in dem mit »ein Ende fände « das Ende selber angekündigt wird. Die Periodik der Singstimme führt nach Dur und auch im Akkord selber klingt Dur durch; ebenso präsent ist die Auflassung des Akkordmodells mit dem einzigen Septakkord des Liedes. Allerdings ist der symmetrische Mollseptakkord ein >milder Akkord, der zu den funktionell

33 »Zu den leeren Quint-Akkorden: die haben mich seither nicht mehr losgelassen und tauchen beispielsweise im Zyklus >De Angelis` (in memoriam Luigi Nono) und im Oratorium `Sola quae cantat audit et cui cantatur « wieder auf.« E-Mail von Daniel Glaus an Roman Brotbeck vom 21.10.2020. 
weniger definierten Septakkorden der tonalen Musik zählt; zudem erklingt der Grundton $a$ im Diskant, sodass ein ambivalentes lieto fine entsteht - eine Art von musikalischem Konjunktiv.

\section{$11.4 \quad J u ̈ r g$ Frey: Lachen und Lächeln (1978), Sachen (1979/80), Und ging I (1996/97), Und ging II (1997/98)}

Mit seinem Zyklus Lachen und Lächeln brachte der in Aarau geborene und bis heute dort lebende Jürg Frey ( ${ }^{*} 1953$ ) einen neuen Ton in die musikalische Walser-Rezeption: Konsonanz, Stille, Ruhe, äußerste Reduktion der Mittel. Lachen und Lächeln ist eine der ersten Kompositionen von Jürg Frey:

Es ist vielleicht dasjenige Stück, über das ich, als es fertig war, dachte: Wahrscheinlich könnte ich Komponist werden. Es hat viele Eigenheiten, die mir lieb sind und die [...] später bei meiner Arbeit ganz wichtig geworden sind. ${ }^{34}$

Tatsächlich ist die spätere Entwicklung zum Komponisten des >FastNichts< eigentlich schon hier vollzogen. So schrieb Thomas Meyer 2010 zum Komponieren von Jürg Frey:

Fast nichts!, möchte man einwenden, und Jürg Frey würde einem vermutlich recht geben: Er hat die Musik reduziert, weil er den Konventionen, den gewohnten Gesten, den faulen Kompromissen misstraute: all dem, was man so an Musik mit sich herumträgt. Wenn er zu komponieren beginne, so sagte er einmal, und das berühmte leere Blatt Papier vor sich habe, sei es erst einmal Teil der Arbeit, »dieses Blatt überhaupt leer zu bekommen, alles, was schon drauf ist, bevor ich den ersten Ton geschrieben habe, davon wegzunehmen, es verschwinden zu lassen und dann in einem Arbeitsprozess das auf das Blatt kommen zu lassen, was vielleicht meine Musik ist. «35

Schon das Bild dieses leeren und von allen Traditionen befreiten Blattes scheint etwa den übervoll beschriebenen Mikrogrammen von Walser zu widersprechen, die dieser vielfach auf vorbedruckte Zettel schrieb.

Wenn man sich allerdings auf die abgeklärte, dissonanzenlose und reine Welt von Freys Lachen und Lächeln einlässt, wird man an Walter Benjamins kurzen Aufsatz von 1929 erinnert:

34 Frey: »so Sachen ...«, S. 49.

35 Meyer: Und das soll Musik sein?, S. 17. 
Denn das Schluchzen ist die Melodie von Walsers Geschwätzigkeit. Es verrät uns, woher seine Lieben kommen. Aus dem Wahnsinn nämlich und nirgendher sonst. Es sind Figuren, die den Wahnsinn hinter sich haben und darum von einer so zerreißenden, so ganz unmenschlichen, unbeirrbaren Oberflächlichkeit bleiben. [...] Nicht jeder sieht, daß nicht die Nervenspannung des dekadenten, sondern die reine und rege Stimmung des genesenden Lebens in ihnen liegt. ${ }^{36}$

Dieses genesene Leben strahlt uns in Freys Lachen und Lächeln entgegen, rein und klar: alle Konflikte, aller Streit ist überstanden. 1976 hatte Jürg Frey Robert Walsers Werk entdeckt und alles gelesen, was damals publiziert war:

Aus den vielen Texten habe ich diesen kleinen Vierzeiler herausgenommen. Ich wollte dabei nicht in erster Linie den Text vertonen, sondern ein Bild von dem Menschen Walser zeichnen. [...] Das ist eine Überlegung, die den formalen Ablauf prägt. Es spielt ein Klavier, und eine Sängerin, Horn, Klarinette und Violine sind dabei. Die Geige haben Sie wahrscheinlich gar nicht gehört. Das ist Absicht: Dass es auch Sachen gibt, die man einfach nicht hört. ${ }^{37}$

Der Zyklus beginnt mit drei einander folgenden Vertonungen desselben kurzen Gedichts, das dem Werk den Namen gab (SW 13, 51); die erste und zweite Vertonung sind fast identisch, erst die dritte verändert das Tonhöhenmaterial und deutet eine Entwicklung an, die aber nicht weitergeführt wird: Es folgt ein karges Nachspiel, das gleich lang dauert wie die drei Lieder zusammen. Im Anschluss daran spielt der Pianist allein weiter, und die anderen sitzen da und warten ab:

Und damit [...] wollte ich eine Situation schaffen auf der Bühne, in der 4 Musiker*innen die meiste Zeit still dasitzen, warten, dem Klavierspieler zuhören, eine Stille neben dem Klavierspieler schaffen. ${ }^{38}$

Auch diese Klavierstücke zeigen keinerlei Entwicklung, und ein deutliches Finale des Zyklus, das man bei solchem Hinauszögern fast zwangsläufig erwartet, trifft nicht ein. Thomas Meyer schreibt in Bezug auf Jürg Frey: »Er spielt mit der Erwartung der Hörenden, dass da doch $>$ mehr $<$ kommen müsste. Diese Erwartung wird erst einmal zum Abwarten aufgefordert.«39

Die Verhältnisse sind bei Lachen und Lächeln besonders krass, denn die gesungenen Lieder dauern zusammen etwa eine Minute, das Nachspiel zum letzten Lied ebenfalls eine gute Minute, während die nun folgenden fünf

36 Benjamin: Robert Walser, S. $128 \mathrm{f}$.

37 Frey nach Houben: Immer wieder anders [Transkription eines Vortrags von J. F], S. 5 ०.

38 E-Mail von Jürg Frey an Roman Brotbeck vom 30.10.2020.

39 Meyer: Und das soll Musik sein?, S. 17. 
Klavierstücke ungefähr zehn Minuten dauern und mit auskomponierter Unterinformation spielen:

Ich wollte den vielen konsonanten Klängen eine Art formale Dissonanz entgegensetzen, eine Unausgeglichenheit, die der harmonischen Klangwelt eine disharmonische Form entgegenstellt.

Das Klavier symbolisiert in einem gewissen Sinn Robert Walser (darum spielt das Klavier im ersten Lied seine vier Töne auch zusammen mit den Vokalen O-E-A-E im Text, die vier Vokale im Namen Robert Walser). ${ }^{40}$ So kann man die Klavierstücke sehen als Charakterstücke für Walser, der seinen (Lebens-)Weg geht, zuerst verborgen, dann in einer Gemeinschaft und später dann allein, beiseit, bis zum letzten, zarten, fast stillstehenden und ganz stillen Stück. ${ }^{41}$

Solch versteckte Bezüge und unhörbare Palimpseste gibt es in Jürg Freys Zyklus Lachen und Lächeln noch manche, allerdings sind dem Komponisten viele davon nicht mehr in Erinnerung, sodass Aufschlüsselungen nur noch ansatzweise möglich sind.

Zwei Jahre später nahm Frey das letzte Wort des Gedichts Lachen und Lächeln - nämlich »Sachen « ${ }^{42}$-als Werktitel einer noch viel experimentelleren und extremeren Walser-Auseinandersetzung. 28 kurze Stücke für 17 unterschiedliche Besetzungen (von Solos, Duos, Trios bis zum Dezett). Auf Robert Walser selbst verweist nur das vierte Stück, eine monodische Vertonung von Mutlos (SW 13, 52) für Stimme allein. Sachen geht in der Reduktion der Mittel noch weiter. Die Noten wirken manchmal wie das erste Notenblatt im Anfänger-Unterricht. So wird beim achtzehnten Stück für Flöte solo sechs Mal mit vier aufsteigenden Tönen und minimalen Veränderungen eine Quinte durchschritten (jeweils mit einer Terz in der Mitte). Die sSensation< besteht darin, dass zum Schluss die Quinte einen Halbton tiefer erklingt als zu Beginn und in eine andere Tonalität gewechselt hat.

Sachen wurde erst 1995 - also fünfzehn Jahre nach der Niederschrift der Komposition - von Urs Peter Schneider und Studierenden der damaligen Musikhochschule Bern uraufgeführt. ${ }^{43}$ In dieser Zeit beschäftigte sich Jürg

40 Die Vokale, auf die die vier Klaviertöne fallen (sie stehen in der Quartenkonstellation cisfis- $h-e$ ), sind im Folgenden mit Majuskeln und fetter Schrift hervorgehoben: »Es kOmmt mich LachEn / und Lächeln An. / Was liegt daran! / Das sind so SachEn ... «(Partiturseite 1 und 2).

41 E-Mail von Jürg Frey an Roman Brotbeck vom 30.10.2020.

42 Von 1989 bis 2006 benutzt Jürg Frey dann den Titel in der miniaturisierten Form: Sächelchen. Insgesamt 111 dieser Sächelchen (für Gitarre, Klarinette, Saxophon, Trompete und Schlagzeug sowie Klavier oder Streichquartett) komponierte Frey in diesen 17 Jahren.

Zum Frühwerk von Jürg Frey vgl. auch Houben: Möglichkeiten des Hörens. 
Frey erneut mit Robert Walser, und zwar in Und ging I (SW 13, 27) für Schlagzeug, Violine und Stimme. Schon diese Reihenfolge mit der Singstimme am Schluss statt am Anfang ist ein deutlicher Hinweis darauf, dass es sich dabei nicht um eine traditionelle Vertonung handelt (vgl. Abb. 69).

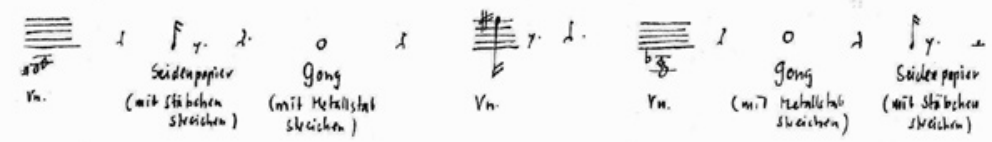

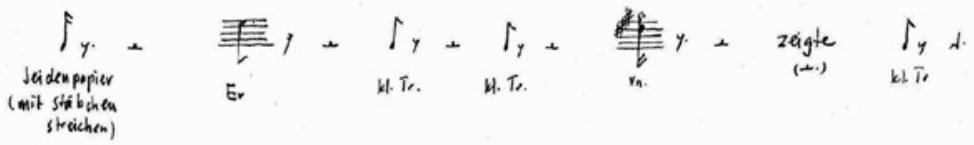

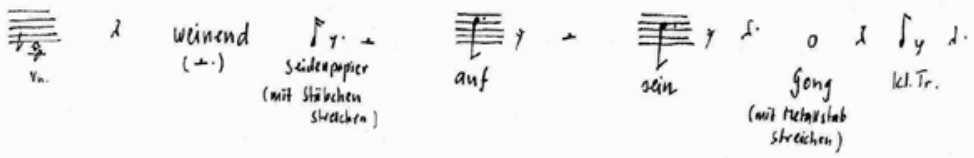

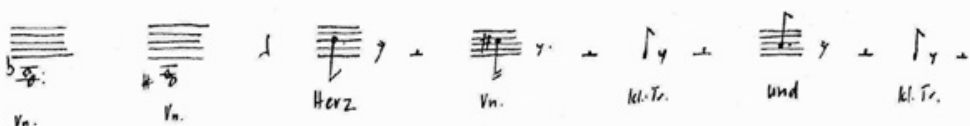

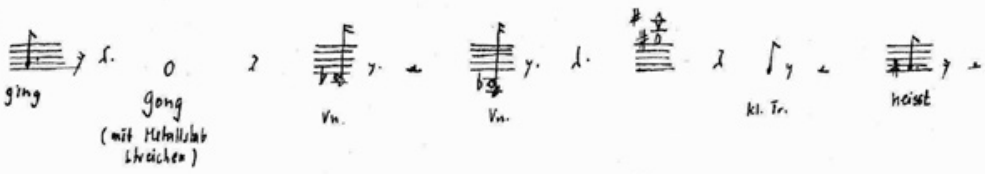

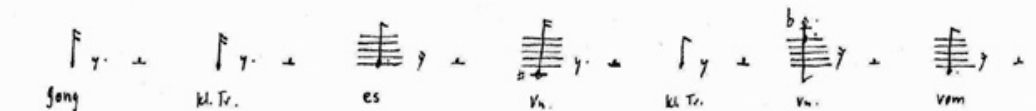

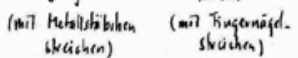

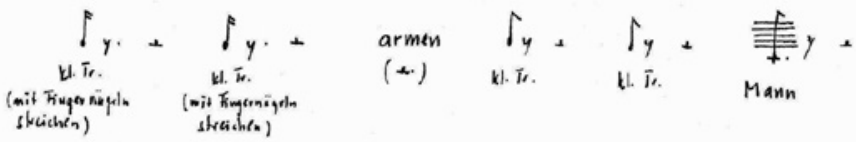

Abb. 69 Jürg Frey: Und ging I, S. 4 
Frey komponierte einen konsequenten Hoquetus; es gibt keinen einzigen gemeinsamen Ton zwischen den drei Ausführenden. Wie die ersten adiastematischen Neumen sind alle drei Stimmen - analog zur Schrift - auf geraden Linien geschrieben, und aus der Ferne erinnert das Schriftbild an japanische oder chinesische Zeichen.

Das Schlagzeug hat den wichtigsten Part; es besteht aus vielen meist kleinen Schlaginstrumenten, darunter auch Alltagsgegenstände wie eine Holzkiste, Papierblätter, ein aufgehängtes Tuch, Seidenpapier und »Blech (Billigware)«. Das Musikbeispiel zeigt die letzte Seite der Partitur:Tonhöhen auf Notenlinien und ohne Text werden von der Violine gespielt; Tonhöhen mit Text werden gesungen. Wörter ohne Tonhöhen werden vom Schlagzeuger gesprochen. Der Unterschied zwischen gesprochenem und gesungenem Text geht auf das Gedicht von Walser zurück. Dieses besteht aus 8o Silben, die sich auf 45 einsilbige, 13 zweisilbige und 3 dreisilbige Wörter, also insgesamt 61 Wörter verteilen: Alle einsilbigen Wörter werden gesungen, die anderen sechzehn werden gesprochen. So wie Walser sein Gedicht mit den zwei- und dreisilbigen Wörtern rhythmisiert, so periodisiert Frey mittels der gesprochenen Wörter auch den Hoquetus: Durch die hohe semantische Verständlichkeit dieser mehrsilbigen Wörter entsteht eine eigene Sinnebene, in der die Hauptstruktur des Gedichts, das Ostinato »und ging, heißt es «, in den mehrsilbigen Wörtern gerade nicht erscheint: »schwenkte leise seinen [...] Wandersmann [...] Blätter [...] rauhen $[\ldots]$ teilte lächelnd Gnaden [...] Majestät [...] klopfte nächtlich [...] Herzeleid $[\ldots]$ zeigte weinend $[\ldots]$ armen $\ll$.

Freys Hoquetus setzt sich aus 220 durch Pausen getrennten Einzelereignissen zusammen:

- 61 Ereignissen mit Sprache (45 für die Singstimme und 16 gesprochenen fürs Schlagzeug);

- 53 Ereignissen für die Violine;

- 106 sprachlosen Ereignissen fürs Schlagzeug.

Man kommt nicht umhin, beim mit ganzzahligen Kosmen sich beschäftigenden Jürg Frey zu vermuten, dass er bewusst 220 Ereignisse gewählt hat, weil 220 die Summe der sich konsekutiv folgenden Primzahlen 47, 53, 59 und 61 darstellt. 47+59 ergibt 106 und entspricht der Anzahl von Schlagzeugklängen.

Im Folgenden sei ein >Stenogramm< von Freys Hoquetus zusammengefasst; $\mathrm{P}=$ Aktion des Schlagzeugs, $\mathrm{V}=$ Aktion der Violine, kursiv = gesungen, normal gesetzt $=$ gesprochen:

[P-P-P-P] Er schwenkte [V-P-P-P-P] leise seinen [V] Hut.

$[\mathrm{P}-\mathrm{P}-\mathrm{P}-\mathrm{V}]$ und $[\mathrm{V}]$ ging, [V-P-P-P-P] heißt [V-P] es vom [V-P-P-P-P-V-P-P] Wandersmann.

[P-V-P-V-P] $\operatorname{Er}[\mathrm{V}]$ riß $[\mathrm{P}-\mathrm{P}-\mathrm{P}]$ die Blätter [V-V-V-V-P] von [V-P-P] dem [P] Baum 
[P-P-P-P] und [V] ging, [V-V] heißt es [P-P-V-V-V-V] vom rauhen Herbst. [P-P-P-P-V-P-V-P] Sie [P-P] teilte [P-P] lächelnd Gnaden [P-P-V-P] aus $[\mathrm{V}-\mathrm{V}-\mathrm{P}]$ und ging, $[\mathrm{P}-\mathrm{P}]$ heißt's $[\mathrm{V}-\mathrm{V}-\mathrm{V}]$ von $[\mathrm{V}] \operatorname{der}[\mathrm{P}]$ Majestät. [P-P-P-P] Es [P-V-P] klopfte nächtlich [P-P-P-P] an die [P-P-V] Tür [P-P-V-P] und ging, [P-P-P-P-P-V] heißt [P-P] es [V-V-V-V-P] vom [P-P-P-P] Herzeleid.

[P-P-V-P-P-V-V-P-P-P] Er [P-P-V] zeigte [P-V] weinend [P] auf sein [P-P-V-V] Herz $[\mathrm{V}-\mathrm{P}]$ und $[\mathrm{P}]$ ging, $[\mathrm{P}-\mathrm{V}-\mathrm{V}-\mathrm{V}-\mathrm{P}]$ heißt $[\mathrm{P}-\mathrm{P}]$ es $[\mathrm{V}-\mathrm{P}-\mathrm{V}]$ vom $[\mathrm{P}-\mathrm{P}]$ armen $[\mathrm{P}-\mathrm{P}]$ Mann.

Im Unterschied zu den frühen Walser-Werken von Jürg Frey lassen sich bei Und ging I trotz der strengen Form und der kargen Mittel ausdeutende Aspekte erkennen, zum Beispiel wenn bei den letzten beiden Versen die Wörter »weinen« und »Herz« von verfremdeten Violinklängen ${ }^{44}$ und mit Hölzchen gestrichenem Seidenpapier umstellt sind. Allerdings ist für Zärtlichkeit und Trost nur wenig Platz, denn der trockene Schlag der kleinen Trommel durchsetzt die ganze Stelle. Die Trommel markiert auch den Schluss mit dem auf den Ton $c$ gesetzten »Mann«.

Ein Jahr später bearbeitete Jürg Frey den Hoquetus für Stimme allein zu Und ging II: Dabei ersetzte er die Schlagzeug- und die Violinstimme durch Pausen und ein neues Element, ein gesummtes cis, das wohl in Anspielung an die zehn Verse des Gedichts zehnmal aleatorisch auftaucht.

Die Beschäftigung mit Walser umfasst fast zwei Jahrzehnte von Freys Komponieren. Im Frühjahr 2015 gab er dem amerikanischen Musikkritiker Brian Olewnick ein schriftlich geführtes und online publiziertes Interview, in dem er die Prinzipien seines Komponierens zusammenfasst und explizit auch seine Walser-Werke einbezieht:

In my work, I consider each note as an individual, I respect each note as a sound personality. This may also be one of the reasons why I continue to compose by hand: I can give my attention to every note. I take responsibility for the note, and I also want that every note itself feels good and right in its place and in the context. And with this work ethic follows a similar attitude towards the musicians: I respect each musician as a personality, I count on their skills, their musicianship, and I hope to write music for them that is rewarding, and for which it's worth taking responsibility. In this way I am seeking personal and social transformations.

I also don't think that a music that is »dealing with the harsh realities of the world « has more to do with life than one that is »contemplative or dwelling on aspects of beauty. ${ }^{45}$

\footnotetext{
44 Die tiefen Klänge der Violinen »sind keine Flageoletts. Es entsteht eine Mischung aus Ton und Rauschen.«Jürg Frey in den Erläuterungen zur Partitur von Und ging I. 


\subsection{Kurt Schwertsik: Das Leben für Sopran und keltisches Naturhorn (1986)}

Er hat an vielen Häfen der Musik des 20. Jahrhunderts geankert: der österreichische Komponist Kurt Schwertsik ( $\left.{ }^{*} 1935\right)$. Ursprünglich studierte er bei Gottfried von Freiberg Horn und war bis 1989 auch als Hornist tätig, zuletzt bei den Wiener Symphonikern. Komposition studierte er beim Traditionalisten und großen Verteidiger der Tonalität Joseph Marx sowie bei Karl Schiske, der sich in den 195oer-Jahren der Dodekaphonie zuwandte. Diese Extreme prägten denn auch die Entwicklung von Schwertsiks Schaffen. Mit 20 Jahren stürzte er sich in die Avantgarde, bildete sich bei Karlheinz Stockhausen, Mauricio Kagel, Luigi Nono und John Cage weiter. $195^{8}$ gründete er zusammen mit Friedrich Cerha das Ensemble »die reihe«, das sich während sechzig Jahren der zeitgenössischen Musik widmete und sich erst 2019 auflöste. ${ }^{46}$ Die Avantgarde, vor allem das harmonische Einerlei der Dodekaphonie, wurde Kurt Schwertsik bald zu einförmig; er begann sich um 1962 erneut mit tonalen Kompositionsverfahren auseinanderzusetzen. Nur ein paar Jahre nach der Gründung des Ensembles die reihe riefen der Komponist und Sprachkünstler Otto $\mathrm{M}$ [atthäus] Zykan und der Komponist und Chansonnier H[einz] K[arl] Gruber ein Gegenkonzept ins Leben, das Ensemble MOB art \& tone ART. Die Idee und der Name mochten auf dem gleichlautenden Slogan Schwertsiks beruhen, den dieser zu jener Zeit auf seine Briefe stempelte. ${ }^{47} \mathrm{HK}$ Gruber beschreibt diesen frühen Versuch, mit den Dogmen der Neuen Musik zu brechen, später folgendermaßen:

MOB stand für die Bedeutung - Musik auch für die untersten Schichten der Gesellschaft. [...] Das waren im Grunde einfache, tonale Werke mit dem Grundprinzip - »Melodie, Rhythmus und Harmonie«. Drei Vergehen, für die man in dieser Zeit aus dem »Zentralkomitee für Neue Musik« fristlos ausgeschlossen wurde. ${ }^{48}$

Mit seiner neuen, tonalen Ausrichtung hatte sich Schwertsik von allen stilistischen Zwängen befreit; in der Folge entstanden auch viele witzige Stücke, die das Geschäft des Komponierens ironisch kommentieren, und sei es nur schon mit den an Satie erinnernden Titeln wie Draculas Haus- und

46 Das Abschiedskonzert unter der Leitung von Christian Muthspiel und Heinz Karl Gruber fand am 3. November 2019 im Wiener Konzerthaus statt. Zum Abschluss wurden zwei Werke der Gründer des Ensembles uraufgeführt: die Neufassung der Mikrogramme op. 206 von Friedrich Cerha und 4 Kinder-Toten-Lieder op. 79b von Kurt Schwertsik. Vgl. den Beitrag von Dorothee Frank für ORF1, Frank: Abschiedskonzert des Ensembles die reihe.

48 Austrian Music Network: $\underline{\text { HK Gruber. }}$. 
Hofmusik (1969) oder Starckdeutsche Lieder und Tänze (1986 und 1991). Als Kompositionslehrer an der Hochschule für Musik und darstellende Kunst Wien (1989-2003) lehrte Schwertsik die Studierenden die gleiche Offenheit. Er trat häufig mit seiner Ehefrau, der Schauspielerin, Sängerin und Chansonnière Christa Schwertsik auf. Auch die Walser-Lieder für Sopran und Horn sind dieser Zusammenarbeit zu verdanken:49

Ein Diplomat der Schweizer Botschaft in Wien hat sich für seinen Abschied eine Komposition von mir gewünscht. Meine Idee war, ein paar Lieder mit Texten von Walser für die Stimme meiner Frau und mich als Hornisten zu setzen. Da es sich um die Schweiz handelte, borgte ich mir ein Alphorn aus, mit dem ich aber bei der Aufführung nicht zurecht kam. Das Alphorn erwies sich im weiteren Verlauf als zu unflexibel und so haben wir den Zyklus meist mit Naturhorn (dessen Stimmung man ja verändern kann) aufgeführt. ${ }^{50}$

In der Partitur steht dazu »keltisches Naturhorn«. In einer Anmerkung gibt Schwertsik folgende Erklärung ab: »Die Stimmung richtet sich nach den Wünschen \& Fähigkeiten von Sopranistin \& Hornist(in). Naheliegend wäre ein Alphorn in Fis.« Mit dem keltischen Naturhorn ist also kein konkretes Instrument gemeint, sondern vielmehr ein Topos für etwas Urtümliches. Auch seinem Alphornkonzert (1975) wird Schwertsik den Titel ... in keltischer Manier geben, ohne dass auch hier präzisiert wird, was genau mit `keltisch` gemeint ist.

Vermutlich beschreibt >keltisch < die extreme Einschränkung und die teilweise fremdartigen Intervalle, welche die Naturtonreihe des Alphorns bzw. Naturhorns mit sich bringt. ${ }^{51}$ In Das Leben - benannt nach dem gleichnamigen letzten Lied des Zyklus (SW 13, 26o) - verwendet Schwertsik in der Hornpartie 12 Töne (2. bis 13. Naturton), wobei die extreme Höhe und die extreme Tiefe - beide blastechnisch anspruchsvoll - nur je einmal vorkommen: Am Schluss von Ein Landschäftchen (SW 13, 20) - nach »Ein Englein kehrt ab sein weinend Gesicht und alle Engel des Himmels dazu « - steigt das Naturhorn hinunter zum zweiten Naturton, in übertragenem Sinne ins Reich der Teufel, die in Walsers Gedicht den Engeln vorangehen.

49 Auf Robert Walser ist Kurt Schwertsik sehr viel früher gestoßen: »Robert Walser habe ich 1959 in Köln zum ersten Mal kennengelernt, als mir Gottfried Michael Koenig [einer der Urväter der elektronischen Musik und damals Leiter des Elektronischen Studios des WDR; RB] einige Geschichten vorlas. Seither meine Verehrung für Walser.« E-Mail von Kurt Schwertsik an Roman Brotbeck vom 22.08.2016.

$50 \quad$ Ebd.

$5^{1}$ Bisher hat neben Schwertsik einzig Gamaliel von Tavel in Walser-Fantasie über Hölderlin (2020) das Alphorn in Zusammenhang mit Robert Walser verwendet. 


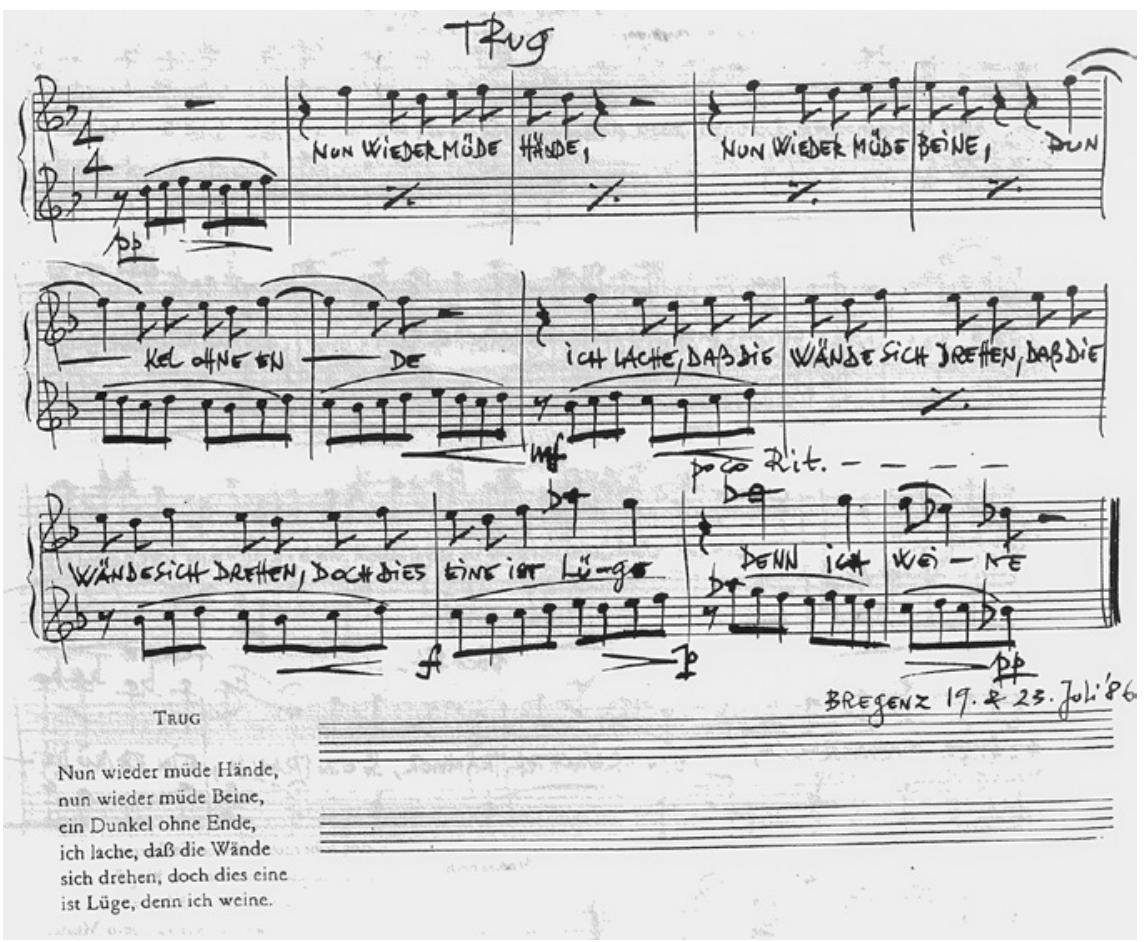

Abb. 70 Kurt Schwertsik: Trug aus Das Leben für Sopran und keltisches Naturhorn

Am Schluss von Trug (SW 13, 28) bringt Schwertsik ein einziges Mal im Zyklus den 13. Oberton des Alphorns ins Spiel (vgl. Abb. 70). Die schiefe Diatonik des siebentönigen Abstiegs des Horns zu »denn ich weine« bringt gewissermaßen die $>$ keltische $<$ Essenz des Instruments zum Klingen: beginnend im zweitletzten Takt mit dem 13. Oberton, dem sogenannten Alphorn-La (entspricht as um einen Fünftelton erhöht), dann dem 11. Oberton, dem sogenannten AlphornFa (entspricht $f$ um einen Viertelton erhöht), das Schwertsik gerade in diesem Lied oft benutzt, und zum Schluss mit dem 7. Oberton, der sogenannten Naturseptime (entspricht $b$ um einen Sechstelton vertieft), die in den acht Liedern sehr häufig vorkommt. Die Demaskierung der Lüge »ich lache« durch »denn ich weine« drückt Schwertsik gezielt mit jenen Tönen aus, die im temperierten Halbtonsystem keinen Platz haben. Dass nicht einfach die Töne der Natur wahr sind, zeigt Schwertsik in der Singstimme, die im Lied Trug nur an dieser Stelle Töne singt, nämlich es und des, über die das Naturhorn nicht verfügt. Das fällt deshalb auf, weil Horn und Singstimme in den ersten fünf Takten im Unisono und später im Terzabstand verlaufen. Das kommt im Pianissimo so unauffällig 
daher, dass die Zusatzdrehung bzw. die wie ein >Hänger wirkende Repetition von »daß die Wände sich drehen« beinahe überhört wird.

Erst bei »Lüge « wird das Zusammengehen von Stimme und Horn gestört und nicht mehr zusammengebracht, weil die Singstimme mit des auf einem dem Horn fremden Ton endet. Mit der >Wahrheit< des Weinens endet auch das >einstimmige Lügen und Lachen des Duos. Mit einfachsten Mitteln, dem Grundbausatz der Musik, schafft es Schwertsik, Walsers Gedicht subtil zu kommentieren.

Obwohl Kurt Schwertsik den Ruf hat, sich im komischen Fach besonders auszukennen, spielt er in Das Leben kaum mit den humoristischen Möglichkeiten des Alphorns. Einzig in der Bierszene (SW 13, 44) bekommt das Horn mit aufschießenden Arpeggien etwas Ironisches und Outriertes, was gut zu Walsers Groteske passt. Sonst aber verbleibt das Naturhorn in Das Leben gerade auch wegen des ausgedehnten Gebrauchs der Naturseptime - jenes schwer greifbare, die ganze deutsche Romantik konnotierende Instrument, das Melancholie und Sehnsucht ausdrückt, auch wenn es nur in Dur spielen kann.

\subsection{Johannes Quint: Das Leben für Sopran und acht Instrumentalisten (1991)}

Der in Bonn geborene Komponist und Musiktheoretiker Johannes Quint ( $\left.{ }^{*} 1963\right)$ studierte Komposition bei Günter Becker in Düsseldorf und später bei Hans Zender (vgl. Kap. 13.5) in Frankfurt. Heute ist er Professor für Musiktheorie an der Abteilung Aachen der Musikhochschule Köln. Seit 2014 widmet er sich verstärkt den Verbindungen von Musik mit dem experimentellen Animationsfilm, bei denen er mit Repetition, Permutation und Verschiebung gleicher Elemente spielt. Mit Robert Walser hat sich Quint sehr früh intensiv beschäftig und »mehr oder weniger alles von ihm gelesen «..$^{52}$ Noch während des Kompositionsstudiums bei Hans Zender schuf Quint mit dem späten Gedicht Das Leben (SW 13, 260) ein Werk, das sich unter den Walser-Vertonungen wie ein Monolith ausnimmt - allein von seinem Umfang her: 74 Partiturseiten und dreizehn Minuten Länge für ein einziges Gedicht. Die Komposition für die ungewöhnliche Besetzung von Klarinette, Posaune, Klavier, Violine, Violoncello und dreifaches Schlagzeug ist additiv aufgebaut, indem verschiedenste mehrfach repetierte musikalische Zellen aneinanderstoßen. In den ersten zwei 
Dritteln des Werks herrscht immer eine ähnliche, nervöse Grundspannung. Das Additive, das klangreiche Schlagzeug und die wie Vogelrufe tönenden Einwürfe des Klaviers und der Klarinette erinnern an Olivier Messiaen.

Quint zerlegt das Gedicht - inklusive des Titels - in zwanzig Zellen, die im Folgenden mit eckigen Klammern markiert sind:

[Das ${ }^{53}$ Leben]
[Nicht nur] [zuweilen auf] [das Dichten]
[man] [hübsch und artig] [muß verzichten];
[noch viel] [wicht'gere Dinge]
[gehen fort]. [Die teuersten Gestalten]
[vermagst du nicht] [am Zipfelchen zu halten],
[bis endlich] [auch] [sogar das Leben],
[als ob ein Vöglein in die Höh' sich schwinge],
[und ob man noch so kräftig ringe],
[man] [willig hin muß geben].

Alle diese Glieder sind zu gesanglich-instrumentalen Zellen geformt, die während des ganzen Werks ihre Gestalt beibehalten und immerzu wiederholt werden. Auf die meistwiederholten Zellen sei hier hingewiesen: »das « kommt $37 \mathrm{Mal}$ allein vor und $48 \mathrm{Mal}$ in Kombinationen mit »das Leben« oder »das Dichten «: es wird immer auf $g^{1}$ gesungen und meist von einem gestrichenen Cello-Flageolett auf derselben Tonhöhe begleitet. 31 Mal wird »das Leben « wiederholt, bestehend aus einer chromatischen Umspielungsfigur $\left(g^{1}-a s^{1}-\right.$ $\left.f i s^{I}\right)$, die mit einem sanften Vibraphon-Akkord gepaart ist - das >Leben $<$ quasi als süße Trauer. 17 Mal wird »das Dichten« repetiert: auf $e^{2}$ mit drei spitzen 32tel-Noten, die vom Glockenspiel zwei Oktaven höher verdoppelt werden und dadurch mit ihrer Helligkeit immer herausstechen - das $>$ Dichten< als etwas Auffälliges, Pointiert-Ornamentiertes, vielleicht auch Aufgesetztes.

Jede dieser Zellen formt Quint zu einer musikalisch-semantischen Einheit. Diese folgen nun nicht linear dem Lauf des Gedichts, sondern scheinen zufällig verteilt, durcheinander, sodass auch neue syntaktische Kombinationen entstehen. Da die Zellen kontrastreich gestaltet sind, entsteht der Eindruck eines sich ständig verändernden Klanggebildes, das sich mit der Zeit aber in ein mobile-artiges statisches Rotieren verwandelt. Zu dieser Statik trägt auch ein rigid eingehaltenes Tonhöhensystem bei, das Quint bei der Singstimme anwendet und bei dem jeder Zelle bestimmte Tonhöhen zugeordnet sind. Das Grundmaterial ist eine chromatische Skala über zwei Oktaven von $h$ bis $b^{2}$. Nur

53 Der Artikel »das « - neben »man« das einzige Wort, das im Gedicht inklusive Titel dreimal vorkommt - wird auch als einzelnes Element behandelt. 
für das Wort »Leben« nimmt Quint zwei Tonhöhen. Im Beispiel sind die entsprechenden Tonhöhen den Wörtern nachgestellt.

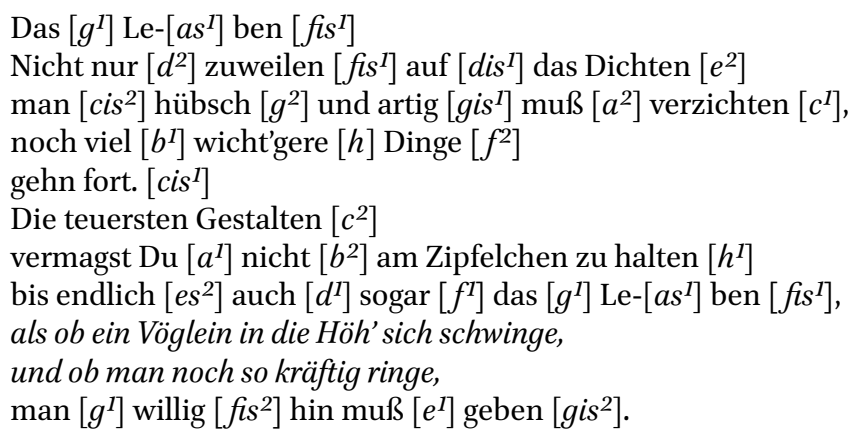

Jede Zelle weist eine eigene Taktart, Dynamik und Rhythmik auf. Die kursiv gesetzten Verse werden nach ungefähr zwei Dritteln linear und »übertrieben harmlos, stilisiert « 54 gesprochen. Sie wirken an dieser Stelle wie ein Kommentar, der rückwirkend die Vogelruf-Motive und das musikalische $>$ Ringen< erklärt; sie leiten aber auch den letzten Formteil ein, in dem die Rotation der musikalischen Zellen zum Stillstand kommt bzw. sich fast gänzlich auf das >nichtssagende〈 »das«, das erste Wort des in diese Vertonung miteinbezogenen Titels, beschränkt. Die Zelle mit dem Schluss des Gedichts, »willig hin muß geben«, erklingt erst in diesem letzten Teil und erscheint sechsmal. Quint gestaltet diese Zelle als ein sehr schnelles und fast nicht verständlich zu artikulierendes Motiv. In diesem durch die Reduktion der Zellen entkräfteten Schlussteil strahlt es eine insektenhafte Aggressivität aus.

Das Leben nimmt die verwickelte Struktur von Walsers später Lyrik zum Ausgangspunkt für eine analoge musikalische Verschachtelung. Der Reim, der in Walsers Gedicht wie eine Kette disparate Elemente verknüpft, wird von Quint gekappt und mit einem eigenen musikalischen Formelwerk ersetzt. Dieser Ansatz ist konträr zu jenem von Frank Bodin. Während Bodin mit seiner leichten und zurückhaltenden Musik das Nicht-Lineare in der Linearität des späten Walser zeigt, zerschlägt Quint die Linearität des Gedichts und enthüllt einen Walser jenseits syntaktischen Sinns. Interpretatorisch ist die Komposition sehr anspruchsvoll; deshalb hat bei der Uraufführung des Werks an der Hochschule für Musik und darstellende Kunst Frankfurt kein Geringerer als Bernhard Kontarsky das Dirigat übernommen. 
Johannes Quint hat später noch ein Chorwerk zu anderen Gedichten von Walser vertont, dieses aber nach zwei Aufführungen zurückgezogen. Im Rückblick betrachtet er Das Leben »als einigermaßen akzeptabel«, allerdings:

Aus heutiger Sicht finde ich es vor allem grundsätzlich problematisch, sich an eine solche Dichter-Ikone zu hängen (ich bin später noch ein paar Mal in die gleiche Falle mit Kafka getappt), ich denke, die Zeiten von >Vertonungen $<$, wie das noch bei Webern sehr gut funktioniert hat, sind vorbei. Aber das ist nur mein persönliches ästhetisches Gefühl [...]. ${ }^{55}$

\subsection{Christoph Neidhöfer: Vier Lieder nach Robert Walser für Sopran und Violoncello (1995)}

Seit 1999 lebt und wirkt der Schweizer Komponist Christoph Neidhöfer ( $\left.{ }^{*} 1967\right)$ als Forscher und Professor für Komposition und Musiktheorie an der McGill University in Montreal. Zuvor studierte er an der Hochschule für Musik in Basel Musiktheorie bei Roland Moser, Klavier bei Jean-Jacques Dünki und Komposition bei Rudolf Kelterborn.

Die Vier Lieder fügt Neidhöfer - ähnlich wie Reinhard Febel in der Winterreise - zu einer kleinen Walser-Szene zusammen, allerdings ohne theatrale Elemente. Dabei übernimmt das Violoncello die Aufgabe, die >innere Stimme zu spielen, während die Singstimme sich in sprungreichen Melodien mit zahlreichen Septim- und Tritonus-Sprüngen in der Tradition der postdodekaphonen Stilistik bewegt.

An den Anfang des Werks stellt Neidhöfer mit Ich wanderte jenes Gedicht, das Walser den Kleinen Dichtungen als Motto voranstellt (SW 4, [6]). Das Cello imitiert mit einem Laufmotiv in hoher Lage die Wanderbewegung, allerdings »col legno tratto« und »ohne Bogenhaare!«, das heißt man hört nur die obertonreichen, aber fast tonlosen und gequetschten Klänge des Bogenholzes. Während die Sängerin das Wandern lobt, werden im Cello die Saiten >gefeilt<. Im zweiten Lied Angst (I) (SW 13, 15f.) spielt das Cello einen wild zerfaserten und panisch wirkenden Part mit Bogen- und Handschlägen sowie vielen Geräuschklängen; die Sängerin flüstert, spricht und schreit dazu. Nach diesem expressionistisch nach außen gestülpten Lied ist Trug (SW 13, 28) nach innen gekehrt, eine >Traurigkeitsarie< en miniature. Unter den zehn Trug-Vertonungen sticht Neidhöfers Version heraus, weil er den Schluss »doch dies eine ist Lüge« ins Pianissimo zurücknimmt und das Lied in depressiver Erschöpfung ausklingen lässt. Das Cello kündigt das Unheil an: Liegeklänge 
mit großen Septimen, zum Schluss geschärft zu kleinen Sekunden. Alle Bewegungen der Singstimme werden von diesem `Schicksalsmotiv $<$ von allem Anfang an als nutzlose Lügen ausgewiesen.

Überraschend dann das letzte Lied Müdigkeit ( $\mathrm{SW}$ 13, 28), in dem »heiliger, süßer Schlaf« als Du angesprochen wird: »Entführ' mich«, sind die ersten Worte; fast neckisch mimt das Cello unterschiedlichste Verführungsgesten, bis es zum Schluss den weit ausgreifenden Gesang in die Tiefen des sheiligen, süßen Schlafs< führt.

In den Vier Liedern komprimiert Neidhöfer vier wichtige Motive von Walser: Wandern, (Angst-)Ausbruch, Entkräftung und (Todes-)Verführung.

\subsection{Michael Reudenbach: Indem man geht (1996)}

Die Verfahren der frühen Avantgarde - Serialismus, Aleatorik und elektroakustische Klanggenese - trifft man bei den Walser-Vertonungen kaum an. Scheinbar eine Ausnahme bildet hier das konsequent aleatorische Werk Indem man geht von Michael Reudenbach ( $\left.{ }^{*} 1956\right)$, komponiert für das Hamburger Ensemble l'art pour l'art mit der seltenen Besetzung von Singstimme, Flöte, Gitarre und Schlagzeug. Als ich mit Michael Reudenbach Kontakt aufnahm, bekam ich eine überraschende Antwort:

Vieles zu »indem man geht « habe ich inzwischen »vergessen«, besonders deshalb, da ich das Stück vor mindestens ${ }_{15}$ Jahren (?) aus meinem Werkverzeichnis herausgenommen habe. Es gibt mehrere Argumente für die Rücknahme zusammenfassend lässt sich aber sagen, dass ich mit der (kompositorischen) Qualität dieses Stückes absolut unzufrieden war/bin. Insofern habe ich die Akte »indem man geht « geschlossen und auch »l'art pour l'art« hat meinem Wunsch entsprochen und das Stück seitdem nicht mehr aufgeführt. ${ }^{56}$

Ich habe mich entschlossen, die Komposition trotzdem kurz zu behandeln, weil Michael Reudenbach eine Form der Aleatorik entwickelt hat, die sich selbst befragt und deren Auswahlmöglichkeiten sich gegen Ende dermaßen einschränken, dass auf einer Metaebene Robert Walsers Umgang mit Zeit, vor allem das Vorwärtsgehen und Stillstehen, musikalisch reflektiert wird. Michael Reudenbach, der 1999-2016 Musiktheorie an der Hochschule für Musik Karlsruhe unterrichtete und seit 2016 als Professor an der Hochschule für Musik und darstellende Kunst in Frankfurt am Main tätig ist, kann als das Gegenteil eines sogenannten Ausdruckskomponisten bezeichnet werden; auch das

$56 \quad$ E-Mail von Michael Reudenbach an Roman Brotbeck vom 28.10.202O. 
Formulieren irgendwelcher Botschaften widerstrebt ihm. Häufig bewegen sich seine Kompositionen im Pianissimo-Bereich, und das Publikum muss die Ohren wie bei einem Clavichord-Konzert auf die minimale Lautstärke dieser Musik einstellen, um von den geräuschhaften Klängen überhaupt etwas mitzubekommen.

Reudenbach wählte für seine Komposition nur Walser-Bruchstücke aus, die in der Aleatorik der Komposition höchstens fragmentarisch oder teilweise auch gar nicht wahrgenommen werden können. Das Werk besteht aus vier Teilen - Reudenbach nennt sie »Blätter «-, in denen verschiedene aleatorische Verfahren zur Anwendung kommen und die mit je unterschiedlichen Verknüpfungsregeln miteinander verbunden sind. Für jedes der vier Blätter wählte Reudenbach Sätze oder Satzfragment aus Walsers Prosawerk aus:

Blatt 1: Aus Schneien: »indem man geht, hofft man«(BA 13, 38)

Blatt 2: Aus Die Straße (I): »Mitten im ununterbrochenen Vorwärts hatte ich Lust stillzustehen.«(SW 16,54)

Blatt 3: Aus Die Straße (I): »Ich und alles schwankte.« (SW 16, 53)

Blatt 4: Aus dem Roman Geschwister Tanner: »in diesem Gehen der Zeit.«(SW 9, 306)

Das erste Blatt hat fünf Abschnitte; diese können in freier Reihenfolge gespielt werden, auch in Kombination mit den Blättern 2 oder 3. In diesem ersten Teil ist der Text in seine Phoneme zerlegt, sodass kein semantischer Sinn durchdringt. Das »indem man geht, hofft man « prägt die eigentliche Form, die eine maximale aleatorische Freiheit bei den Kombinationen zulässt und im eigentlichen Sinne das Gehen zu einem Hoffen darstellt.

Blatt 2 basiert auf einer simultanen Aleatorik, welche die »Lust stillzustehen « ins Formale übersetzt (vgl. Abb. 71). Das Blatt besteht nur aus einem Abschnitt, der aber in fünf übereinander gelagerten Varianten realisiert werden kann: »Jeder Ausführende hat fünf Varianten von drei notierten Takten. Die Ausführung erlaubt es, daß von Segment zu Segment [...] frei gewechselt werden kann. «57

Auch in Blatt 2 ist Walsers Text nur verständlich, wenn die Sängerin bei Takt 1 und 2 die Variante E und in Takt 3 die Variante D nimmt. Das Stillstehen ist in jeder der Varianten gegeben, weil in allen Stimmen und Varianten die Bewegungen eingefroren sind. 


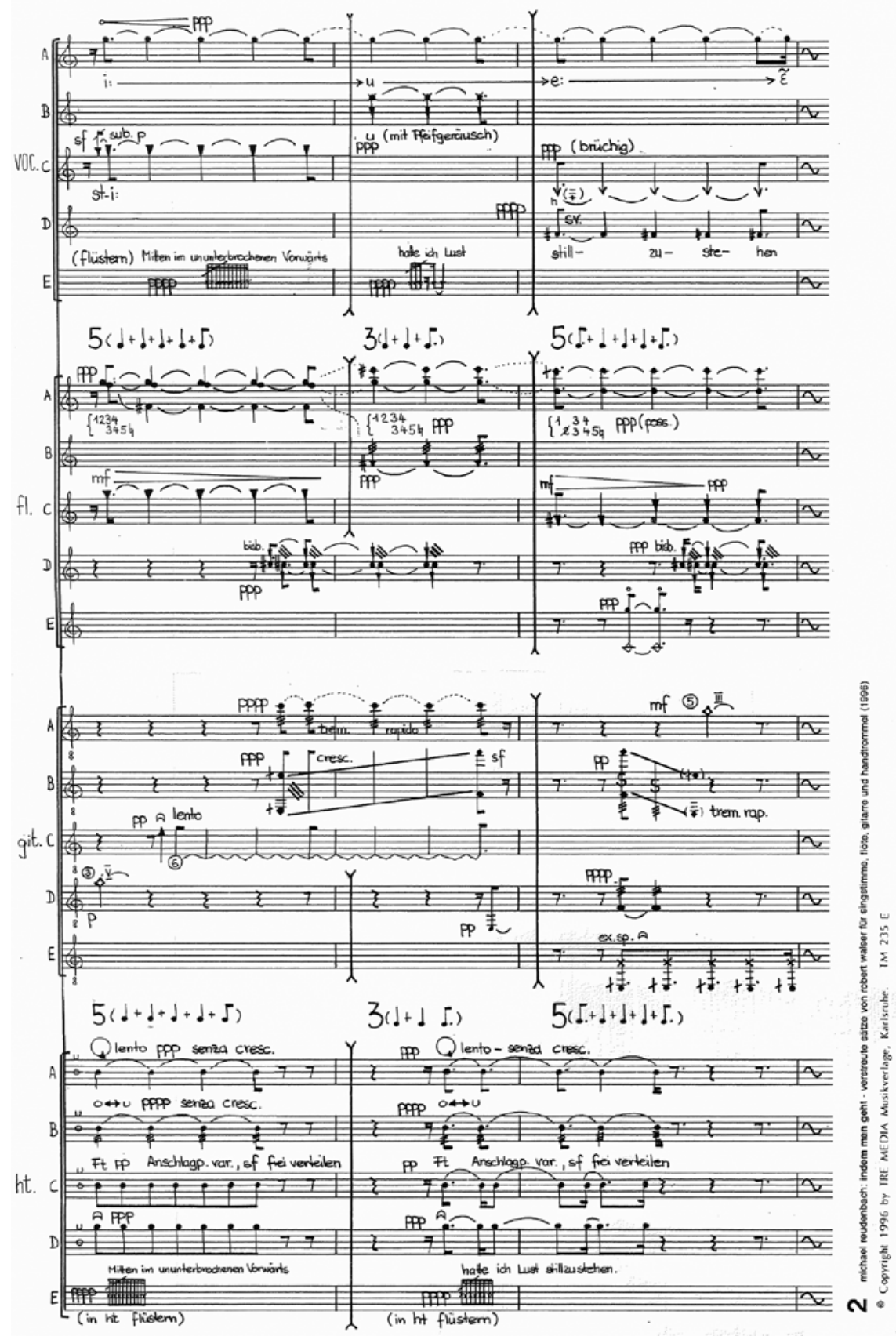

Abb. 71 Michael Reudenbach: Indem man geht, Blatt 2 
Blatt 3 besteht aus drei Abschnitten, die in wechselnder Reihenfolge gespielt werden müssen. Durch diese Vorgabe schränkt Reudenbach die Aleatorik bereits deutlich ein. Der Text ist nun in allen Abschnitten verständlich und die Musik schwankt zwischen Fortissimo und Pianissimo.

In Blatt 4, das aus vier Solostimmen besteht, kommt die Aleatorik fast zum Stillstand, denn dieser Teil muss zwingend den Abschluss des Werks bilden und kann nur in drei festgelegten Varianten erklingen.

Auch bei Reudenbachs Indem man geht bleibt, trotz des differenziert angelegten Formkonzepts, das grundsätzliche Problem der Aleatorik bestehen, dass diese nur von den Interpreten nachvollzogen, nicht aber vom Publikum wahrgenommen werden kann, weil dieses die Entscheide des Ensembles weder kennt noch überprüfen kann.

\subsection{Heinz Holligers Walser-Kompositions- und Interpretationskurs in Biel (1996)}

1996 gab Heinz Holliger am damaligen Konservatorium Biel (heute Hochschule der Künste Bern) einen seiner seltenen Kompositionskurse. Teilnahmebedingung für die Komponistinnen und Komponisten war die Vertonung eines Walser-Textes. ${ }^{58}$ Holliger besprach nicht nur die Kompositionen, sondern studierte diese auch mit den Interpretationsklassen des Konservatoriums ein. Komponieren, Interpretieren und Reflektieren griffen auf diese Weise eng ineinander. ${ }^{59}$

\subsubsection{Xavier Dayer: In hellem stillem Zimmer (1996)}

Der in Genf geborene und aufgewachsene Xavier Dayer (*1972) studierte Komposition bei Eric Gaudibert in Genf, später bei Tristan Murail und Brian

$5^{8}$ Dieser Kurs fand im Rahmen der Holliger-Walser-Woche statt (15.-21.12.1996). Der damalige Direktor des Konservatoriums und der Musikschule Biel, Samuel Dähler, und der Leiter der Berufsabteilung, Pierre Sublet, gaben mir freie Hand, um vom Konservatorium aus eine musikalisch-literarische Woche in Biel zu veranstalten. Fast alle damaligen Bieler Kultur-Institutionen beteiligten sich am Projekt. Der Bieler Literaturkritiker Heinz Schafroth unterstützte mich beim literarischen Programm. Mit einer von Bernhard Echte konzipierten Straßenausstellung wurde Walser in seiner Geburtsstadt in Erinnerung gerufen und damit in Biel auch der Nährboden dafür gelegt, dass 2001, kurz vor der Expo 2002, der Schweizer Landesausstellung, endlich ein Platz nach Robert Walser benannt wurde.

59 Der Beitrag von Gloria Isabel Ramos Triano, die ebenfalls am Kompositionskurs teilgenommen hat, wird im Kapitel 10.9 zu den Beiseit-Vertonungen behandelt. 
Ferneyhough am IRCAM ${ }^{60}$ in Paris. Er komponiert für alle Gattungen und macht in jüngster Zeit mit verschiedenen Opernprojekten von sich reden. Xavier Dayer unterrichtet heute Komposition, Musikgeschichte und Musiktheorie an der Hochschule der Künste Bern und leitet dort den Master in Composition and Theory, zu dem auch der von Georges Aperghis begründete Studiengang Théâtre musical zählt.

Beim Kompositionskurs von Heinz Holliger wählte Xavier Dayer als einziger die Besetzung mit einem Vokalduo und einem Instrumentalquartett von Flöte, Violine, Violoncello und Akkordeon. In der westlichen Musik steht das Vokalduo meist für eine Form des `Wir im Sinne eines Paars, sei es real, gewünscht oder erinnert. Ein solches >Wir< passt nicht zu den Ich-Fiktionen von Walsers Schreiben. Das ist ein Grund, weshalb Vokalduos unter den Walser-Vertonungen selten auftreten und, wenn doch, höchst reflektiert sind wie bei Alexander Goehr (vgl. Kap. 10.14) oder Michel Roth (vgl. Kap. 9.14). Um das einfache >Wir-Paar zu vermeiden, entwickelte Xavier Dayer für In hellem stillem Zimmer ein vernetztes Kompositionskonzept »selon le principe d'un instrument >conducteur< sur lequel un, ou plusieurs autres instruments, s'ajoutent.«61

Die Stimmen sind in der Partitur nur an einzelnen Stellen >traditionell übereinander notiert. Stattdessen folgen sie jeweils abschnittweise separiert aufeinander. In der Stimme, die einen Abschnitt eröffnet und dadurch die Rolle des >instrument conducteur< übernimmt, wird für das Zusammenspiel der Einsatz der weiteren Stimmen mit Buchstaben angegeben. Eine einheitliche Zeitstruktur geht dabei verloren, weil: »Chaque instrument, ou groupe d'instruments, doit chercherà évoluer dans son propre Tempo.«Da die Stimmen meist in unterschiedlichen Tempi singen und spielen, gibt es kein einziges gemeinsames Duo der beiden Singstimmen, vielmehr wird ständig aneinander vorbei gesungen. Dayerhat in seinem System, in dem die Instrumente den Vokalstimmen strukturell gleichwertig sind, auch die Möglichkeit, gewisse Stimmen synchron zu koppeln, während andere in eigenem Tempo laufen. Dayers Aleatorik ähnelt jener des polnischen Komponisten Witold Lutosławski: Ziel ist das Asynchrone des musikalischen Moments und nicht eine offene Form: Dayer kontrolliert die Abfolge streng, indem er überall angibt, welches Ereignis abzuwarten ist. Beim von Überlagerungen dominierten letzten Lied Angst (II) (SW 13, 38), garantiert ein solches Wartezeichen, dass der letzte Vers nur vom

6o $\quad$ IRCAM = Institut de recherche et coordination acoustique/musique. Das Institut für musikalische Innovation, Kreation, Vermittlung und klangphysikalische Forschung wurde 1977 von Pierre Boulez gegründet.

61 Dayer: In hellem stillem Zimmer, S. [2], (Vorbemerkung zur Partitur). 
Bass allein vorgetragen wird: »im hellen stillen Zimmer«. Damit hebt Dayer die Spiegelung des synonymen und klanglich nur minimal variierten ersten Verses »In hellem stillem Zimmer «, der dem Zyklus den Titel gab, plastisch hervor.

Der vierte Teil Stimmen (SW 13, 38f.) ist ein reines Instrumentalstück; der Verzicht auf die Vokalstimmen wurde wohl von der letzten Strophe des Gedichts ausgelöst, in der das lyrische Ich danach trachtet, die >Herzstimmen< beiseitezulassen (»Die milden blassen / Herzstimmen lassen, / da sie umnachten, / ist jetzt mein Trachten.«). »La pièce `Stimmen< est une tentative de traduire le poème du même nom sans qu'il soit exprimé vocalement. «62 Es handelt sich tatsächlich um eine Art Programmmusik, mit der die Stimmungen und Inhalte der vier Strophen des Gedichts Stimmen mit musikalischen Mitteln ausgedrückt werden.

\subsubsection{Rico Gubler: Streif(f)lichter einer Morgenstunde (1996)}

Der Schweizer Musiker und Jurist Rico Gubler (*1972) hat sich als Saxophonist auf zeitgenössische Musik, freie Improvisation und Live-Elektronik spezialisiert. Seit 2014 leitet er die Musikhochschule Lübeck. Komposition studierte Gubler bei Balz Trümpy in Basel und Salvatore Sciarrino in Florenz. In Florenz ist auch die Komposition Streif(f)lichter einer Morgenstunde für Violine solo entstanden - nach dem Prosatext Morgenstunde (SW 16, 1of.), den man als Idylle bezeichnen könnte. Im Kompositionskurs von Holliger war es das einzige Werk ohne Singstimme. Der Titel spielt auf den Geiger Egidius Streiff an, dem die Komposition gewidmet ist, ${ }^{63}$ aber er verweist in seiner Verspieltheit auch auf das Flüchtige der Komposition: ein Flirren von Flageoletts, Tremoli, Pizzicati, Registerwechseln. Nur an wenigen Stellen wird Walsers Text geflüstert:

Mit dem Kurztext Morgenstunde des Schweizer Autors Robert Walser nahm ich keine Textvertonung vor, sondern quasi eine Schreibvorgangsanalyse, um den künstlichen Improvisandovorgang [...] in Form einer musikalisch-fabulierenden Arbeit nachzuvollziehen. Der Text taucht nur in kurzen Fragmenten, durch den Ausführenden quasi in die Geige geflüstert, auf. Diese Textbehandlung scheint für mich beinahe von Walser selbst vorgegeben, durch die Hermetik seiner Texte, der Vermeidung jeglicher echten Dialogform und seinem virtuosen Umgang mit Sprachfloskeln und -feldern. Das Flüstern gibt der Stimme eine völlig veränderte Formantgestalt, der ich versucht habe in der Ausgestaltung der Geigenstimme Rechnung zu tragen. ${ }^{64}$

\footnotetext{
62 Ebd.

63 Egidius Streiff hat das Werk für eine Porträt-CD von Rico Gubler auch eingespielt. Vgl. Gubler: Streif $(f)$ lichter einer Morgenstunde (2016).

64 Gubler: Streiflichter, S. 36.
} 


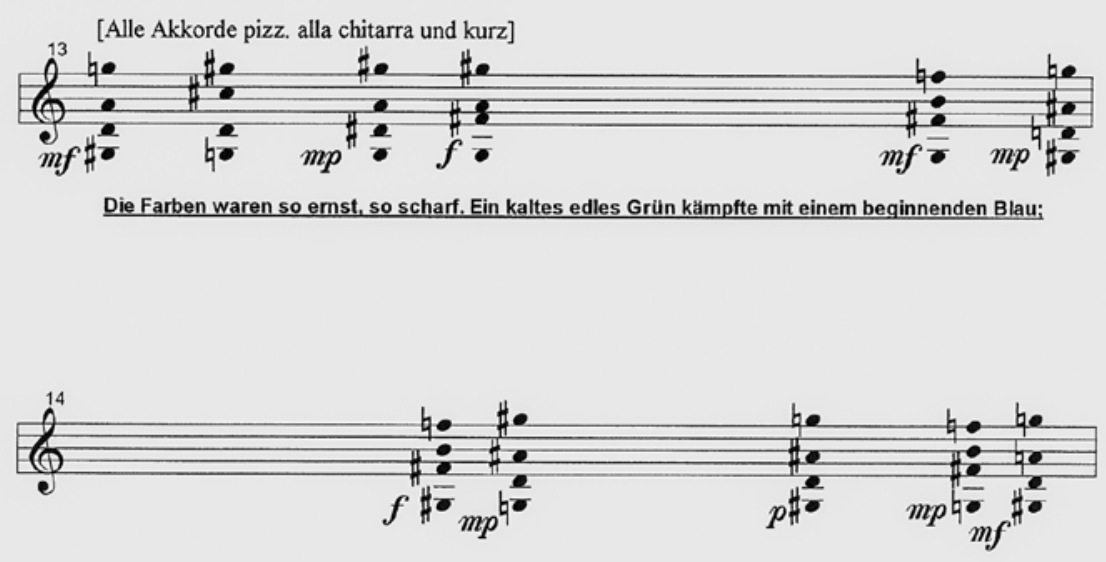

der Himmel war voller rosenroter Wolken. Himmlisch schön dünkte mich der erwachende Taq, der

T. $1^{\circ}$

$[\mathrm{I} \rightarrow \mathrm{II}]$

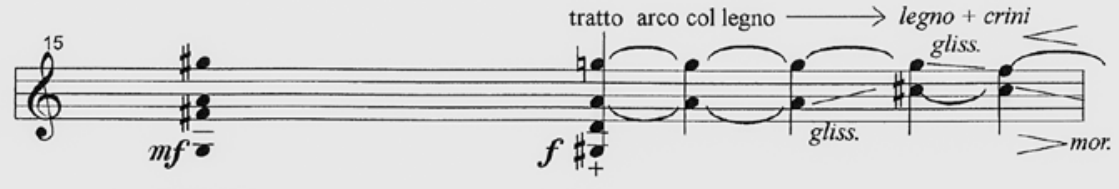

an seinem Hals den Mond noch als Silberschmuck truq.

Abb. 72 Rico Gubler: Streif( $f)$ lichter einer Morgenstunde, S. 5

Tatsächlich übernimmt die Violinstimme den Gestus gesprochener Sprache, und einzelne der Texte können auch als Kommentare zur Musik verstanden werden, zum Beispiel »seltsam Schönes« zu einer aufsteigenden Kantilene, deren Klangfarben von sul-tasto- zu ordinario-Spiel wechseln; oder »zarte und zugleich grenzenlose« nach einer schnellen, partita-ähnlichen zweistimmigen Stelle der Violine. ${ }^{65}$

In der Mitte der Komposition gibt es den einzigen längeren Text aus Morgenstunde $^{66}$ (vgl. Abb. 72). Hier steigt Gubler für einen Moment komplett aus dem etablierten System aus und begleitet mit der im Arm gehaltenen Geige >alla chitarra< den Kampf der Farben und das wunderbare Bild des Mondes als Silberschmuck. Dabei wird das in sich hinein geflüsterte Selbstgespräch zum Bänkelsang und die Geige zum Begleitinstrument. Gubler reflektiert mit

65 Ebd., S. 1, T. 2 bzw. S. 7, T. 21.

66 »Ein kaltes edles Grün kämpfte mit einem beginnenden Blau; der Himmel war voller rosenroter Wolken. Himmlisch schön dünkte mich der erwachende Tag, der an seinem Hals den Mond noch als Silberschmuck trug.« $\left(\mathrm{SW}_{16}, 10\right)$ 
diesem plötzlichen Rollenwechsel sein eigenes System und legt zugleich das versteckte Programm offen: »der erwachende Tag, der an seinem Hals den Mond noch als Silberschmuck trug.« (SW 16, 10) Das Enigmatische steht für den >erwachenden Tag`, das Virtuose und Farbenreiche für den Mond >als Silberschmuck .

Ein Tonika-Dominant-Geschrummel ist die Begleitung allerdings nicht. Gubler verwendet insgesamt acht verschiedene vierstimmige Akkorde. Sie sind nicht leicht zu spielen, weil er höchstens zwei leere Saiten zulässt und bei »rosenroter Wolken« einen Vierklang ohne eine einzige leere Saite verlangt $\left(g i s-f i s^{1}-h^{l}-f^{2}\right)$. Nach diesem Wendepunkt in der Mitte des Stücks pendelt die Komposition Streif $(f)$ lichter einer Morgenstunde wieder zurück ins Instrumentale, allerdings gewinnen danach die geflüsterten Partikel an semantischer Kraft und bekommen den Charakter magischer Zauberformeln.

\subsubsection{Edu Haubensak: Sechs Walserminiaturen (1996)}

Die Walserminiaturen von Edu Haubensak (*1954) sind wie in Stein gehauen und erinnern in ihrer Strenge, Abstraktheit und Präzision an die miniaturisierten Kykladenidole aus der Jungsteinzeit. ${ }^{67}$ Siebzehn Sätze hatte Robert Walser im April 1927 in der Beilage »Für die Frau« der Frankfurter Zeitung publiziert. Daraus hat Edu Haubensak (*1954) sechs Sätze ausgewählt; in eckigen Klammern die Nummern der Sätze bei Walser (SW 19, 231f.).

[6] Wenn ich hier Aphorismen schreibe, so scheint es wahr zu sein, daß mich etwas Schwieriges beschäftigt.

[9] Für einen Intelligenten bedeutet es eine sehr feine Freude, es fertigzubringen, an nichts zu denken.

[7] Musik macht auf mich einen mathematischen Eindruck, mithin einen poetischen.

[13] Wie interessant sind verbrecherische Frauen.

[10] Schreiben scheint vom Zeichnen abzustammen.

[12] Ich bin überzeugt, daß wir viel zu wenig langsam sind.

Als wäre die fünfte Miniatur mit dem Vergleich des Schreibens mit dem Zeichnen Programm, gestaltete Edu Haubensak schon die Kompositionsskizzen fast grafisch. So wird in der zweiten Miniatur der >Intelligente< bereits in der Skizze mit zwei Geraden symbolisiert (vgl. Abb. 73): Die oberste Saite der Violine, die E-Saite, wird als leere Saite gespielt, auf der zweitobersten A-Saite

67 Vgl. die Aufnahme des Stücks: Haubensak: Sechs Walserminiaturen (2009). 
erklingt ein kontinuierliches Glissando über eine Oktave von $a^{2}$ hinunter bis $a^{1}$, der leeren A-Saite, also von einer Quarte über der leeren E-Saite zur Quinte darunter. Dabei sind der Ausgangs- und der Endklang sehr verschieden: $\mathrm{Zu}$ Beginn die stumpfe leere E-Saite und die gepresste und in hoher Lage gespielte A-Saite, Symbol für den >Intelligenten`; zum Schluss zwei fahle leere Saiten, Symbol für die »feine Freude, $[\ldots]$ an nichts zu denken«.

Nach dem Studium bei Robert Suter und Thomas Kessler an der Musik-Akademie Basel hatte sich Haubensak vorerst musikszenischen Werken und einem von der amerikanischen Minimal Music beeinflussten Stil zugewandt. Bald aber begann er sich mit Mikrotönen auseinanderzusetzen. Diese immer tiefergreifende und völlig undogmatische Beschäftigung mit Mikrotönen, die oft nur partiell, also gerade nicht als >System < im eigentlichen Sinne eingesetzt werden, bestimmt Haubensaks Komponieren bis heute. Sie taucht in spezifischer Weise auch in den Walserminiaturen auf, am deutlichsten in der vierten Miniatur beim Satz über die sverbrecherischen Frauen< (vgl. Abb. 74). Auch hier legt Haubensak zwei >Geraden<: eine Gerade als Orgelpunkt $(b)$ in der Violine, von der aus alle mikrointervallischen Töne der Singstimme als Intervalle exakt wahrnehmbar sind, und eine zweite $>$ Gerade in der Singstimme, die in Zehnteltönen (2o Cent) absinkt von $b$ (um einen Zehntelton vertieft) über $a$ bis zu as. Und dann - ausgerechnet auf der letzten und dreizehnten (!) Silbe des Satzes - bricht Haubensak aus dem äquidistanten Zehnteltonabstieg aus und bringt stattdessen im Verhältnis zum darüber liegenden $b$ der Violine den übergroßen Ganzton von 231 Cent im Schwingungsverhältnis 8/7.68 Von der äquidistanten Welt, die vom Publikum mehrheitlich als Glissando wahrgenommen wird, wechselt Haubensak für einen kurzen Moment in die >natürliche< Klangwelt reiner Intervalle.

Der implizite Subtext dieses abstrakten Tonzeichens: >Verbrecherische Frauen « wagen den Ausbruch aus dem (Ton-)System - und sie tun es, weil sie sich entgegen dem System snatürlich verhalten; deshalb nach dem as die schiefe, aber im Obertonsystem durchaus naheliegende >übermäßige< Sekunde 8/7. Die Violine spielt zum Abschluss quasi als Kadenz noch das $g$, um deutlich zu machen, dass diese Miniatur im Gesamtumfang einer kleinen Terz insgesamt fünfzehn Tonhöhen aufweist - streng und präzise, ein Kykladenidol eben.

68 Edu Haubensak notiert in den Anmerkungen unten an der Partiturseite »Umkehrungsintervall der Natursept «, vgl. $7 / 4$ (Natursept) $+8 / 7=7 / 4 \times 8 / 7=2 / 1$ (Oktave). 


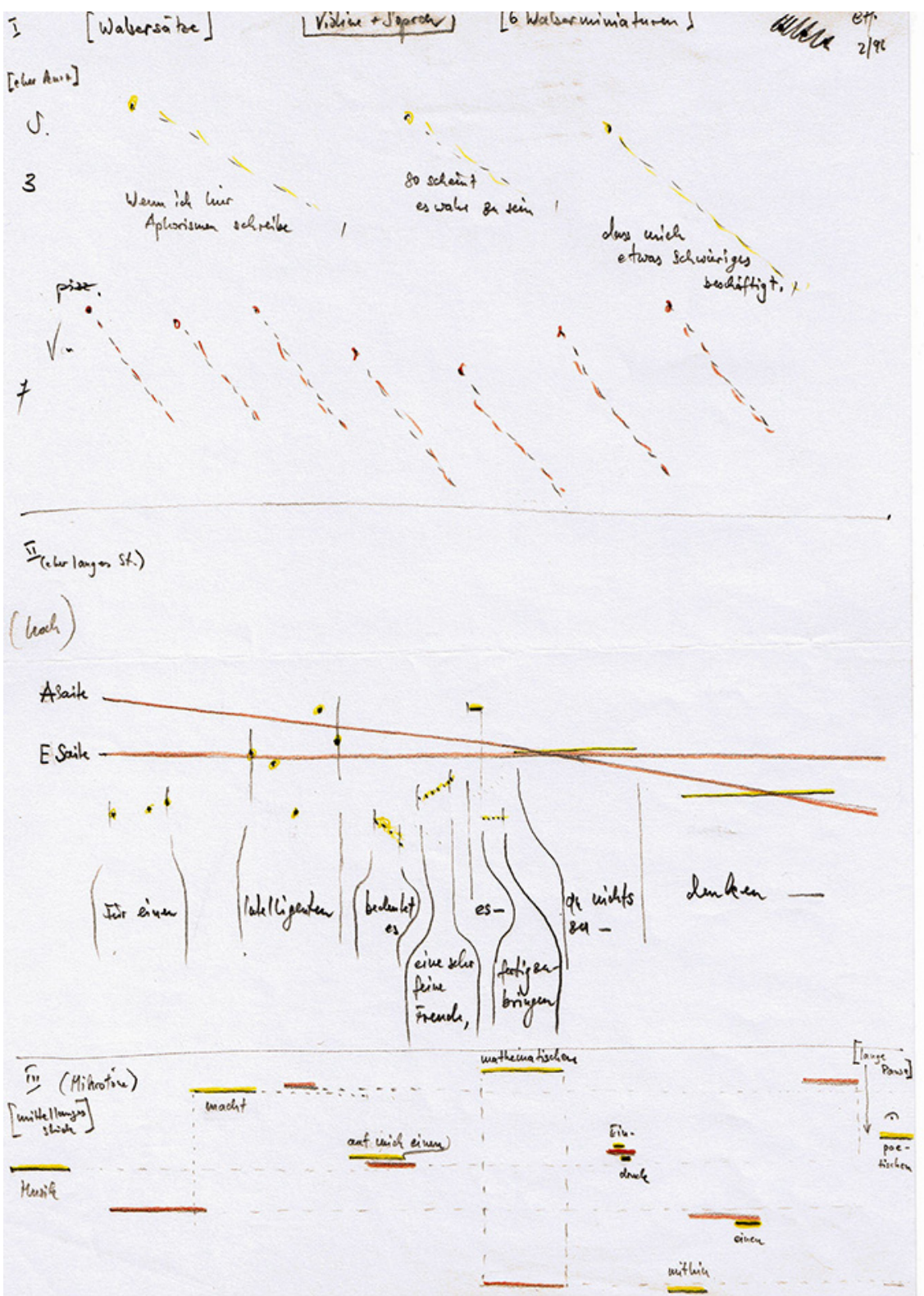

Abb. 73 Edu Haubensak: Skizzen zu Walserminiaturen 


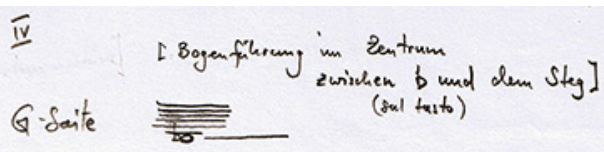

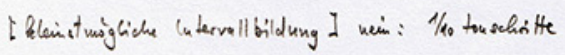

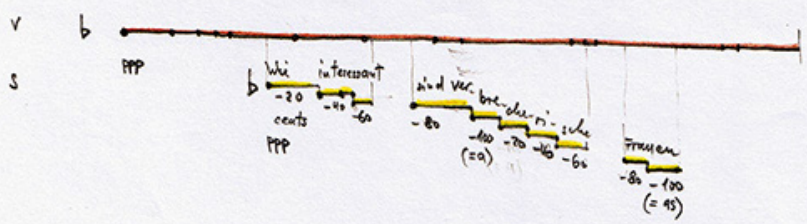

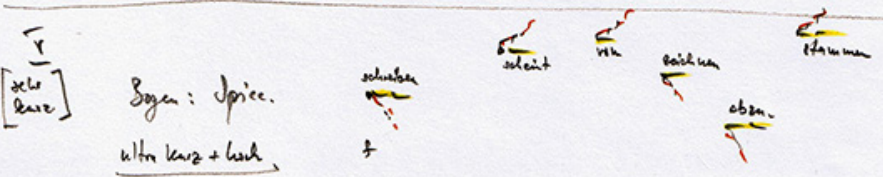

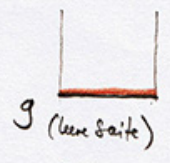

minp

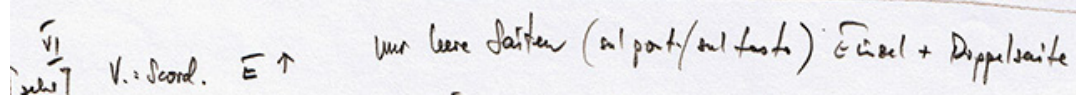

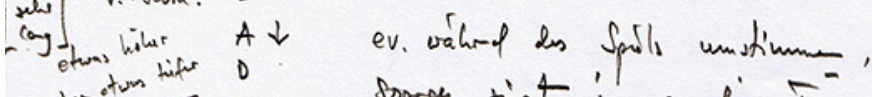

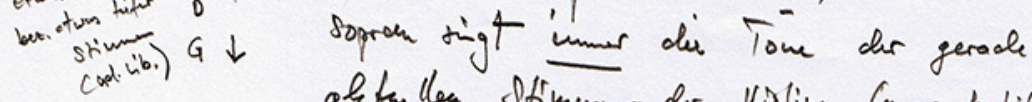
abtanllea stimenny der visline (anser dastifig)

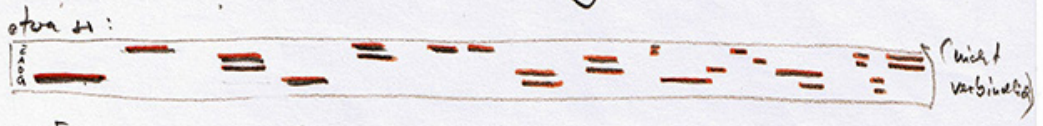
Tangere,

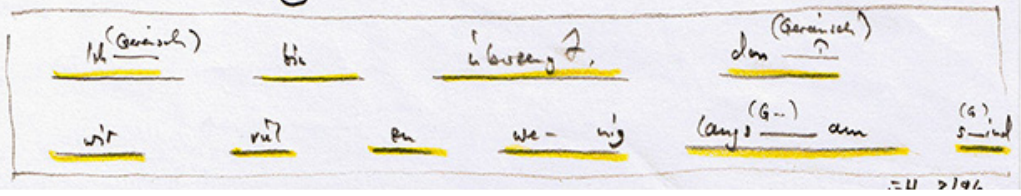


II
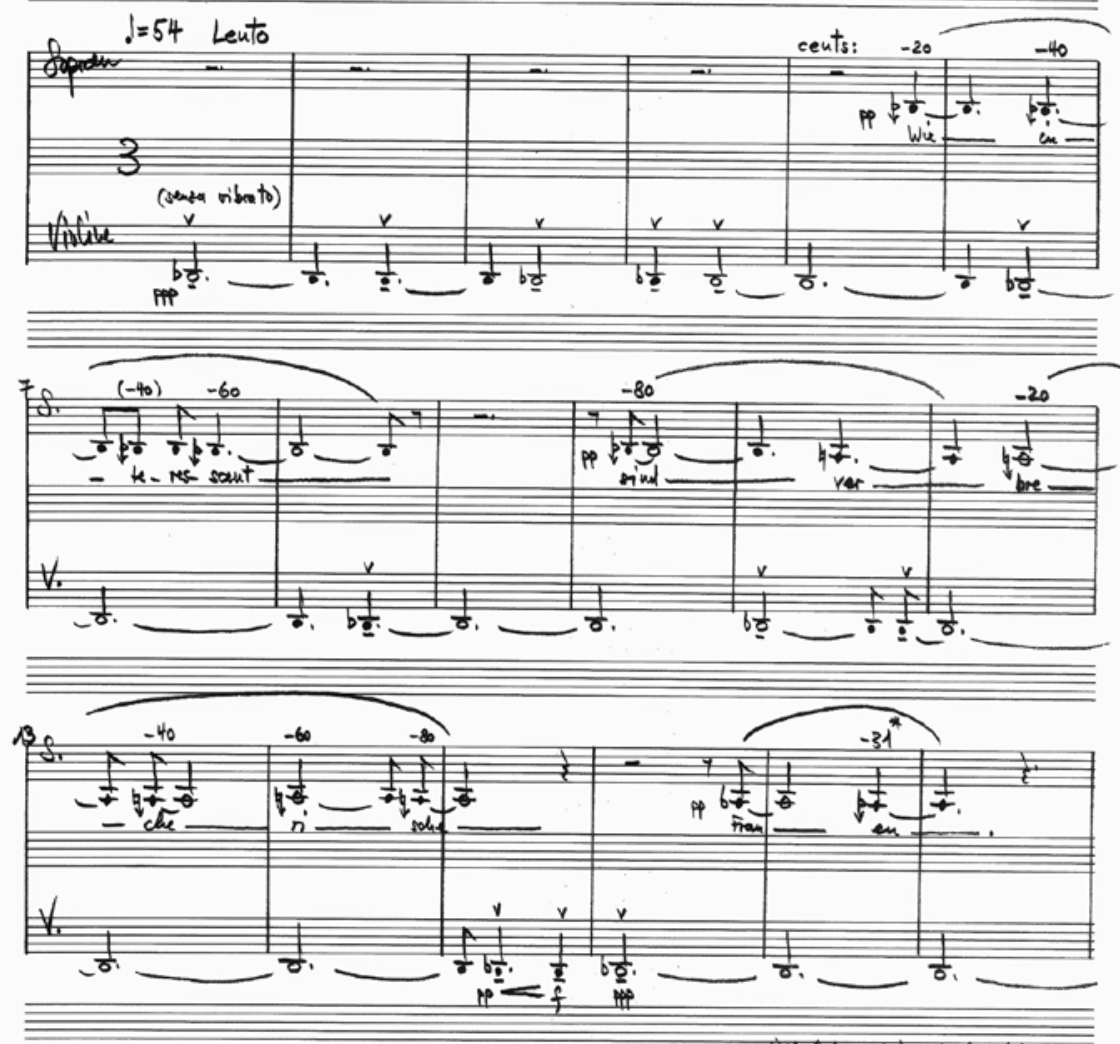

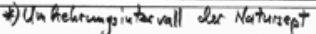

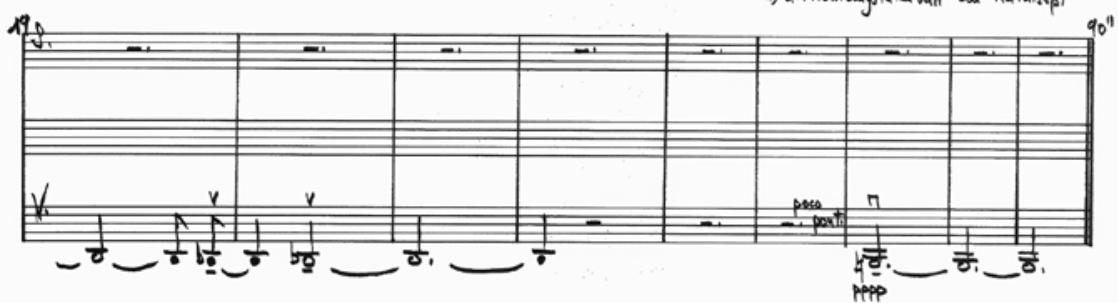

Abb. $74 \quad$ Edu Haubensak: Walserminiaturen IV 
11.9.4 Burkhard Kinzler: Langizit (1996), Trug (1996), winterreisen (2008) Burkhard Kinzler ( $\left.{ }^{*} 1963\right)$ reichte für den Kompositionskurs von Heinz Holliger einen zufällig eben gerade fertig gewordenen kleinen Liederzyklus für Bariton und Streichtrio (mit Kontrabass anstelle des Violoncellos) ein, den er mit dem Schweizerdeutschen Langizit ${ }^{69}$ (für Langeweile und Sehnsucht) betitelte. Die Streicher sind skordiert, das heißt die Saitenstimmung weicht von der Standard-Stimmung ab, um andere Doppelgriffe und Flageoletts zu ermöglichen, »nur die Bratsche ist nicht betroffen - sie ist ein bisschen als alter ego Robert Walsers gedacht - der von seiner Umwelt als > verrückt < wahrgenommen wird, hier mit dem einzigen >un-verrückten $<$ Instrument assoziiert. « ${ }^{70}$

Kinzler studierte nach einem Abschluss in Kirchenmusik Komposition und Musiktheorie bei Roland Moser an der Musik-Akademie Basel. Später folgte ein Dirigierstudium. Seit 2003 ist Kinzler Professor für Musiktheorie an der Zürcher Hochschule der Künste (ZHdK).

Burkhard Kinzler entwickelte - ähnlich wie Heinz Holliger im BeiseitZyklus - für jedes der sechs Lieder von Langizit ein eigenes kompositorisches Verfahren, sodass man verschiedene Autoren hinter den Liedern vermuten könnte. Seht ihr (SW 13, 26f.) wird von einem um den Ton $a$ gelegten mikropolyphon verdichteten Vierteltoncluster dominiert. Wintersonne (SW 13, 8f.) ist ein expressionistischer Ausbruch mit weitausgreifenden melodischen Gesten und einer Satzweise, die an die Zweite Wiener Schule erinnert. Weiter (SW 13, 18) wird als schauerliche Ballade mit >Gitarrenbegleitung ${ }^{71}$ und Zupfbass umgesetzt. Bei Im Mondschein (SW 13, 19f.) muss der Bariton mit Ausnahme der letzten beiden Töne (auf »noch wach «) alles mit der Kopfstimme singen. Auch weil Kinzler in der Setzweise der Streicher den Akkordeonklang evoziert - als Bezug zur im Gedicht angesprochenen $>$ Handharfe $<$ - wird man entfernt an Holligers Version für Countertenor erinnert (vgl. Kap. 6.4). Allerdings ist ein Bariton kein ausgebildeter Altist, der die Falsettstimme ssicher beherrscht; bei Kinzler bewegt sich der Bariton auf unsicherem Terrain, zumal seine Partie sich oft im Kippbereich zur Bruststimme bewegt. Das »lag lang noch wach« ist bei Holliger ein Aushauchen, bei Kinzler das

69 Der Titel dürfte von Walsers Gedicht Langezeit (SW 13, 7f.) abgeleitet sein, das Kinzler aber nicht vertonte.

70 E-Mail von Burkhard Kinzler an Roman Brotbeck vom 11.10.2020.

71 Violine und Bratsche müssen ihre Instrumente quer halten und zupfen, als wären es Gitarren. 
Zurückkommen nach einem Spaziergang auf dünnem Eis in den ordinarioGesang des Baritons. Angst (I) (SW 13, 15f.) und Stille (SW 13, 17f.) sind komplementär vertont: In Angst (I) ist der Text teilweise in die Bratsche verlegt, die rein instrumental die Worte »Ich möchte, die Häuser regten sich « artikulieren muss; der Sänger singt und spricht fast nur noch die Konsonanten: »s(i) $\operatorname{khäm}(\mathrm{e}) \mathrm{u}$ a $\rightarrow$ of $\mathrm{m}(\mathrm{i}) \operatorname{ch}(\mathrm{i}) \mathrm{l}(\mathrm{u} \rightarrow \mathrm{o}) \mathrm{s}(\mathrm{i}) \ll$; über der Stimme des Sängers und nur für ihn sichtbar steht: »sie kä- men auf mich los«. Einzig der Refrain in Walsers Gedicht »das wäre schauerlich« bleibt immer klar verständlich. Im Gegensatz dazu hört man im letzten Lied Stille nur noch die Vokale (vgl. Abb. 76). Auch hier steht der eigentliche Text über den Noten des Sängers. Im Vergleich zur Konsonantenversion löscht diese Vokalvariante jeden semantischen Sinn aus - Sprache wird zur Musik. Kinzler ordnet die zwölf chromatischen Halbtöne in eine symmetrische Anlage von knapp zwei Oktaven $\left(c-h^{1}\right)$ mit der großen Sekunde $b-d e s^{1}$ als Mittelachse. Für einen Bariton ist das eine sehr weite Tessitura. Die Vokale aus Walsers Gedicht werden unterschiedlichen Tonhöhen zugeordnet (vgl. Abb. 75).

\begin{tabular}{|c|c|c|c|c|c|c|c|c|c|c|c|}
\hline$c$ & & es & & $f$ & & $g$ & & $a$ & & $b$ & \\
\hline & 3 & & 2 & & 2 & & 2 & & 1 & & 2 \\
\hline $\mathrm{i}$ & & $\mathrm{e}$ & & $\mathrm{e}$ & & $\mathrm{o} / \mathrm{a}$ & & $\mathrm{a} / 0 ̈$ & & $\mathrm{u}$ & \\
\hline
\end{tabular}

\begin{tabular}{|c|c|c|c|c|c|c|c|c|c|c|}
\hline des $^{1}$ & & $d^{1}$ & & $e^{1}$ & & fis $^{1}$ & & gis $^{1}$ & & $h^{1}$ \\
\hline & 1 & & 2 & & 2 & & 2 & & 3 & \\
\hline $\mathrm{a}$ & & $\mathrm{i}$ & & ä/ö & & $\mathrm{e} / \mathrm{o}$ & & 0 & & $\mathrm{i} / \mathrm{u}$ \\
\hline
\end{tabular}

Abb. 75 Tonhöhenverteilung in Stille von Burkhard Kinzler

Der Vokal i ist im Gedicht dominierend und hat in Kinzlers System drei Tonhöhen, darunter die tiefste $(c)$ und die höchste $\left(h^{I}\right)$; am häufigsten ist aber $d^{1}$. Von den 23 Tönen des Baritons im Musikbeispiel fallen elf auf i-Töne (acht $d^{1}$, zwei $h^{1}$ und ein $c$ ).

Bei diesem großen Umfang werden auch die Vokalformanten gut hörbar. Ein gesungenes i in der kleinen Oktave hat eine andere Klangfarbe als in der eingestrichenen, dasselbe gilt für das u. Überraschenderweise ordnet Kinzler das u ebenfalls dem höchsten Ton zu, auf dem dieser Vokal schon leicht ins ü verfärbt klingt. 

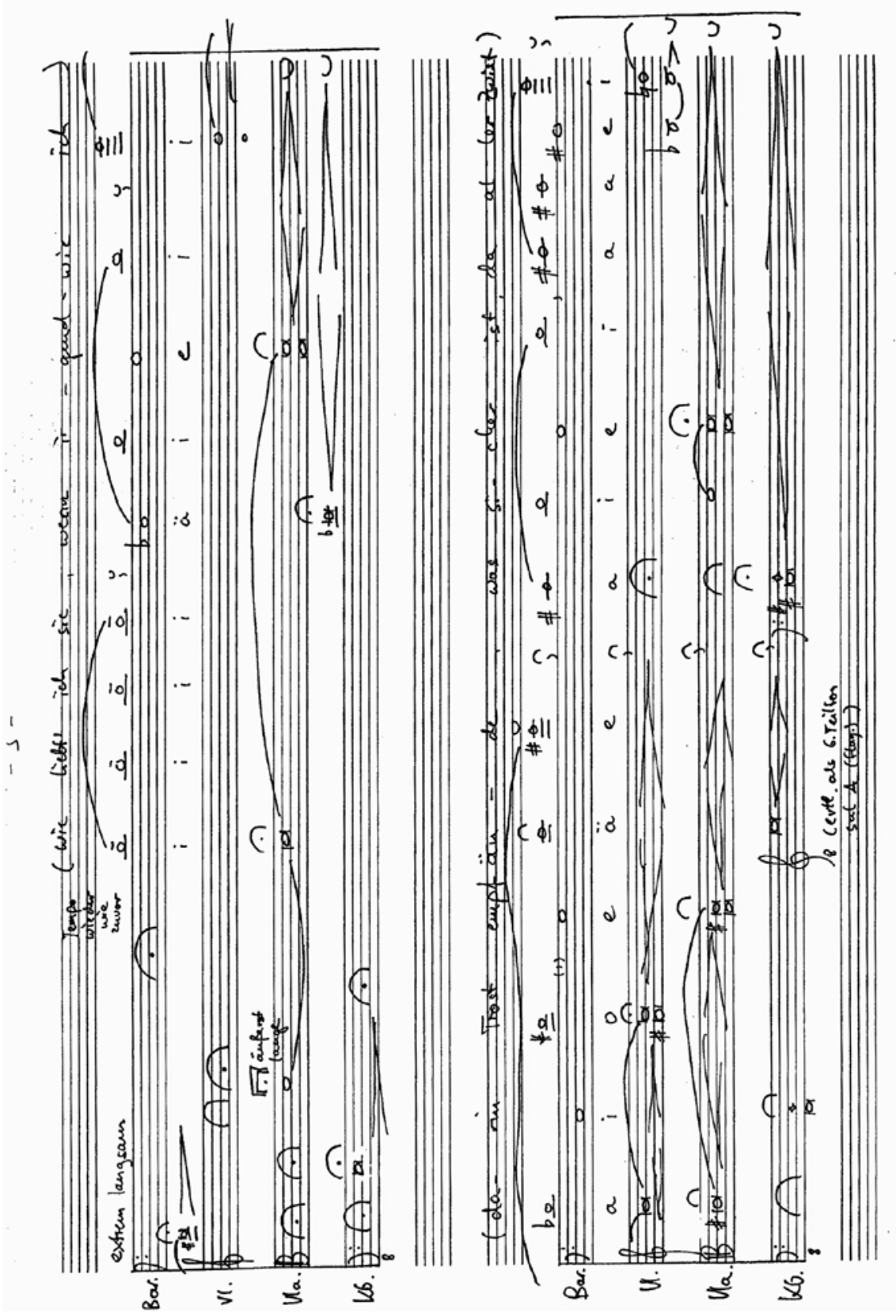

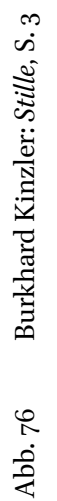


Ebenfalls 1996, noch unter dem Eindruck der Holliger-Walser-Woche, komponierte Burkhard Kinzler ein kurzes Chorstück über Walsers Text Trug (SW 13, 28), das bis heute nicht aufgeführt wurde, aber in seiner Mischung aus Solos und Chorklang bereits auf die Erweiterung von Langizit vorausweist, die der Komponist mit winterreisen 2008 realisierte. Anlass für letztere Komposition war das 100-Jahr-Jubiläum des Oratorienchors seiner Heimatstadt Heidenheim an der Brenz, bei dem vier in der Stadt wirkende oder mit ihr verbundene Komponierende gefragt wurden, sich an einem Jahreszeiten-Projekt zu beteiligen. ${ }^{72}$ Kinzler wählte den Winter und komponierte eine Kantate für Bariton, gemischten Chor und kleines Orchester (mit drei Hörnern). Ihm liegt es, sich mit den Einschränkungen auseinanderzusetzen, die es bedeutet, für Laien zu komponieren.

Das Hauptproblem bei solch einer Aufgabe ist der Bereich der Harmonik. Eine gespannte harmonische Sprache, wie sie auch von mir in anderen Zusammenhängen gerne verwendet wird, ist Laiensängern und -sängerinnen einfach nicht zugänglich. So habe ich versucht, für dieses Stück eine spezifische Tonalität zu entwickeln, die durchaus mit »vertrauten« Konsonanzen arbeitet, aber von der Dur-moll-Tonalität weit entfernt ist und kompositorisch-harmonische Konzepte der letzten sechzig Jahre nicht verleugnet. ${ }^{73}$

Schon im Titel winterreisen ist der Schubert-Bezug offensichtlich. In der Einführung zum Konzert schrieb Kinzler:

In Walsers Gedichten spüre ich auch eine Nähe zur Erstarrung in der Schubertschen Winterreise, jedoch ist Walsers Sprache viel weniger romantischtodessehnsüchtig und gefühlig als die seines romantischen Vorgängers Müller, sondern nüchterner und klarer, bei aller scheinbaren Lieblichkeit. ${ }^{74}$

Zwei Lieder (Seht ihr und Im Mondschein) hat Kinzler aus seinem Zyklus Langizit übernommen und als Orchesterlieder konzipiert. Insgesamt besteht auch der neue Zyklus aus sechs Liedern. Der Schubert-Bezug wird vor allem im zweiten Teil manifest. Das dritte Lied ist eine teilweise ironisch wirkende Collage aus mehr oder weniger bekannten Weihnachtsliedern:

Diese Melodiefragmente haben ihren angestammten Text verloren und sind mit Walserschen Worten unterlegt, der das brüchige Idyll einer bürgerlichen

72 Am Projekt mit dem Namen »Heidenheimer Jahreszeiten« beteiligten sich neben Kinzler noch Ulrike Zürn, Veit Gruner und Eric Mayr.

73 Kinzler: Einführungstext zum Konzert des Oratorienchores Hildesheim, 05.04.2008, Waldorfschule Hildesheim (Mailkopie an Roman Brotbeck vom 30.09.2018.).

Ebd. 
Weihnachtsfeier beschreibt, und zwar in einem derart zugespitzt lieblichen Tonfall, dass schon das Gedicht klar werden lässt, wie wenig die beschriebene Weihnachtsfeier mit dem eigentlichen Inhalt des Weihnachtsgeschehens zu tun hat, ja wie weit sie davon entfernt ist. ${ }^{75}$

In den letzten drei Liedern erscheint dann der Schubert-Geist fast leibhaftig: zuerst mit Im Mondschein, das in der Orchesterfassung den Akkordeonklang der >Handharfe $<$ noch magischer evoziert als die Kammermusikversion, dann das abgründige Ein Landschäftchen (SW 13, 20), in dem Schuberts Frühlingstraum (Winterreise, Nr. 11) anklingt, bis zum abschließenden Der Handharfer (SW 13, 53f.), den Kinzler mit Schuberts Der Leiermann (Winterreise, Nr. 24) kurzschließt. Zwei A-Klarinetten spielen gedehnt und perforiert, aber sofort erkennbar, Schuberts Drehorgelmotiv. Im Folgenden passt Walsers Gedicht so genau zum Schubert-Lied, dass man denkt, Walser müsse die Winterreise gekannt haben (vgl. Kap. 8.5.1).

\subsubsection{Annette Schmucki: am fenster und am fenster. zwei (1996)}

Von 1989 bis 1993 studierte Annette Schmucki ( ${ }^{*}$ 1968) in Winterthur Gitarre und nahm Kompositionsunterricht bei Cornelius Schwehr; von 1993 bis 1997 absolvierte sie ein Aufbaustudium Komposition (Master) bei Mathias Spahlinger in Freiburg im Breisgau sowie ein Studium elektronischer Musik bei Mesías Maiguashca. Schmucki entwickelte sich schon bald zur Sprachkomponistin und zunehmend auch zur Sprachperformerin. 2000 gründete sie mit Reto Friedmann das Duo blablabor, das Hörstücke, Installationen und Performances mit Sprache realisiert. Seit 2010 spielt sie zusammen mit der Pianistin Petra Ronner in der experimentellen >band «. Schmucki interessiert sich für Alphabete, Vokabularien und Wörterbücher aller Art. 2017 komponierte sie für das Musikfestival Bern mit dem Berliner Ensemble Maulwerker und dem Ensemble Proton Bern das Théâtre musical Frucht \& Durst für fünf Stimmen und Instrumental-Ensemble, in dem sie die Arbeit am Deutschen Wörterbuch von Jakob und Wilhelm Grimm als irrlichterndes Musiktheater gestaltete. Dabei hütete sich Annette Schmucki auch hier vor sprachvirtuosen Bravourstücken. Sie will die Musikalität der Sprache jenseits der Worte zum Klingen bringen und lässt das Semantische bloß durch Ritzen oder deformiert hindurchschimmern. Das ist durchaus anspruchsvoll, und für die auf lustige Unterhaltung getrimmte Kritik war Frucht \& Durst denn auch gleich ein »akademischer Murks «. ${ }^{76}$

75 Ebd.

76 Wäch: Ermüdende Wortsuche, S. 4. 
Im Werk am fenster (Am Fenster (II), SW 13, 33) für Sopran und Akkordeon, das Annette Schmucki 1996 für den Kompositions- und Interpretationskurs von Heinz Holliger komponierte, ist schon vieles dieser späteren Entwicklung angelegt: Das beginnt mit dem Ein- und Ausatmen der Sängerin - in Analogie zum >atmenden< Balg des Akkordeons - das in der Partitur exakt vorgegeben und einzuhalten ist, denn in den Aufführungshinweisen steht explizit, »zusätzlich soll nicht geatmet werden «. Und so wie das Akkordeon auf Zug und Stoß Töne spielen kann, muss auch die Sängerin beim Aus- und Einatmen singen oder sprechen. Bei Schmuckis Komposition müsste man eigentlich weniger von einer Vertonung als vielmehr von einer zweimaligen >Betonung « sprechen, denn die Komponistin hebt einmal gewisse Verben (hier kursiviert) und einmal die Substantive (gefettet) in Walsers Gedicht hervor.

\author{
Zum Fenster sehe ich \\ hinaus, es ist so schön, \\ hinaus, es ist nicht viel. \\ Es ist ein wenig Schnee, \\ auf den es regnet jetzt. \\ Es ist ein schleichend Grün, \\ das in ein Dunkel schleicht. \\ Das Dunkel ist die Nacht, \\ die bald in aller Welt \\ auf allem Schnee wird sein, \\ auf allem Grün wird sein. \\ Hin schleicht sich freundlich Grün \\ ins Dunkel, ach wie schön. \\ Am Fenster sehe ich's.
}

In der Mitte des Stückes wird am fenster wie ein Prosatext »quasi >für sich< gesprochen « (vgl. Abb. 77). Schmucki fokussiert darin die zwölf Substantive des Gedichts, die aus insgesamt sechs Wörtern bestehen (je dreimal »Dunkel « und »Grün«, je zweimal »Fenster« und »Schnee« und je einmal »Welt« und »Nacht«). Diese Substantive werden mit den Harmoniewechseln des Akkordeons betont.

Schmucki greift hierbei auf das in der zeitgenössischen Akkordeonmusik kaum benutzte Register des Standardbasses zurück. Es zeigt ihr durchaus politisches Bestreben, sich quasi in das Instrument hinein zu begeben, »in die Geschichte des Instruments, in seine subversiven Möglichkeiten. In die Aktion.« ${ }^{77}$ Der Standardbass referiert nämlich auf die populärmusikalische Herkunft des Akkordeons. Das Instrument war leicht lernbar, weil auf dem 


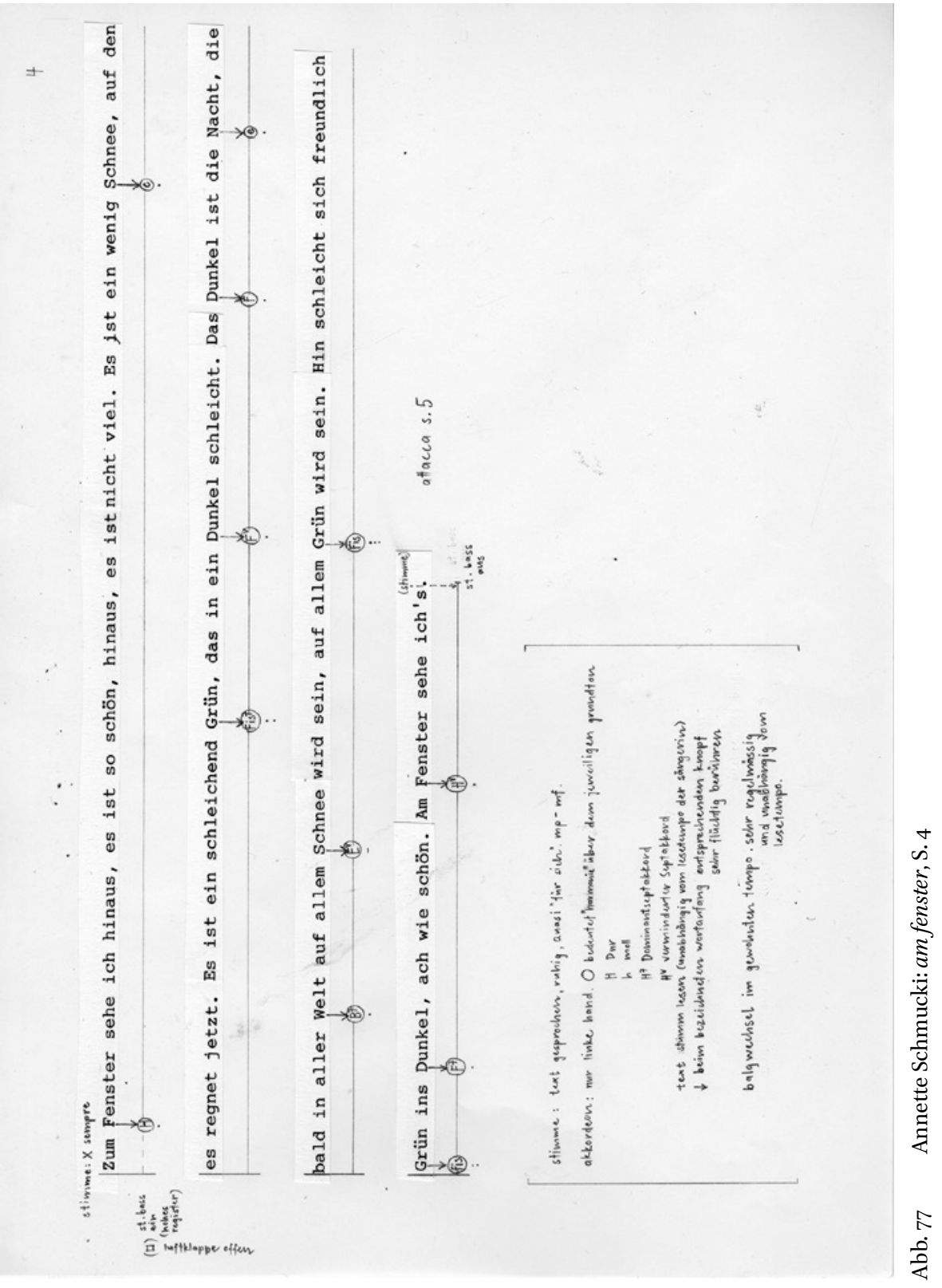


linken Manual nur Harmonien gespielt werden konnten (je eine Reihe Dur-, Moll-, Dominantsept- und verminderte Septakkorde). Vor allem deutsche Firmen wie Hohner in Trossingen hielten bewusst an diesem Harmoniebass fest, obwohl schon in den 193oer-Jahren andere Hersteller sporadisch Einzeltonmanuale für die linke Hand bauten. Vor allem Hugo Herrmann, >Akkordeon-Papst< und NSdAP-Mitglied, verhinderte 1939 entsprechende Entwicklungen. Für ihn war der Standardbass in einer quasi >rassischen< Einteilung der Instrumente »eine typische Arteigenheit der Handharmonika«, die »nicht aufgelöst werden « sollte. ${ }^{78}$ Aus kommerziellen Interessen versuchte Hohner das Akkordeon auch noch nach 1945 und bis in die 196oer-Jahre hinein als Massenprodukt für die zahlreichen Handharmonika-Orchester herzustellen. Aus purer Not wandten sich die innovativen Akkordeon-Solisten an italienische Akkordeonbauer, die die Entwicklung zum Einzelton- und Knopfakkordeon mitmachten; deshalb spielen heute nahezu alle, die professionell Akkordeon spielen, italienische Instrumente, meist in der sogenannten Convertor-Variante, die es erlaubt, mit einfacher Umschaltung den Standardbass auf den Knöpfen des Einzeltonakkordeons ein- und auszuschalten. Mit einem solchen Akkordeon muss auch am fenster gespielt werden, in dem dieser Umschaltmechanismus ständig verlangt wird. Es ist durchaus hintersinnig, wenn Annette Schmucki auf diesen >primitiven< Standardbass zurückgreift, denn sie bezieht die Geschichte des Instruments aktiv mit ein und restituiert damit das Instrument, das Walser in seinen Schriften mit >Handharfe bezeichnet. ${ }^{79} \mathrm{Zu}$ Walsers Lebzeiten gab es - von sehr seltenen Ausnahmen abgesehen - keine anderen Akkordeons.

Schmucki bildet zur Betonung der Substantive gleich ein doppeltes Alphabet von Zuordnungen: Einerseits lässt sie dreimal die Reihe von Durdreiklang $(X)$, Molldreiklang (x), Dominantseptakkord $\left(\mathrm{X}^{7}\right)$ und vermindertem Septakkord $\left(\mathrm{X}^{\mathrm{v}}\right)$ durchlaufen; andererseits sind die Tonhöhen der Akkorde den einzelnen Substantiven von Walsers Gedicht zugeordnet:

Fenster: $\quad \mathrm{H}, \mathrm{H}^{7}$

Schnee: $\quad c, E^{v}$

Grün: $\quad$ Fis ${ }^{7}$, Fis, fis

Dunkel: $\quad \mathrm{F}^{\mathrm{v}}, \mathrm{F}, \mathrm{F}^{7}$

Nacht: $\quad$ e

Welt: $\quad B^{7}$

78 Zit. nach Eschenbacher: Musik und Musikerziehung mit Akkordeon, Bd. 3, S. 14. Eschenbacher fasst die schwierige Entwicklung zum Einzeltonakkordeon umfassend zusammen, ebd., S. 6-30.

79 In ähnlicher Weise hat sich auch Annette Schmuckis erster Kompositionslehrer Cornelius Schwehr in seinem Werk aus den kamalattanischen liedern für Akkordeon (1991/92) mit der Geschichte dieses Instruments auseinandergesetzt. 
Auf jeder Tonhöhe werden die Akkorde variiert; es wird kein Akkord wiederholt. Es gibt zwölf unterschiedliche Akkorde, die auf sechs Tonhöhen erscheinen: $c, e, f, f i s, b, h$. Diese Töne lassen sich in Tritonuspaare ordnen: $b-$ $e, h-f, c-f i s$. Damit korrespondiert die Struktur der Standardbass-Akkorde mit jener der Substantive in Walsers Gedicht. Wie definierte Farbflächen auf einem abstrakten Bild wirken diese von Schmucki betonten Substantive.

Die >Betonung « in der Mitte des Werks wird von einer zweiten, komplementär dazu angelegten Betonungsvariante umspielt, in der das Gedicht Phonem für Phonem vorgetragen wird, oft ins Konsonantische verkürzt. Viele Stellen muss die Sängerin stumm lesen; sie bekommt damit Informationen, die dem Publikum nicht zugänglich sind. Lange, quasi vereiste Haltetöne dominieren, oft in Sekund- oder Tritonusreibung, aber auch hier durchsetzt mit Ein- und Ausschaltungen des Standardbasses. In diesen den Mittelteil umrahmenden Elementen >betont« Schmucki die fünf aktiven Verben des Gedichts: »sehen«, »regnen«, »schleichen«, »schleichen«, »sehen«. Und sie lässt diese Verben ohne Flexion von der Sängerin nicht nur singen, sondern auch sprechen, wobei jeweils das »n« am Schluss der Infinitiv-Form hochgezogen und beim Einatmen gesungen wird.

Annette Schmuckis am fenster ist eine vielfach reflektierte Auseinandersetzung mit Walsers Gedicht, dessen Konstruktionsformeln sie in zweifacher Weise betont. Eine eigentliche Vertonung im Sinne einer den Text bereichernden Musik wird verweigert; dafür wird die Schwierigkeit, Walser zu vertonen, zum Thema der Komposition gemacht. Als Untertitel könnte man setzen: Von der Chance, Walser betonen zu dürfen. Nach ähnlichem Prinzip schrieb Annette Schmucki 1996 für das Vokalensemble Turicum auch am fenster. zwei für elf Stimmen.

\subsubsection{Franco Tosi: Mutlos (1996)}

Der heute vor allem als Musikpädagoge für Klarinette und Musikschulleiter tätige Franco Tosi $\left({ }^{*} 1965\right)$ nahm an Holligers Kompositionskurs mit einer kammermusikalisch geprägten Vertonung teil. Mutlos ( $\mathrm{SW}$ 13, 52) ist ein abgründiges Gedicht, in dem die »stille Trauer « das lyrische Ich besucht. Schon fast in einer gewissen $>$ Dissonanz $\prec$ zum Inhalt des Gedichts ist dessen Form sehr klar aufgebaut; alle vier Strophen weisen mit fünfsilbigen Außenversen und einem viersilbigen Innenpaar die gleiche Struktur auf und bis auf eine Ausnahme fehlen die bei Walser häufigen Enjambements. Franco Tosi folgt dieser Struktur, setzt nach jedem Vers ab und betont speziell die dreimal auftretenden Reime mit »mich«. Den Höhepunkt setzt Tosi beim einzigen Enjambement: »Die Trauer führte // dann so mich weiter / durch dunklen Gram«. »Gram« wird als einziges Wort mit einem langen Melisma und mit dem höchsten Ton $\left(a s^{I}\right)$ hervorgehoben; die Instrumente müssen dazu »ff 
tutta forza « spielen. Tosis expressionistischer Ansatz bricht sich hier Bahn. Danach wird die Vertonung unruhiger, wechselt ins Sprechen (bei der Bitte »behalte mich«) oder wird affirmativer, so beim als Befreiung konzipierten Schluss, wo die Trauer in deutlichem Forte »auf neue Reise « weicht und das lyrische Ich ins Leben entlässt. Das Lied klingt mit schwebenden Klängen im Pianissimo aus.

\subsection{Roland Moser: Walser-Liedchen (1996)}

Zum Abschluss der Holliger-Walser-Woche in Biel schenkte mir Roland Moser (*1943) ein Walser-Liedchen für Sopran allein. Er hatte es auf einer Zugfahrt von Biel nach Basel komponiert. Roland Mosers Vorfahren waren mit Robert Walser bekannt. ${ }^{80}$ Trotz diesem persönlichen Bezug ist diese kurze Komposition bisher die einzige öffentlich aufgeführte Vertonung eines Walser-Texts von Roland Moser. Man könne an Walser nur scheitern, meinte der Komponist in vielen Gesprächen, denn er stelle einem immer ein Bein, und zwar genau an jener Stelle, wo man es am wenigsten erwarten würde. Das sagt ein Komponist, der mit Literatur aufs Engste verwachsen ist und sich kompositorisch mit zahlreichen Dichtern - auch >schwierigen $<$ wie Clemens Brentano, Heinrich Heine und Friedrich Hölderlin - auseinandergesetzt hat.

Als ich Roland Moser nach Skizzenmaterial für das Walser-Liedchen fragte, kam die Fotokopie einer undatierten Skizze für ein anderes Werk zum Vorschein (vgl. Abb. 78), die bereits auf das Musiktheater Die Europäerin vorausweist.

Es ist eine frühe »lettristische Übung«, wie ich sie jetzt auch für die »Europäerin« »perfektioniert« habe. Buchstaben werden zu Noten (jetzt auch Buchstaben

8o Vgl. die leicht ambivalente Erwähnung von Roland Mosers Großonkel Hans Rudolf Moser in einem Brief vom 31.08.1917 aus dem Militärdienst in Roveredo von Robert an Fanny Walser: »Hier wurde von Hans Moser's Unglücksfall erzählt. Das ist traurig. Du wirst auch schon davon gehört haben, und Du wirst es als überflüssig, wenn nicht als unfein empfinden, daß ich Dich daran erinnere, woraus Du ersehen magst, daß ich vom Wunsch und guten Willen beseelt bin, Dir nur Angenehmes und Nettes mitzuteilen.« (BA 1, 398f.). Diesem Hans Moser mit seiner »etwas wirren Intelligenz « widmet Walser in Zu Frau Kappeler sprach in hellstem Morgenlicht Frau Rese (AdB 1, 121-124) eine glänzende Karikatur: »Ganghofer war und blieb sein Lieblingsschriftsteller, und seine Hauptbeschäftigung bestand in einem Sichromantischvorkommen.« (AdB 1, 122) Hans Mosers dort ebenfalls erwähnte »Schrittart eines Brigadegenerals« ist für den Großneffen Roland Moser der mutmaßliche »Grund für den Unfall. Er ging meistens auf der Strassenmitte und weigerte sich, den Autos auszuweichen. So wurde die Geschichte in unserer Familie erzählt.« E-Mail von Roland Moser an Roman Brotbeck vom 27.11.202O. 
aus Solmisationssilben). Das Gedicht habe ich danach sogar fertig komponiert. Einer der schönsten Schnee-Texte [Vielleicht wäre der Schnee, AdB 4, 276f.]. ${ }^{81}$

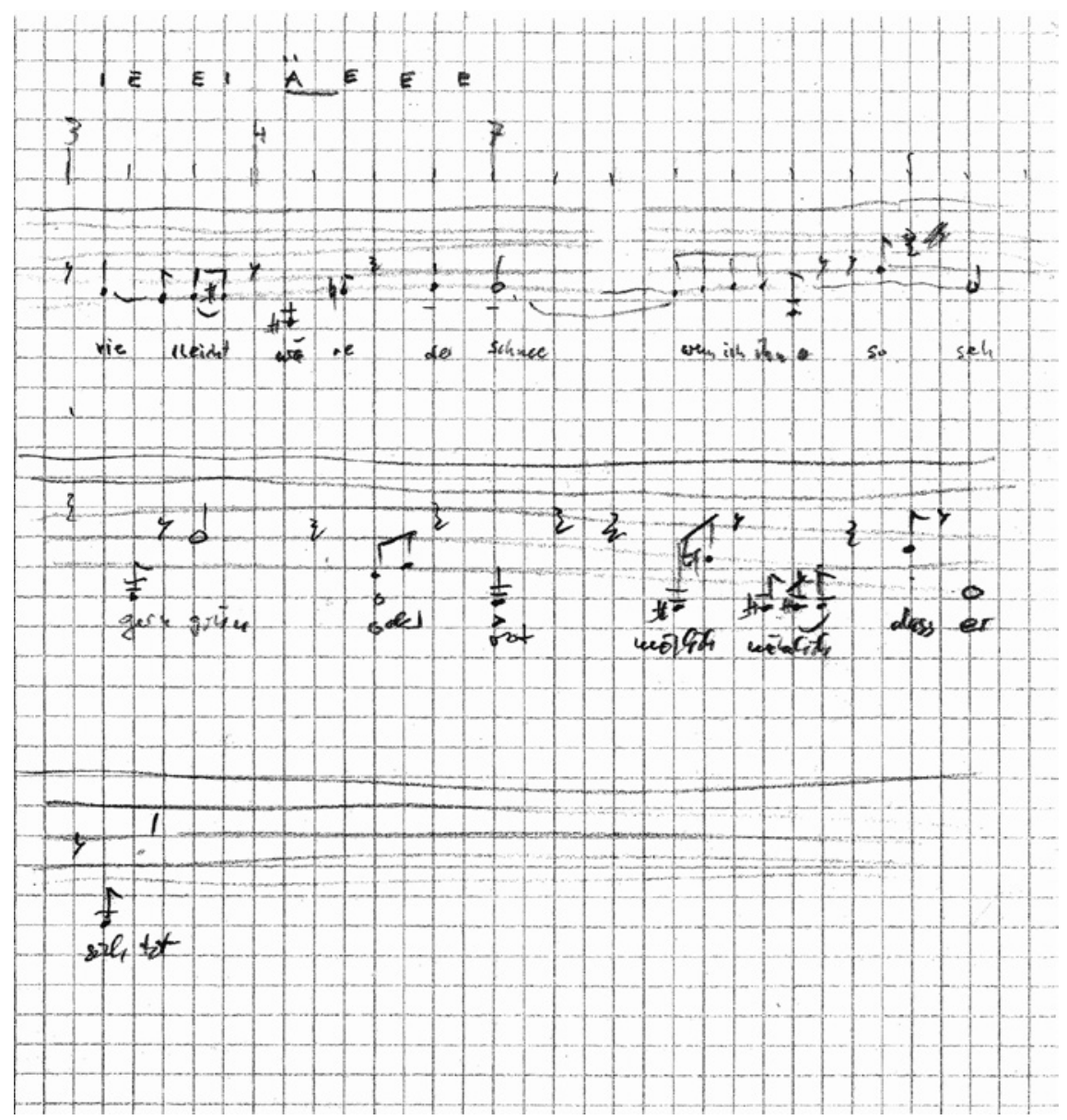

Abb. 78 Roland Moser: Skizze zu Vielleicht wäre der Schnee

81 Brief von Roland Moser an Roman Brotbeck vom 25.11.2020. Diese Beschäftigung mit Walser ist in die Jahre 2017 und 2018 zu datieren. In der Folge hat Roland Moser noch weitere Entwurfsfassungen zu Vielleicht wäre der Schnee gefunden, ebenso Entwürfe zu einer Vertonung von Der Lärchen helle Äste (AdB 4, 265f.). E-Mails von Roland Moser an Roman Brotbeck vom 01.12.202O und 12.12.2020. Die letzterwähnte Vertonung mit dem Titel Der Lerchen/Lärchen helle Äste für Mezzosopran allein wurde am 14.01.2021 vollendet. Die sehr tief gesetzte Partie verlangt bei »Die Stimme, die unhörbare, ist süß und bedeutend « auf die Worte »die unhörbare« ein dis und auf »(be-)deutend « sogar ein $d$; das ist eine Tiefe, welche die meisten Sängerinnen - wenn überhaupt - nur grummelnd und quasi tonlos realisieren können. 
Einstimmige Musik, wie das Walser-Liedchen sie darstellt, spielt im Werk Roland Mosers eine wichtige Rolle. Dabei interessiert ihn nicht das Virtuose, sondern die Melodie und ihre Gesetze, die auf einer jahrtausendealten musikalischen Tradition beruhen. Vor dem Hintergrund dieser weltumspannenden Tradition ist die westliche mehrstimmige Musik - trotz ihrer globalen Ausbreitung immer noch als Sonderfall zu betrachten, der in den Klöstern des Mittelalters entwickelt wurde. So wie man ganz selbstverständlich mit einer Stimme spricht, hat man bis zur Wende zum zweiten Jahrtausend nach Christus auch mit einer Stimme gesungen.

Schon 1979 hat Roland Moser mit dem Stück Alrune für Altblockflöte die komplexe Einfachheit weniger Töne erprobt und bewusst gemacht, welch ein Abenteuer eine einfache Melodie bedeuten kann. Seine einstimmigen Werke sind oft Exerzitien - sieben winzige Kompositionen über dasselbe kurze Gedicht von Klaus Merz für Mezzosopran solo (1996) tragen denn auch den Titel Kleines Exercitium -, in denen die Intervallfortschreitungen in unterschiedliche tonale Kontexte führen. Einstimmige Teile integriert Moser ebenfalls in größere Werk-Zyklen, zum Beispiel in Musik zu Pontormo (1986) oder in Brentanophantasien (1988-1995), in denen sie besondere Umschaltpunkte der Werke darstellen.

Oft thematisiert Moser in den einstimmigen Werken die Fragen des Fortschreitens und des nächsten Schritts: Welches soll der nächste Ton sein? Und wohin wird dieser führen? Soll ich an den Anfang zurückkehren oder mich wegbewegen?

Bei diesen Fragen sind wir essentiell bei Walsers Spätwerk, das von diesen selbstreflektierenden Fragen des Fortschreitens bestimmt ist. Aus diesem Spätwerk wählte Roland Moser für das Walser-Liedchen das Gedicht Aufrichtigkeit ist banal (AdB 2, 318) aus (vgl. Abb. 79). Das Hin und Hergehen ist diesem Text eingeschrieben, zugleich auch das Weitergehen und Variieren, ablesbar schon in der Versanlage. Im Folgenden sind am Rand die Anzahl Silben und die Anzahl Wörter angegeben; bei keinem Vers ist sie identisch. Die 24 mehrsilbigen Wörter in dem von 41 einsilbigen Wörtern dominierten Gedicht sind in den Versen an unterschiedlichen Stellen eingelassen, sodass hier die rhythmischen Ostinati, welche die frühen Gedichte oft antreiben, fehlen. Jeder Vers ist eine neue Variation. (Kursiv gesetzter Text bezieht sich auf Abschnitte, in denen Moser Töne repetiert.)

(1) Aufrichtigkeit ist banal,

(2) und keiner wird von Wahrheiten satt.

(3) Ich ändere an der Welt nichts,

(4) wenn ich vom Ändern rede.

$\begin{array}{ll}7 & 3 \\ 9 & 6 \\ 8 & 6 \\ 7 & 5\end{array}$




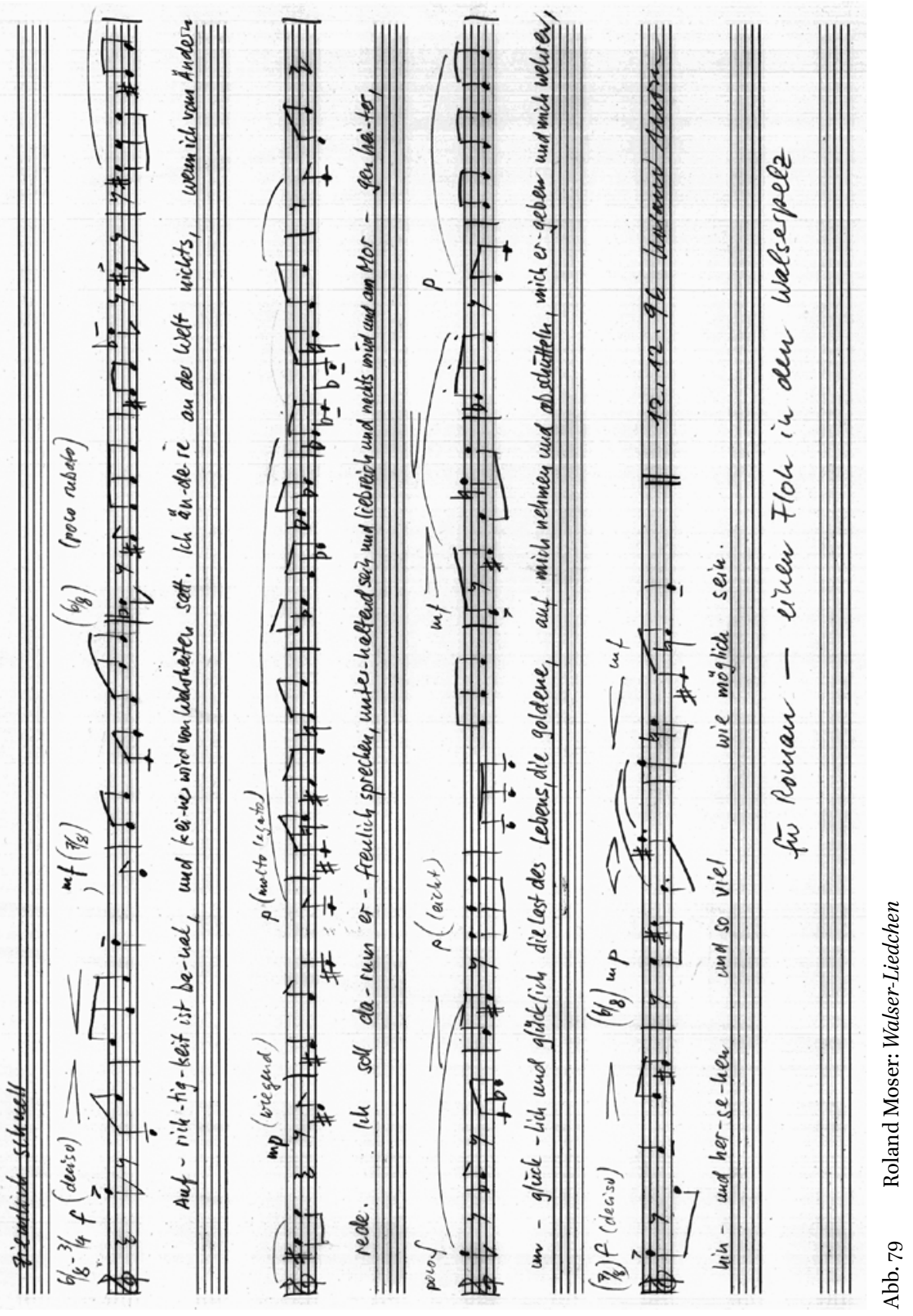


(5) Ich soll darum erfreulich

(6) sprechen, unterhaltend sein

(7) und liebreich und nachts müd und

(8) am Morgen heiter,

(9) unglücklich und glücklich,

(10) die Last des Lebens, die goldene,

(11) auf mich nehmen und sie abschütteln,

(12) mich ergeben und mich wehren,

(13) hin- und hersehen und so viel wie möglich

(14) sein.

Roland Mosers Vertonung reagiert fast seismografisch auf die Richtungs- und Stimmungswechsel des aus drei Sätzen bestehenden Gedichts. Zugleich ist es eine Wanderung durch unterschiedlichste Intervallkonstellationen einstimmiger Musik. Das Tonhöhenalphabet besteht aus 21 Tönen (chromatische Halbtonskala von $b$ zu $f s^{2}$ ); von dieser Zahl sind auch die 21 Takte abgeleitet. ${ }^{82}$ Mit Ausnahme des dritten Takts (7/8) changiert die Taktorganisation zwischen 3/4- und 6/8-Takt. Mit den Intervallfortschreitungen prägt Moser die unterschiedlichen Abschnitte des Gedichts; das ist wie bei Walser höchst kalkuliert. Ein paar kurze Hinweise sollen das im Folgenden andeuten.

Die ersten beiden Verse werden in klarer Diatonik mit einer palindromischen Figur umgesetzt. Wegen großer Sprünge und der anfänglich weiten Lage nimmt man das Palindrom nicht direkt wahr. Im Folgenden sind in eckigen Klammern einerseits die weiten Intervalle ohne Oktaven und andererseits die absteigenden Intervalle als Komplementärintervall dargestellt (zum Beispiel die absteigende Sexte von neun Halbtönen als Kleinterz von drei Halbtönen).

Palindromische Intervallabfolge T. $1-3$

$$
\begin{array}{r}
f^{2}(-18)[6] h(13)[1] c^{2}(4) e^{2}(-9)[3] g^{1}(2) a^{1}(5) d^{2}(-12) \\
d^{1}(5) g^{1}(2) a^{1}(-9)[3] c^{1}(4) e^{1}(1) f^{1}(6) h^{1}
\end{array}
$$

$82 \quad 21$ ist eine besondere Fibonacci-Zahl, bei der auch die Ziffern $(2,1)$ sowie deren Quersumme (3) Fibonacci-Zahlen darstellen. »[D]as hat früher eine wichtige Rolle gespielt. Es ging schliesslich fast automatisch. Vielleicht ist das in meinem Liedchen sogar so ein Automatismus. [...] Übrigens sind mir diese Zahlen mittlerweile etwas verleidet. Deshalb habe ich ganz einfach eine neue Pseudofibonacci gemacht mit dem Austausch der ersten beiden Zahlen: 2134711182947 ... Vor allem 4711 finde ich immer noch ganz heiss. Auch der Schritt zurück nach der ersten Zahl.« E-Mail von Roland Moser an Roman Brotbeck vom 01.12.2020. Mit oder ohne Fibonacci bleibt es fast magisch, wie oft die Zahl 21 in Walser-Vertonungen auftaucht. 21 Lieder bei Gloria Isabel Ramos Triano, 21 Walser-Texte bei Christian Henking, Nr. 21 aus der Winterreise als Bezugspunkt bei Thomas David Müller und vor allem die Hausnummer 21 bei Robert Walsers Schwendimann: das Totenhaus. 
Das ist allerdings nur der äußere >Phänotypus< des Tonhöhensystems. Roland Moser wies mich auf den im Hintergrund wirksamen >Genotypus $<$ hin:

Es ist eigentlich fast noch ein bisschen einfacher. Du gehst bei den Zahlen von Strecken aus, ich von Entfernungen im Quinten-Quartenzirkel, also von Spannungsgraden. ${ }^{83}$

Um das zu verstehen, stelle man sich am besten einen Quintenzirkel als >Uhr< vor und zähle die `Stundenabständeく darauf: $f-h$ ergibt dann 6 Stufen, $h-c$ ergibt 5 Stufen etc.

Der Anfang ist dann 6543210123456 sogar orthografisch noch weiter geführt mit 789 10, danach endlich enharmonisch verwechselt (gis statt as) [Ende Takt 6], dass das ausgerechnet auf das Wort »Ändern« fällt, ist wohl einer der glücklichen Zufälle (vielleicht auch Absicht, das weiss ich nicht mehr). ${ }^{84}$

Mit diesem Überdrehen des Quintenzirkels ab »satt« wird auch die Diatonik zunehmend erweitert und in enharmonische Bereiche geführt: fis - es in Takt 5 hat dann neun Stufen (bzw. drei, wenn dis geschrieben würde) und es - cis zehn Stufen (bzw. zwei, wenn des geschrieben würde). Trotz dieser >prästabilisierten< Harmonik kann Moser Walsers Text in all seinen Ausfransungen in der konkreten Gestaltung präzis umsetzen.

Man kann mit diesem etwas hybriden Verfahren je nach Text passende »Inseln« machen. Dass so etwas mit spätem Walser besser funktioniert als mit jedem anderen Autor liegt am Porösen seiner Sprache. Es gibt bei ihm fast keinen Leim zwischen den Wörtern, er springt hin und her, verführt oft einzig vom Klang. ${ }^{85}$

Eine für Mosers Intervall-Alchimie typische Stelle ist »erfreulich sprechen, unterhaltend sein und liebreich und nachts müd« (T. 9-11), bei der Moser in Dreiklangfiguren von D-Dur (2 Kreuze) bis ins entfernte Ces-Dur (7 Bes) dreht, und zwar mit dem scheinbar einfachen Kniff, regelmäßig zwischen auf- und absteigenden großen und kleinen Terzen zu wechseln. Um das deutlich zu machen, werden im Folgenden alle Sexten als Umkehrungsintervalle geschrieben - eine aufsteigende kleine Sexte $(+8)$ wird also zur großen Terz (-4).

83 E-Mail von Roland Moser an Roman Brotbeck vom 01.12.2020.

84 Ebd.

85 Ebd. 
er $[+3]$ freu[-4]lich [-3] spre[-4] chen, $[+3]$ un $[+4] \operatorname{ter}[+3]$ hal $[-4]$ tend $[-3]$ sein $[-4]$ und $[-3]$ lieb $[-4]$ reich $[-3]$ und $[-4]$ nachts $[-1]$ müd

Der Effekt dieser Stelle ist verblüffend: Man hört die allbekannten Intervalle der tonalen Musik, die Wirkung aber ist eine fast schmerzhafte Verdrehung; ein eindrücklicher Nachvollzug der Verbiegung, die das lyrische Ich von Walser bei seinem Lob der gesellschaftlichen Anpassung vollziehen muss.

Es sei noch auf die beiden Intervallaggregate der letzten drei Verse hingewiesen: Nach »mich ergeben« kehrt Moser zur Diatonik des Anfangs zurück, allerdings in einer Fünftönigkeit und in einer Disposition von reinen Quinten und Oktaven. Der Teilvers »soviel wie möglich sein« ist der Zerrspiegel davon: Nun dominieren Tritonus und zwei große Septimen - es sind die einzigen im ganzen Lied. Dazu gibt es das einzige Melisma auf »viele« und dort auch ein einziges Mal den höchsten Ton. Das Intervall-Exerzitium ist erfüllt. Vor der Uraufführung des Stücks (2009) veränderte Moser den letzten Ton, indem er ihn in einen zusätzlichen Takt setzte: ${ }^{86}$ »Das letzte Wörtchen bildet ja bei Walser einen ganzen Vers: den kürzestmöglichen (deshalb piano und in verkleinertem Takt). ${ }^{87}$

Damit bricht Moser zwar mit der von ihm gesetzten Grundstruktur der 21 Takte, aber auch dieser kleine >Systemverstoß passt durchaus zu Walser, zumal dieses als Schluss und eigener Vers gesetzte »sein « mit all seinen existentiellen Konnotationen wirklich zu den zahlreichen literarischen Sensationen des Spätwerks zählt.

Vor einigen Jahren hat Roland Moser seine Skepsis gegenüber einer eigenen musikalischen Beschäftigung mit Robert Walser überwunden und mit Die Europäerin. Musiktheater nach dem Mikrogramm 400 von Robert Walser für tiefen Mezzosopran, hohen Bariton, einen Schauspieler, tief scordierte Viola und Blockflöte(n), resp. Okarina seine erste größere Arbeit gewagt. ${ }^{88}$ In diesem Mikrogramm wird ein witzig-kritischer Aufsatz zu den undramatischen, weil

86 Das Musikbeispiel zeigt die erste Fassung mit 21 Takten.

87 Brief von Roland Moser an Roman Brotbeck vom 21.09.2009.

88 Kompositionsauftrag Festival für Neue Musik Rümlingen. UA 21.08.2021 am Festival Les Jardins musicaux in Rondchâtel, Péry-La Heutte. Die Europäerin: Leila Pfister; Ihr Freund: Niklaus Kost; Ihr Begleiter/Autor:Jürg Kienberger; Bratsche: Alessandro D’Amico; Okarina und Blockflöten: Conrad Steinmann. Regie, Bühne und Kostüme: Ingrid Erb; Dramaturgie: Pierre Sublet. Da die Uraufführung nach Redaktionsschluss dieses Buches stattfindet, kann dieses Werk hier nur kurz erwähnt werden. Das betrifft alle im Herbst 2021 am Festival für Neue Musik Rümlingen in den Kantonen Appenzell uraufgeführten Werke (vgl. Vorwort). 
zu lyrischen Dramen von Kleist mit zwei Gedichten und einem an Undramatik kaum zu übertreffenden Dramolett kombiniert. ${ }^{89}$

Vieles von dem, was Roland Moser im Walser-Liedchen en miniature erprobte, taucht auch in diesem >Gesamtkunstwerk auf: eine präzise Kammermusik, viel Einstimmiges - Teil V ist mit »Soli« beschrieben und besteht aus Soli der fünf Ausführenden. Mit nur zwei Melodieinstrumenten komponiert Moser eine fintenreiche Musik, die auf abgelegene Pfade führt und mit der Okarina zu Beginn des Stücks >vorweltlicheく Zeiträume öffnet. Die Gefäßflöte, die seit dem 19. Jahrhundert als Okarina ( $>$ Gänschen $<$ ) vor allem in der Volksmusik Verwendung findet, ist nämlich eines der ältesten Instrumente der Menschheitsgeschichte und taucht in fast allen eurasischen und lateinamerikanischen Hochkulturen auf. ${ }^{90}$

\subsection{René Mense: Vier Lieder (1997)}

Wie die Walser-Vertoner Martin Wistinghausen (vgl. Kap. 10.13) und Erich S. Hermann (vgl. Kap. 8.6.3) war auch René Mense (*1969) Schüler von Ulrich Leyendecker. René Mense studierte nicht nur Komposition, sondern auch Gitarre, Klavier und Gesang und ist vielseitig tätig. Als Komponist nutzt er eine breite stilistische Palette und schreibt bisher - mit Ausnahme der Oper - für alle Gattungen, darunter auch viel geistliche Musik.

Für Vier Lieder wählte Mense zwei Texte aus dem oft vertonten Korpus von Walsers 1909 veröffentlichten Gedichten aus. Er nahm zwei Gedichte, die bis heute nur von ihm in Musik gesetzt wurden: Helle (SW 13, 12) und Welt (I) (SW 13, 11). Helle zählt zu den sieben von vierzig Gedichten ohne explizites lyrisches Ich. ${ }^{91}$ Für Welt $(I)$ verwendet Mense den Titel der Erstveröffent-

89 Es handelt sich um folgende Texte: Das Dramolett Die Europäerin, Ihr Freund, Ihr Begleiter (AdB 4, 364-366), die Gedichte »Blonde Bestie, stör' mich nicht« (AdB 4, 311) und Frauen sind in Gemächern (AdB 4, 311f.) sowie Entwurf zu Theateraufsatz aus Potpourri (AdB 4, $378-380)$.

90 »Eine Gefäßflöte aus Ton mit einem Tierkopf, welche in Yarim Tepe, $75 \mathrm{~km}$ von Niniveh entfernt, gefunden wurde (Hassuna Periode, 6. Jahrtausend v. Chr.), gilt als das älteste musikalische Zeugnis Mesopotamiens überhaupt.« Betz: Gefäßflöten, Sp. 585 .

91 Die Vertonungsfrequenz dieser sieben Ich-losen Gedichte in der Sammlung von vierzig Gedichten differiert stark: Vier Gedichte wurden nur einmal vertont - neben Helle sind dies Tiefer Winter (SW 13, 14f.) von Daniel Glaus; Knabenliebe (SW 13, 23f.) von Bruno Karrer sowie Enttäuschung (SW 13, 24) von Wilhelm Arbenz. Drückendes Licht (SW 13, 25) wurde dreimal vertont (Henking, Holliger, Kinzler), Ein Landschäftchen (SW 13, 20) viermal (Fischer, Girod, Kinzler, Schwertsik), Und ging (SW 13, 27) sogar sechsmal (Febel, Frey (2), Holliger, Schneider, Schweitzer). 
lichung: Glück. Hier taucht das lyrische Ich erst zum Schluss auf. Für Hubert Thüring erfolgt hier »die subjektbestimmte Erfahrung der einen stabilen Welt, der Welt als Welt, d. h. der Realität, die das zuvor offenbar bedrohte Ich nun angstfrei erkunden kann.« (RWH, 345; kursiv i. O.) Allerdings tut das Ich dies sprachlich ziemlich patzig, sodass diese stabile Realität behelfsmäßig wirkt und es im Gebälk ächzt: »Ich bin nicht mehr bekümmert, / da ich kann unzertrümmert / die Welt als Welt durchstreben.«

Die beiden Walser-Gedichte kombiniert Mense erstaunlicherweise mit zwei Gedichten von Rainer Maria Rilke, Vorfrühling (1924) und Die Bettler (1908). ${ }^{92}$ In beiden Rilke-Gedichten ist ein lyrisches Du auffällig - suggestiv in Vorfrühling (»Unvermutet siehst du seines Steigens / Ausdruck in dem leeren Baum«), irritierend bei Die Bettler, wo das lyrische Du sich in die dritte Person verschiebt, sobald die Bettler erscheinen und zu sehen ist, »wie ihr Aussatz frißt«.

Walser mochte Rilke nicht sonderlich: Schon auf dem allerersten Spaziergang mit Carl Seelig lobt er Eichendorff und Gottfried Keller, »Rilke hingegen gehöre auf den Nachttisch der alten Jungfern. ${ }^{93}$ Das Gedicht Rilke (SW 13, 181f.), das Walser auf dessen Tod schrieb, streift die Glosse. Walser münzt die von Rilke oft verwendete Du-Form nun direkt auf diesen selbst: »Frieden sei nun / mit dir, du Zier im Lyrikersaale, / schimmernde Frucht in schöngeformter Schale.«

Mense gelingt die Zusammenführung der zwei gegensätzlichen Dichter, indem er Rilke wie Walser in den musikalischen Kontext ihrer Schaffenszeit stellt. Rilke wird in die Verbindung mit der Wiener Schule gebracht: Vor allem Anklänge an Webern und Schönberg sind zu hören, besonders die Vertonung von Die Bettler wird ins Expressionistische gesteigert. Die Walser-Lieder hebt Mense davon mit einer doppelbödigeren Vertonung ab. Helle behandelt das gleiche Thema wie Vorfrühling, wirkt im Zyklus aber wie eine Parodie auf Rilkes sublimes Frühlingsgedicht, denn die Wintersonne wird mit einer »bleichen Nonne« verglichen und der Frühling setzt sich ohne »Federlesens« durch und braucht dazu »nicht Raketen und nicht Zunder«, sondern »nur klare Nacht«. Um solche textimmanente Selbstkommentierung musikalisch zu vermitteln, wählt Mense eine Chanson-ähnliche Form mit komplexer Harmonik. Er übernimmt die Periodizität von Walsers Versstruktur, was es ihm erlaubt, Einzelheiten zu überspitzen, harmonisch zu verdichten, auffällige Bilder zu markieren und trotzdem den Schluss mit »nur klare Nacht« poetisch verträumt zu gestalten. Beim letzten Lied Glück ist dieser Chanson-Aspekt verstärkt, und man fühlt sich auf die Bühne des literarischen Kabaretts versetzt.

92 Rilke: Werke, Bd. 1, S. 539 und Bd. 2, S. 315.

93 Seelig: Wanderungen, S. 11. 
Walser dürften Menses Vertonungen in ihrer Mischung aus scheinbarer Einfachheit und überraschenden Pointen gefallen haben. Und man bedauert, dass Robert Walser im literarischen Kabarett der Jahrhundertwende nicht rezipiert wurde. René Mense vereint die beiden Positionen von Expressionismus und dessen Widerpart in einem Zyklus, ohne dass sie sich gegenseitig denunzieren. Alle vier Lieder behalten ihren Wert, ihre Qualität und ihre Eigenständigkeit.

\subsection{John Woolrich: Little Walserings (1999)}

Der englische Komponist John Woolrich ( $\left.{ }^{*} 1954\right)$ nimmt im englischen Musikleben wichtige Positionen ein, leitete verschiedenste Musikfestivals und wurde von Kompositionsaufträgen geradezu überhäuft - außerhalb von Großbritannien kennt man ihn aber kaum. Die Gründe dafür könnten in seinem gemäßigten Stil und in seinem Bemühen liegen, mit seinen Werken an die musikalischen Traditionen anzuknüpfen. Am offensichtlichsten wird dies, wenn er Monteverdi und Mozart in unterschiedlicher Weise >rekomponiert<, sowie an seinen Solokonzerten, in denen er ohne Bedenken die virtuose Tradition dieser Gattung weiterführt. Woolrich hat für alle Gattungen komponiert. Seine Partituren zeigen ein kompositorisches Handwerk, das sich auf die ganze Musikgeschichte seit dem Mittelalter abstützt.

John Woolrichs Musik lebt von der ambivalenten Mischung aus Pathos in der Tradition Benjamin Brittens und Witz im Sinne des Neoklassizismus. Das führt beim Hören immer wieder zur Frage, ob eine plakative Stelle oder ein überraschendes Zitat nun wirklich ernst gemeint oder nur ein >Als-ob< ist. Diese Ambivalenz passt gut zu Robert Walser, ${ }^{94}$ mit dem sich John Woolrich bisher in drei Werken auseinandergesetzt hat. ${ }^{95}$ Walser ist für den Komponisten auch über die einzelnen Kompositionen hinaus von zentraler Bedeutung: »Walser's words and ideas are deeply embedded in my work, even if his name isn't directly connected to it. «96

Zwei der Walser-Auseinandersetzungen von Woolrich sind Kammermusikwerke. 2005 entstand Quiddities oder als alternativer Titel Lake Greifen: »The

\footnotetext{
94 Vgl. Lüscher: Robert Walsers Sensibilität für Ambivalenzen, S. 15-19.

95 Momentan ist ein viertes Werk im Entstehen, das Texte von Walser enthält: »My song cycle is called `That long journey«, for tenor and piano. It uses fragments of texts by Walser mixed with words by many other writers. « (E-Mail von John Woolrich an Roman Brotbeck vom 21.09.2020). >Schweizerisches< interessierte Woolrich früh; schon 1992 komponierte er einen elfteiligen Zyklus zu Skulpturen von Jean Tinguely mit dem Titel It is midnight, Dr Schweitzer für elf Streicher.

96 E-Mail von John Woolrich an Roman Brotbeck vom 25.05.2016.
} 
narrator swims in a small hidden lake. What will such a swim be like when the lake is dark and the sky full of stars? «97

Dieser nächtliche Schwimmer, der sich in den Wassermassen, im Sternen-

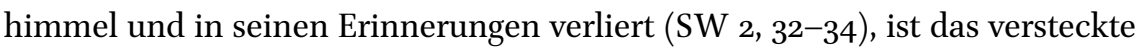
Programm des Werks für solistisches Englischhorn und Streichsextett, wobei das Englischhorn mit dem Schwimmer - »ich schwimme mit größter Fröhlichkeit weit hinaus « (SW 2, 34) - und das Streichsextett mit der »süße[n], stille[n] Tiefe« (SW 2, 34) des unheimlichen Greifensees assoziiert ist.

2008 komponierte Woolrich A Dramolet für Klarinette, Violoncello und Klavier. Er bezieht sich dabei auf die gleich besetzten Werke von Ludwig van Beethoven (op. 11 B-Dur, »Gassenhauer-Trio«) und Johannes Brahms (op. 114 a-Moll). Woolrich verknüpft das Werk mit den späten Dramoletten von Walser:

I've borrowed the title from the Swiss writer Robert Walser, whose writing became more and more condensed. His microscopic texts (written in miniscule pencil writing) are complex and allusive montages. ${ }^{98}$

In Bezug auf das 1891 komponierte Trio von Brahms kommt es zu einer Umkehrung der Verhältnisse:Während Brahms' Werk wie ein Abgesang wirkt, bei dem die erschöpfte und wenig konturierte Motivik allerdings die Kontrolle bis in die letzte Verästelung der Musik zu bewahren versucht, zerfällt Woolrichs kurze Komposition in Fragmente und die Instrumente tauschen die Rollen: Die hohen Kantilenen spielt das Violoncello, eigentlich das Bassinstrument; die Klarinette, eigentlich das Sopraninstrument, grummelt über weite Strecken in tiefer Lage. Das Klavier steht wie daneben und zeigt fast neurotisches Verhalten, etwa wenn der Interpret wie in einem Krampf aufs Klavier einschlägt. Vieles ist unberechenbar, weil sich zwischen den Instrumenten keine Kommunikation über musikalische Elemente ergibt; vielmehr werden diese in einen vertrackten Hoquetus eingebunden, bei dem sie ständig aneinander vorbei spielen müssen - eine klare Anspielung auf die aneinander vorbei sprechenden Figuren in Walsers Dramoletten.

Nur einmal hat John Woolrich bisher Texte von Walser vertont: Für den BBC Choir komponierte er 1999 Walserings für gemischten Chor und Streicher. Er wählte Ausschnitte aus Walser Kurzprosa, die an Topoi der Chorliteratur

$97 \quad$ Ebd.

98 Woolrich: $\underline{\text { A Dramolet. }}$. 
erinnern: enttäuschte Liebe (Pferd und Bär, SW 8, 22f.), ${ }^{99}$ Natur und Tod (Dorfgeschichte, SW 18, 320-322) ${ }^{100}$ sowie Musik (Musik, BA 4, 38-40). ${ }^{101}$

Allerdings ist Woolrich insofern der professionelle Komponist und erfahrene Librettist geblieben, als er sich erstens des Paradoxes eines »Ich « singenden Chors bewusst ist und sich zweitens auf Experimente mit Walsers autoreflexiver Fantastik nicht einlässt. Entsprechend wählt er seine Textausschnitte aus. Im Falle von The Bear lässt er die Erwägungen zur empfindlichen Psyche des Bären weg - zum Beispiel »Bedenkst du nicht, daß du ihn mit deiner Furcht verletzen könntest?« (SW 8, 23) - und beginnt mit der eigentlichen Geschichte. Dabei verteilt er die Ich-Aussagen geschickt auf die vier Stimmregister. Im Folgenden wird kursiv gesetzter Text von einer oder zwei Stimmen, normal gesetzter von drei oder vier Stimmen gesungen; in eckigen Klammern sind die entsprechenden Stimmregister angezeigt. Dadurch wird klar, dass Woolrich immer dann zur Drei- und Vierstimmigkeit wechselt, wenn der Chor vom Bären in der dritten Person spricht.

[S,A] Last night I dreamt of a bear; [T] this curious vision made me feel all shaggy. [A] I pitied him, the way he reached out to a girl, [S] she delicacy itself, [A,T,B] he clumsy, not even combed; he could have done something about that. $[\mathrm{S}] »$ Leave me alone, « $[\mathrm{A}, \mathrm{T}, \mathrm{B}]$ she said, $[\mathrm{S}, \mathrm{A}, \mathrm{T}, \mathrm{B}]$ and he went off again, upright, $[\mathrm{S}, \mathrm{A}, \mathrm{B}]$ like a man who understands speech and gestures, $[\mathrm{S}, \mathrm{A}, \mathrm{T}, \mathrm{B}]$ went to bed and pulled the covers over himself.

Damit komponiert Woolrich eine packend-humoristische Chorgeschichte, die mit einem witzigen »went to bed and pulled the covers over himself« der drei oberen Stimmen im Piano endet; der Bass sekundiert in der Kadenz nur mit »the covers «. Allerdings: Das ganze Spiel von Walsers autoreflexivem Schreiben und der Identifikation des Ich-Erzählers mit dem Bären geht mit dieser Form von >Story-Telling< verloren. ${ }^{102}$

Es folgt als instrumentales Zwischenspiel ein ziemlich schiefer und einigermaßen > verstimmt < klingender Choral der Streicher. In der zweiten Geschichte gelingt es Woolrich, den Ich-Erzähler auszublenden. Er lässt den abgründiggeistreichen Anfang der Dorfgeschichte mit der Gleichsetzung von Klavierspielen und Schreiben - »Ungern genug setze ich mich an den Schreibtisch,

\footnotetext{
99 Walser: Horse and Bear, S. 158.

100 Walser: $A$ Village Tale, S. $167 \mathrm{f}$.

101 Walser: Music, S. gf.

102 Marlise Muralt weist daraufhin, dass das Wort >Bär $<$ auch in der französischen Aussprache von Robert enthalten ist. Der Bär wäre dann nicht nur eine anthropomorphe Fabeltiermaske, sondern als >Roh-Bär auch eine Klangmaske von Walsers autofiktionalem Schreiben. Vgl. Muralt: Ambivalenzen und Provokationen, S. 39.
} 
um Klavier zu spielen, das heißt anzufangen von der Kartoffelnot zu sprechen, die vor Jahren ein Dorf heimsuchte « (SW 18, 320) - einfach weg und setzt erst dort ein, wo das Erzähler-Ich explizit nicht erkennbar ist:

Die Sterne schimmerten am Himmel; der Pfarrer des Dorfes, worin sich zutrug, was hier aufgetischt wird, erklärte seinen jugendlichen Schutzbefohlenen das Planetensystem auf offenem Felde. Ein Schriftsteller schrieb in einer lampenbeleuchteten Stube an seinem zusehends wachsenden Werk, als die von Visionen geplagte Magd aus ihrem Bett aufstand, um ins Wasser zu laufen, was mit beinahe belachenswerter Promptheit ausgeführt wurde. (SW 18, 320)

Bis zur Magd ist alles vierstimmig gesetzt, mit Imitationen und Engführungen verfeinert und in einem rasanten Tempo vorgetragen. Der Selbstmord der Magd wird - im gleichen zügigen Tempo - nur von den Sopranen gesungen.

Der letzte Text Musik ist der einzige Teil, in dem Chor und Streicher zusammengeführt werden. Und nun wird bei $»$ Music is the sweetest thing in the world «103 auch >richtig« Musik gemacht, sogar mit Tremoli in den Streichern; und es bleibt die Frage, ob hier die emotionalisierende Macht der Musik gelobt oder verspottet wird. Woolrich löst diese Ambivalenz nicht auf; er beschließt das Werk mit einem kurzen instrumentalen Epilog mit der solistischen Bratsche. Dieser Epilog wirkt wie eine auskomponierte Frage und erinnert in der Stimmung an Charles Ives' The Unanswered Question.

\subsection{Christoph Schiller: An den Schlaf. Fünf Lieder nach Gedichten von Robert Walser (200o)}

Christoph Schiller ( ${ }^{*} 1963$ ) ist über die bildende Kunst zur Musik gekommen. Er absolvierte eine Ausbildung an der Hochschule für bildende Kunst in Hamburg, bevor er in Basel Klavier und Musiktheorie studierte. Er hat sich auf die freie Improvisation spezialisiert, in die er zunehmend die eigene Stimme einbezieht; inzwischen hat er vom Klavier aufs Spinett gewechselt, das er wie eine Zither behandelt. Den Spinettsaiten entlockt er mit selbst entwickelten Spieltechniken im Innern des Instrumentes experimentell-surreale Klangwelten.

Die im Jahr 2000 entstandenen Lieder für Sopran und Klavier An den Schlaf verlangen keine speziellen Spieltechniken, zeigen aber den Hintergrund des improvisierenden Musikers. Da ist mehr skizziert und gezeichnet als kompositorisch streng strukturiert. Im dritten Lied Schlaf wohl (SW 13, 123),

103 Woolrich: Little Walserings, S. 6. 

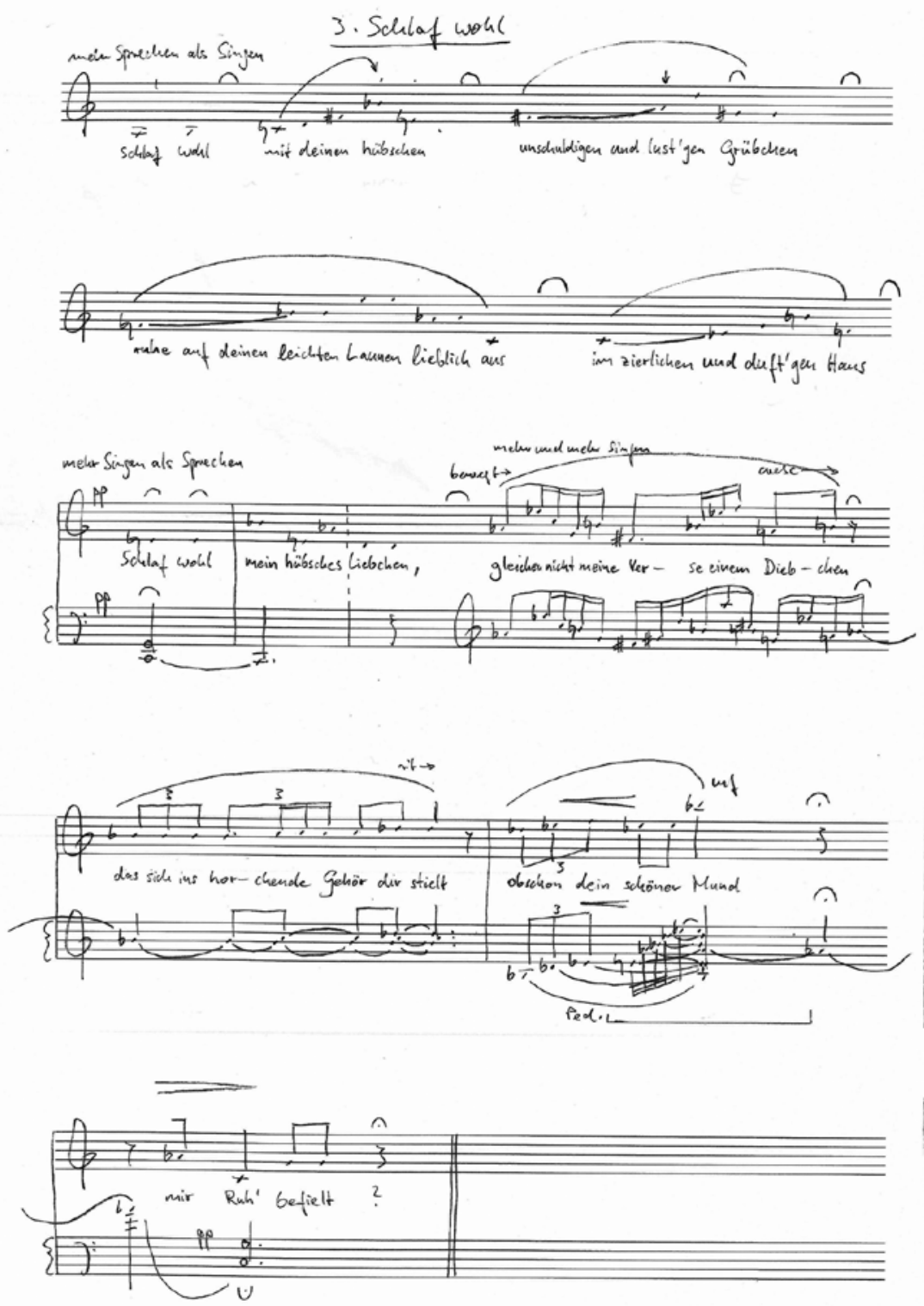

- 4-

Abb. 8o Christoph Schiller: Schlaf wohl aus An den Schlaf

das Christoph Schiller bisher als einziger vertont hat, ist dieses Zeichnerische schon im Manuskriptbild zu sehen (vgl. Abb. 8o). Die Singstimme entwickelt sich aus einem Sprechgesang zu fast opernhafter Geste bei »Mund«. Das Klavier setzt erst dort ein, wo der Ich-lose Teil des Gedichts mit dem »Schlaf 
wohl « beendet wird. Dann folgt etwas, wovon man im Kompositionsunterricht eigentlich abrät, nämlich eine Art Überschreibung: Das Klavier spielt in der gleichen Lage, mit fast denselben Tönen und denselben Gesten wie die Singstimme, quasi wie das »Diebchen« im Gedicht, das sich auch ins »Gehör dir stiehlt $\ll$.

Beim emotionalen Höhepunkt des Liedes, nämlich dem ambivalent schönen »Mund«, der das lyrische Ich nicht zum Kuss einlädt, sondern ihm das Schweigen befielt, erklingt der einzige Akkord des Liedes, ein schwebender Quartenakkord (e-b-es-as-des), der nach keiner Auflösung strebt - quasi der Traum vom Kuss; dann folgt prosaisch der >enttäuschende< Schluss.

Christoph Schiller zwingt im Zyklus An den Schlaf Walsers Gedichten keine eigene musikalische Form auf, sondern umstellt sie mit musikalischen Symbolen. Diese wirken zuweilen wie Randbemerkungen, die einen beim Lesen der Gedichte auf Besonderheiten hinweisen.

\subsection{4}

\section{Daniel Andres: Winternacht. Sechs Lieder nach Robert Walser (2000/01)}

Daniel Andres ( ${ }^{*} 1937$ ) ist aus Biel nicht wegzudenken - Urgestein und Faktotum zugleich. Er fiel mir schon in meiner Bieler Jugend in den frühen 1970er-Jahren auf: Bei allen Konzerten Neuer Musik saß da immer ein oft mürrisch in die Gegend blickender Besucher. Erst mit Zwanzig wurde mir anlässlich der Uraufführung seines Doppelkonzerts für Klarinette und Schlagzeug bewusst, dass es sich bei diesem Herrn im Publikum um Daniel Andres gehandelt hatte. Später kaufte ich in Andres' Musikantiquariat wichtige Bestände der frühen musikwissenschaftlichen Sekundärliteratur. Und noch heute: Jedes Mal, wenn ich in Biel ein Konzert mit Neuer Musik besuche oder auch während Thomas Hirschhorns Robert Walser-Sculpture, Daniel Andres ist auch 5o Jahre später noch immer da.

Im Arbeitermilieu Biels aufgewachsen, absolvierte er das Lehrerseminar Hofwil und studierte später Orgel und Komposition am Konservatorium Bern. ${ }^{104}$ Sein Lehrer war Sándor Veress, dessen Einfluss in der rhythmischen Agilität vieler seiner Werke, besonders in ostinaten Abschnitten, sowie in den weiten harmonischen Räumen spürbar ist. Musikalisch war Daniel Andres als Komponist, Organist, Dirigent, Konzertveranstalter und langjähriger Musikkritiker beim Bieler Tagblatt tätig. Aber er war auch Kellner, Wirt, Lehrer,

104 Daniel Andres beschreibt sein Aufwachsen in der Erzählung Mösli. Eine Kindheit und in seiner autobiografisch geprägten Publikation zum Bieler Musikleben Musik, ein Leben lang. 
Buchantiquar, Verleger, Librettist, Schriftsteller, Fachautor zur Bieler Baugeschichte und machte lange Zeit mit seinem sozialen Engagement und als Politiker von sich reden. Wenn man den Namen Daniel Andres bei der Schweizer Mediendatenbank SMD eingibt, erscheint vor allem seine politische Karriere, beginnend bei den Sozialdemokraten über die Freien Bieler Bürger bis hin zum Präsidenten des Schweizerischen Landesrings der Unabhängigen (LdU). Aber trotz dieser nationalen Karriere blieb Andres immer in Biel: »Ich konnte mir nie vorstellen fortzugehen, [...] ich fühlte mich immer mit Biel verbunden und wollte hier etwas machen. $\ll^{105}$

Das Komponieren bleibt trotz den vielseitigen Tätigkeiten das Zentrum seines Lebens, und seine Werke werden aufgeführt, »wenn auch nur in Biel oder Bern « ${ }^{106}$ Obwohl er selbst internationale Erfolge aufzuzählen hätte, beschönigt Andres nichts an seiner >provinziellen< Karriere. Große Worte sind ihm fremd, und für Bieler Ensembles und Musikschaffende zu komponieren, ist ihm wichtiger, als im Avantgarde-Kabinett irgendwann zuvorderst gewesen zu sein. Insgeheim ist er wohl sogar stolz darauf, ein >Stadtpfeifer von altem Schrot und Korn zu sein, dem keine Aufgabe zu schade ist:

Ich spiele praktisch jeden Sonntag irgendwo. Ich gebe aber keine grossen Orgelkonzerte mehr, weil die Konzentration im Alter leider nachlässt. Ich leite auch die Weihnachtskonzerte in der Zwinglikirche. Die sind mir wichtig. ${ }^{107}$

Für das Seniorenorchester der Pro Senectute Biel schrieb er 2011 Alptraumsegen (nocturne alpestre) für Viola, Fagott, Streichorchester und Kuhglocken; der Titel ist ein Beispiel für den bissig-freundlichen Humor des Komponisten, der mitten in der Gesellschaft steht und doch als Einzelgänger wahrgenommen wird und sich auch als solchen versteht:

Mein Lieblingsschriftsteller ist Robert Walser, der auch ein Einzelgänger war, ein Genie, das immer an sich zweifelte und in der Irrenanstalt endete. Ich fühle mich nicht so wie er, und ich werde auch nicht in einer Irrenanstalt landen, aber eine gewisse Affinität spüre ich doch. ${ }^{108}$

Erst im Jahr 2000 wagte sich Daniel Andres an eine Vertonung von Robert Walser. Die sechs Lieder auf frühe Gedichte von Walser fallen im Gesamtwerk von Andres aus dem Rahmen, denn er komponiert vor allem Instrumentalwerke, und die wenigen Vertonungen beziehen sich fast alle auf Texte aus dem Alten Testament.

\footnotetext{
105 Zit. nach Tanner: Als Strawinsky Biel schockte, S. 22.

106 Zit. nach König: Cellokonzert zum Geburtstag, S. 24.

107 Alder: »Ich wollte immer etwas in Biel bewirken «, S. 12.

108 Andres: Etwas aus meinem Privatleben.
} 
Walsers frühe Gedichte sind zwar von Sehnsucht und Weltschmerz durchzogen, aber in ihrer poetologischen Struktur geradezu experimentell modern gefasst. Sie nehmen eigentlich schon die absurde Lyrik des Dadaismus voraus, zum Beispiel Alles Nacht (SW 13, 37f.), das vierte Lied des Zyklus:

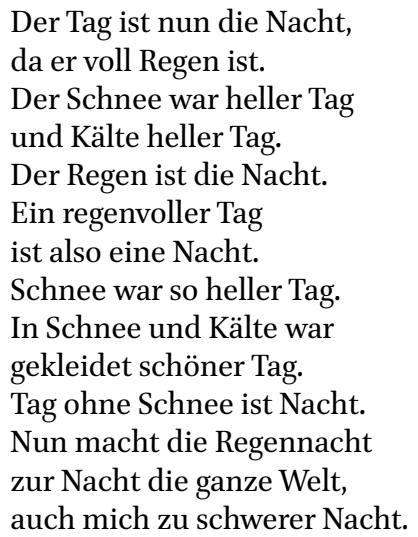

Man könnte die >Vorgaben` für das Gedicht folgendermaßen formulieren: Schreibe ein Gedicht von 14 sechssilbigen Versen. Es stehen dir die fünf Substantive »Kälte«, »Schnee«, »Regen«, »Tag« sowie »Nacht« zur Verfügung, wobei nur die beiden letzteren als Reimwörter benützt werden können; zudem müssen diese in gleicher Anzahl verwendet werden (7+7) und dürfen zusammen höchstens sooft vorkommen, wie das Gedicht Verse hat (14). Ein weiteres Substantiv ist frei wählbar, darf überall eingefügt, aber nur ein einziges Mal eingesetzt werden (»Welt«). Dem Wort »Nacht« darf nur einmal ein Adjektiv zugeordnet werden (»schwerer Nacht«), und dem lyrischen Ich ist nur im letzten Vers ein Auftritt gestattet (»mich «). Es sind ein- oder zweisilbige Wörter zu verwenden; drei Ausnahmen werden zugelassen (»regenvoller«, »gekleidet«, »Regennacht«).

Mit diesen Vorgaben schafft Walser ein geniales Gedicht, bei dem das musikalische Mobile aus gleichen Elementen vom Inhaltlichen ablenkt und dadaistisch-abstruse Thesen wie »Der Regen ist die Nacht« und die triviale Folgerung daraus »Ein regenvoller Tag / ist also eine Nacht« gleichsam überspielt werden.

Daniel Andres folgt in seiner Vertonung der Versstruktur von Walsers Gedicht, vermeidet aber das aussichtslose Unterfangen, Tag und Nacht zu illustrieren (vgl. Abb. 81). Die einzelnen Verse von sechs Silben sind in der Singstimme mit unterschiedlich vielen Tonhöhen vertont, anfänglich mit vier Tönen, am Schluss des Musikbeispiels (viertes System) nur noch mit zwei Tönen. 


\section{Alles Nacht.}

Langsam und schwer Lent et lourd
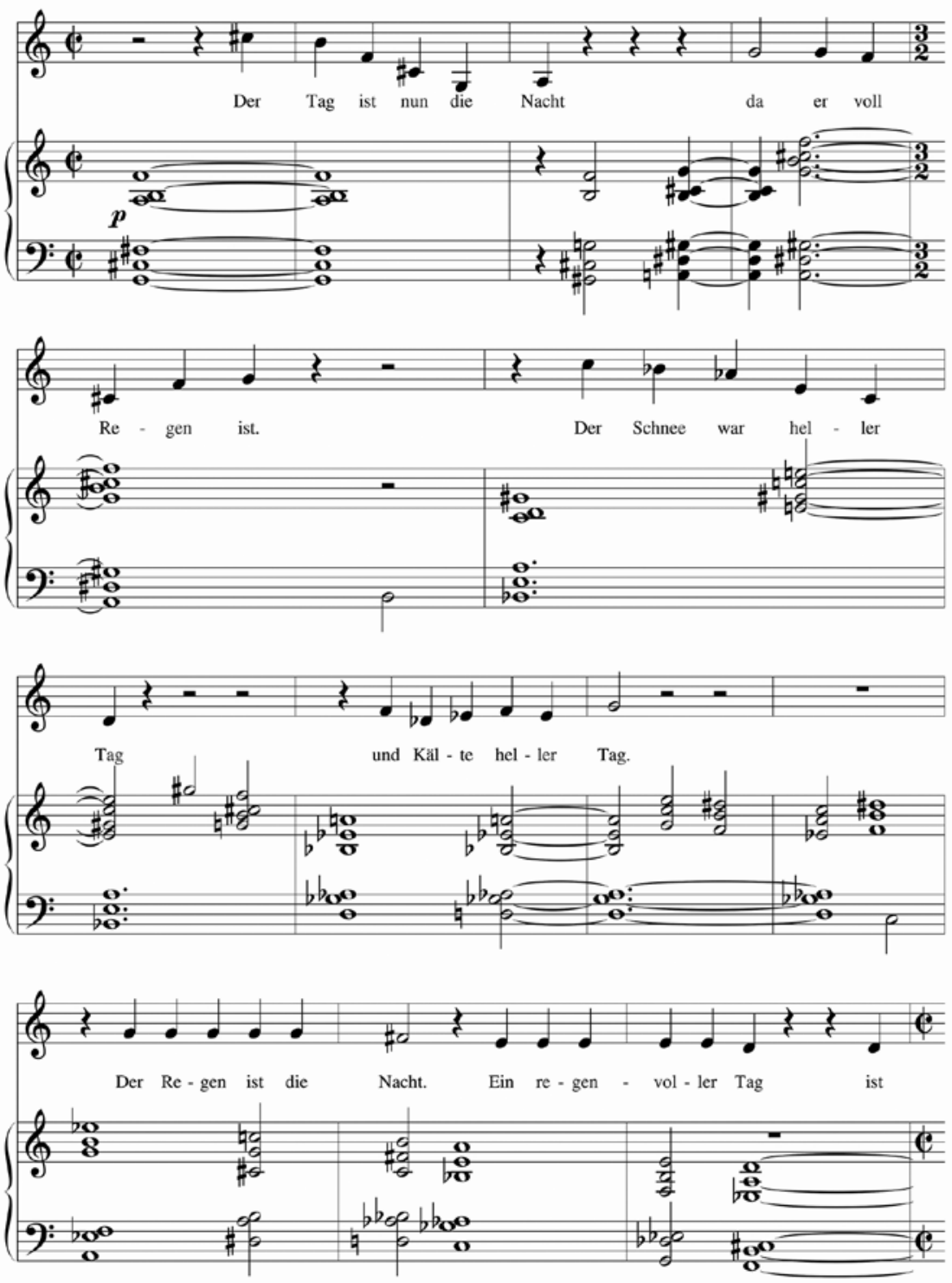

Abb. $81 \quad$ Daniel Andres: Alles Nacht, S. 1 
Auffällig ist die häufige Schreibweise der verminderten Quarte, zum Beispiel schon im zweiten Takt $f^{1}-$ cis $^{1}\left(\right.$ statt des $\left.^{I}\right)$, mit der Andres wohl eine latente tonale Spannung trotz der die verminderte Quarte umgebenden Tritoni aufrechterhalten will. Bei Takt 6 wird diese enharmonische Spannung dann explizit, weil dort in der Singstimme die verminderte Quarte $a s^{1}-e^{l}$ die zwei symmetrisch zueinander stehenden Trichorde $c^{2}-b^{1}-a s^{1}$ und $c^{1}-d^{1}-e^{1}$ trennt.

Die Klavierbegleitung beschränkt sich weitgehend auf Liegeklänge; meist sind es Sechsklänge - ein direkter Bezug zum von der Zahl 6 dominierten Gedicht. Die Harmonien haben es in sich, denn Andres verengt die anfänglich impressionistisch wirkende Quartenharmonik zum >Nacht-Akkord, der bei »ist die Nacht. Ein regenvoller Tag« im untersten System von Abbildung 81 erklingt. Da spielt das Klavier mittels Rückungen des gleichen Sechsklangs eine absteigende Melodie. Im Aufbau besteht dieser Akkord aus Tritonus, zwei großen Sekunden, Tritonus und reiner Quinte. Er erinnert an den mystischen Akkord von Aleksandr Skrjabin. ${ }^{109}$ Ein Vergleich der Akkorde zeigt, dass fünf gemeinsame Töne vorliegen:

Andres, >Nacht<-Akkord auf $c$ (T. 12, 2. Halbe):

Skrjabin, Mystischer Akkord:

$$
\begin{aligned}
& c-g e s-a s-b-e^{1}-a^{1} \\
& c-f i s-b-e^{1}-a^{1}-d^{2}
\end{aligned}
$$

Im weiteren Verlauf des Liedes entwickelt dieser >Nacht<-Akkord einen Sog, der zum Ende hin alles dominiert. Dieser Quartenharmonik stellt Andres bei vielen $>$ Tag $<$-Stellen eine traditionelle Harmonik im Terzaufbau gegenüber - zum Beispiel bei Takt 9 am Ende des dritten Systems, wo über den verklingenden Tönen der linken Hand ein C-Dur-Quartsextakkord, ein Durdreiklang mit verminderter Quinte und ein verminderter Dreiklang gespielt werden. Die Wirkung ist polytonal. Man mag darin den Einfluss von Veress und dessen Lehrer Béla Bartók sehen, wichtiger scheint mir aber das Bipolare oder besser das >Bisystemische $<$ zu sein: Der Quartenharmonik, die die Oktavgrenze überschreitet, wird die Terzenharmonik gegenübergestellt, die von der Oktave ausgeht. Im weiteren Verlauf des Liedes wird dieses $>$ Bisystemische noch akzentuiert und Walser wird als Dichter greifbar, der nicht in einem System aufgeht, sondern nur mit zwei sich gegenseitig kommentierenden Systemen

109 »Mir ist schon früher aufgefallen, dass die Melodie des Walser-Liedes fast identisch ist mit dem Beginn meines Violinkonzertes Nr. 1 aus dem Jahr 1976. Was damit zusammenhängt, dass beide auf dem >mystischen Akkord beruhen, ursprünglich c - fis - h - f (Tritonus-Quart-Tritonus), wenn man den um je eine grosse Terz transponiert, erhält man einen Zwölftonakkord. Erstmal angewendet habe ich den in meinem Orchesterstück >Sambhoga-Kaya v von 1972/73.« E-Mail von Daniel Andres an Roman Brotbeck vom 10.11.2020. 
darstellbar ist. - Für jedes seiner sechs Klavierlieder findet Andres einen Zugang, der mit dieser Doppelbödigkeit spielt.

\subsection{Das Zürcher Robert Walser-Liederbuch-Projekt (2001/o2)}

In den Jahren 2001 und 2002 wurde an der damaligen, von Daniel Fueter geleiteten Musikhochschule Winterthur-Zürich (heute integriert in die Zürcher Hochschule der Künste) ein großes Walser-Projekt durchgeführt. Auf Initiative von Felix Falkner, Leiter der Bibliothek der Musikhochschule, entstanden zahlreiche Walser-Lieder; das Projekt wird im Folgenden Robert Walser-Liederbuch genannt: Dozierende und Studierende in Komposition und Theorie wurden aufgefordert, Lieder auf Texte von Robert Walser zu schreiben. Fünfzehn Komponistinnen und Komponisten beteiligten sich am Projekt und 29 Walser-Lieder wurden am 18. März 2002 von Studierenden und wenigen zugezogenen Gästen uraufgeführt.110

Junge Interpretinnen und Interpreten kamen in den Kontakt mit Komponisten, was eine spannende Erfahrung ist. Und nebenbei wurde gezeigt, dass man auch heute noch Klavierlieder komponieren kann. ${ }^{111}$

Das Projekt zeigt in einem vielseitigen Querschnitt den Stand dessen, was Walser-Vertonen zu Beginn des 21. Jahrhunderts bedeutete. Die Ambivalenz zwischen Sprechen und Singen ist sehr vielen Teilen dieses Liederbuchs eingeschrieben, erste Kritik an sensibilistischen Vertonungstraditionen, die Walser in kargen Pianissimo-Stücken quasi auf `Schnee`, `Todく und `einsames Spazieren< reduzieren, wird laut, und sogar Walsers Frauenbild wird thematisiert und kritisch reflektiert.

\subsubsection{Melodramatisches: Peter Wettstein, Philipp Neukom, Philippe Racine, Natalia Sidler}

Bei Peter Wettstein ( $\left.{ }^{*} 1939\right)$ erscheint die Ambivalenz zwischen Singen und Sprechen schon in den ersten Annotationen zu seiner Vertonung des Prosatextes Die Göttin (SW 4, 11f.), in dem in einer Stimmung, die »etwas Süßes, etwas Freundliches« hat, eine Wolke in Form eines Schwans mit einer nackten Frau

110 Die Namen der Beteiligten: André Bellmont, André Fischer, Dominique Girod, Sebastian Guralumi, Michael Heisch, Hans Hoerni, Thomas David Müller, Philipp Neukom, Andreas Nick, Kit Powell, Philippe Racine, Natalia Sidler, Mathias Steinauer, Peter Wettstein, Hans Wüthrich.

111 Zimmerlin: Unerwartete Illumination, S. 44. 
niedersinkt (vgl. Abb. 82). Wettstein unterscheidet Sprechen, Sprechgesang und Singen: Gesungen wird nur in jenen Momenten, in denen die Metapher des Schwans mit dem Fantasiebild der nackten Göttin auftaucht; dazwischen sieht er Sprechgesang vor; alle anderen Teile plante Wettstein als gesprochen. In der kompositorischen Umsetzung hielt er sich weitgehend an diese Disposition. Die gesungenen Teile treten mit langen Melismen hervor, und $» O$ wie ihr Haar « wird sogar wiederholt, um das Hingerissensein zu betonen. Interessant ist, wie Wettstein den Schluss im Verlauf des Komponierens verändert: Ursprünglich sollte er gesprochen werden; noch auf der Skizze ändert er mit Umtauschpfeil auf Sprechgesang, in der eigentlichen Komposition wird der Schluss gesungen. Das ist klug überlegt, denn der Zauber der Göttin ist eben immer noch präsent.

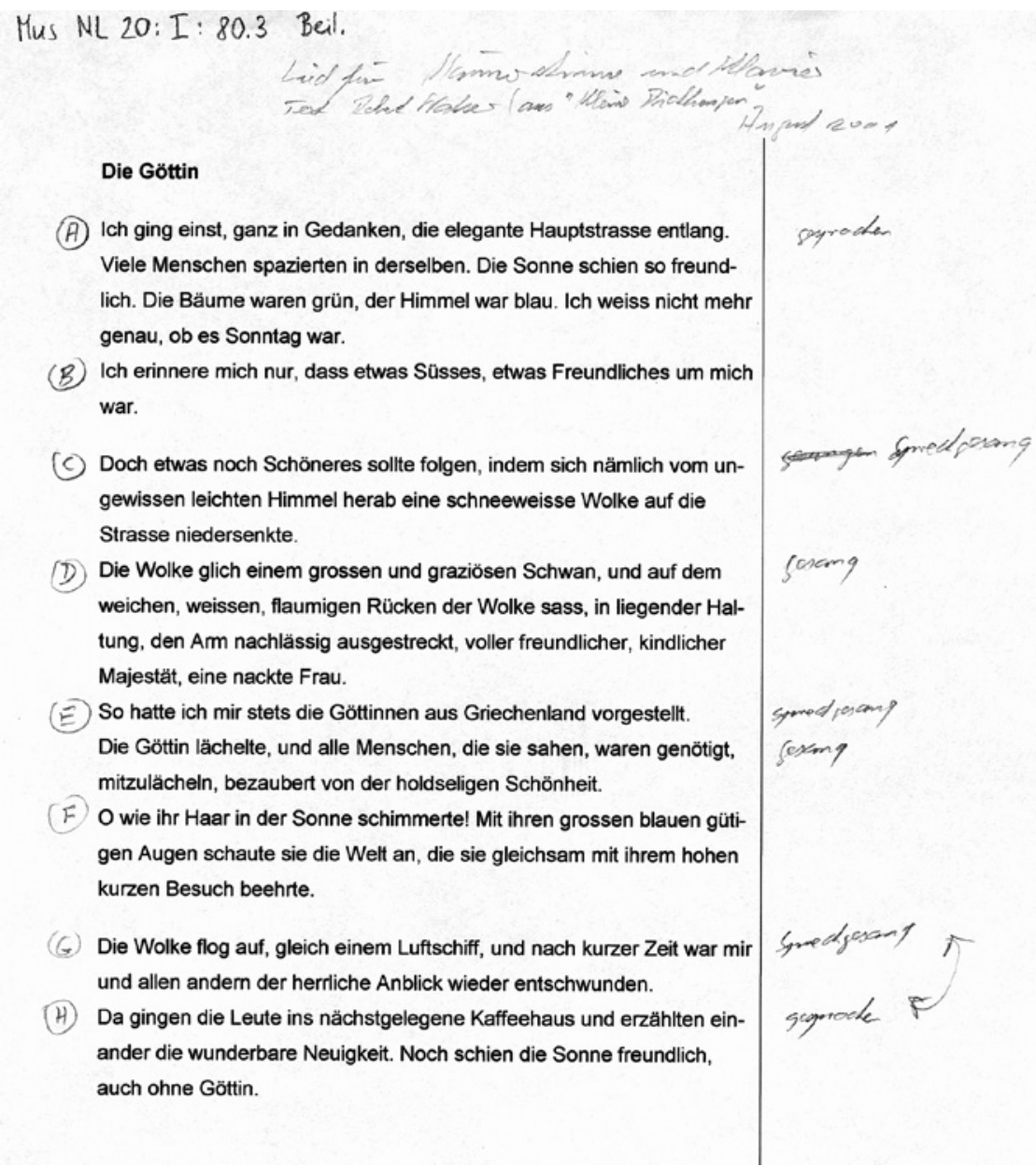


Philipp Neukom schreibt über seine Vertonung der Bierszene (SW 13, 44):»mehr rezitierend als aussingend «. Zum artifiziellen Text (vgl. die Bemerkungen zu diesem Gedicht in der Einleitung) komponiert er provozierend einfache Melodien, die an Kinderlieder erinnern. Der Gesamtumfang der Singstimme beträgt eine Sexte, nur im letzten Abschnitt wird die Diatonik mit zwei chromatischen Tönen durchbrochen. Das Klavier grummelt während des ganzen Liedes in tiefer und tiefster Lage und irritiert die einfache KinderliedWelt der Gesangslinie.

Bei Philippe Racines 3 Lieder pour voix wird der Großteil des Textes auf einer einzigen Tonhöhe oder auf Wechselsekunden rezitiert. Nur einzelne exklamative Stellen wie »ich weine« in Trug (SW 13, 28) oder »und meine Sehnsucht, ah « in Wie immer (SW 13, 14) werden mit übertrieben weiten Melodiebögen hervorgehoben; das Gesungene wirkt hier wie ein ironischer Kommentar des Rezitierten.

Natalia Sidler wählte für das Gedicht Die kleinen Dinge (SW 13, 227f.) ein reines Melodram, das die gesprochenen Worte mit einem ausgreifenden Klaviersatz belebt. Sidler teilt dazu das Klavier in zwei Register auf: Auf den Tasten entfalten sich ausladende Arpeggien, im Innern des Flügels werden die Saiten gezupft, was zwei gänzlich unterschiedliche Klangwelten erzeugt. Dabei ist das Spiel im Innern des Flügels kein bloßer Effekt - es wird durch das ganze Melodram hindurch beibehalten und bei der Frage »was ich wohl morgen sehe? «112 muss sogar eine choralähnliche vierstimmige Partie gezupft werden. Bei der gleich darauf anschließenden Frage »Neugierde, bist du des Lebens Zierde? « folgen nach »Neugierde« zuerst ein langsamer werdendes Arpeggio in die höchste Lage des Klaviers und dann auf »des Lebens Zierde« im dreifachen Pianissimo ein hoher gezupfter Ton, der wie ein helles Glöckchen das Melodram beendet und zugleich die »Zierde« illustriert.

Sidler komponierte für das Robert Walser-Liederbuch auch ein richtiges Lied (Die Dame am Klavier, SW 13, 257) in der Balladentradition, mit ironisch übertriebenen Madrigalismen und zum Schluss einer theatralischen Gegenüberstellung des als unbegleitetes Solo gesungenen Textes »o, schließ dein Ohr vor dem, was ich dir hier lispelnden Munds zu sagen wage, nicht zu«. Es folgt ein längeres und sehr >beredtes< Klavierzwischenspiel und dann die irritierende Frage $»$ Warum bist du so stumm?«.

112 Sidler: Die kleinen Dinge, S. 4. 


\subsubsection{Derbes und Ironisches: Mathias Steinauer und André Fischer}

Sehr viel derber, direkter - und wohl auch gegen die >sublime< Tradition gewisser Walser-Vertonungen gerichtet - ist Mathias Steinauers Es kommt mich ... nach Lachen und Lächeln (SW 13, 51):

Es kommt mich Lachen

und Lächeln an.

Was liegt daran!

Das sind so Sachen ...

Wie im Regietheater Texte durch gezielte Schnitte und Kürzungen neu gedeutet werden, um Latentes und Verdrängtes bewusst $\mathrm{zu}$ machen, will Steinauer das »sachermasochelig[e]«(SW 19, 123) Schreiben Walsers thematisieren. Er isoliert dazu die ersten drei Worte: »Es kommt mi[ch]« und gestaltet das Gedicht als Sadomaso-Szene: Angetrieben von einem Spezialwerkzeug - vorne Hammer, hinten Klappe, die ein peitschenartiges Geräusch erzeugt - werden die drei ersten Worte als Lustschreie komponiert. Die Behandlung des Klaviers mit dem Spezialhammer führt die Auspeitschung vor. Nach der Ekstase wird »Das sind so Sachen ... « gesprochen, und ein letzter Hammerschlag ins Klavierinnere beendet die Szene. ${ }^{113}$

Ins ironische Fach greift auch André Fischer mit einer speziellen Aufführungsperformance des raffinierten Gedichts Ein Landschäftchen (SW 13, 2o), in dem virtuos mit Diminutiven jongliert wird. André Fischer greift diese Diminutive mit einem Glöckchen-Klang musikalisch auf. Drei Pianisten begleiten am selben Klavier den Bariton mit diesem Glöckchenmotiv, immer lauter und höher. Dabei spielen die Interpreten stellenweise auf engstem Raum, was auf der Tastatur zu einem >Gewusel< von Händen führt. Zum Schluss steigert sich das Stück zu einem grellen Schellenbaum-artigen Klang.

113 Besonders fulminant haben Altus Kai Wessel und der Pianist und Hammerspieler Roman Digion diese ironisch-doppelbödige Szene realisiert. Vgl. OMaclac: Mathias Steinauer ... Es kommt mich... . Vgl. auch die Aufnahme mit den gleichen Interpreten auf der PorträtCD von Steinauer: Es kommt mich (2008). 


\subsubsection{Tonales: André Bellmont, Andreas Nick, Hans Hoerni, Sebastian Guralumi, Dominique Girod}

Im Robert Walser-Liederbuch gibt es auch Kompositionen, in denen Walsers schiefe Idyllik und die Allusionen an romantische Topoi ungebrochen in unterschiedliche Musik-Idiome umgesetzt werden. So komponierte André Bellmont zu Gelassenheit (SW 13, 28f.) einen anfänglich sanft und später keck groovenden »Jazz-Song à la Dave Frishberg ${ }{ }_{1}^{114}$ in dem mit dadaistisch anmutenden Wortwiederholungen (»Und ich bin ich bin ich bin der Bürd' entladen«) der Text ins Takt-Schema eingepasst wird. Andreas Nick vertonte Die ersehnte Insel (SW 13, 9of.) in reiner Idyllik und Hans Hoerni fasste das Gedicht Welt $(I)(\mathrm{SW}$ 13, 11) in ein berührendes romantisches Lied. Gelassenheit (SW 13, 28f.) wurde auch vom Komponisten Sebastian Guralumi in Musik gesetzt. Er machte aus den zwei Gedichtstrophen ein einfaches Strophenlied mit Wiederholungszeichen - eine Rarität bei Walser-Vertonungen. Allerdings fügte er einen Epilog an, der die Einfachheit des Strophenliedes konterkariert und nur noch auf dem nasalen $n$ gesummt wird. ${ }^{115}$ Gesummt statt gesprochen oder gesungen wird auch im längeren Mittelteil von Dominique Girods Unter grauem Himmel (SW 13, 41). Es ist ein >ungestaltes< Stück mit sehr wenigen, in keine Taktrhythmik eingebundenen Tönen und einer alles dominierenden Quinte $a s^{1}-e s^{2}$ (vgl. Abb. 83); jeder von dieser Quinte abweichende Ton wird in einer derartigen Struktur bedeutungsvoll. Die Partie der Singstimme besteht aus 91 Tönen, nur sieben Tonhöhen werden verwendet, fast zwei Drittel der Töne fallen auf die Quinte $a s^{1}-e s^{2}$ (22 as und 35 es). Des ${ }^{1}$ kommt nur ein einziges Mal vor, nämlich auf »wein'« im letzten Vers (»Wegen diesen Wiesen / wein' ich bitterlich $\ll) .{ }^{116}$

114 Zimmerlin: Unerwartete Illumination, S. 44.

1152003 komponierte der in Tirana geborene Sebastian Guralumi noch ein weiteres WalserLied, Im Wald (SW 13, 108). Es ist gegensätzlich zu Gelassenheit gestaltet und enthält als Deklamationslied zahlreiche affirmierende Textwiederholungen, welche die Strophenform des Gedichts ignorieren.

116 Ein Jahr später hat Dominique Girod das Lied in einen fünfteiligen Liedzyklus integriert, in dem er in ähnlich zurückhaltender Weise mit wenigen Tönen und einfachen Melodien Walser vertont. Vgl. Girod: Fünf Lieder nach Gedichten von Robert Walser. 
"Unter gravem Himmel"
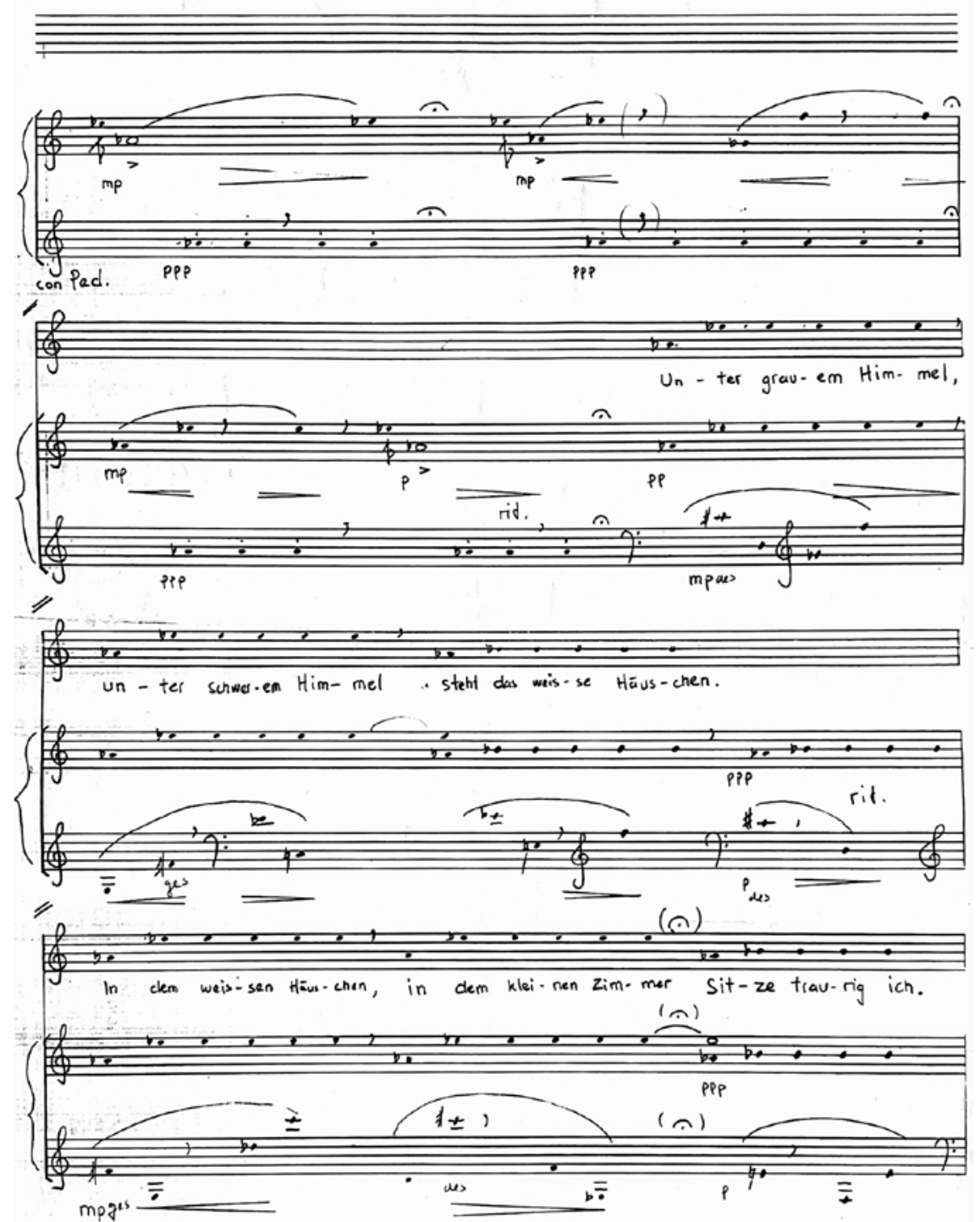

Abb. 83 Dominique Girod: Unter grauem Himmel 

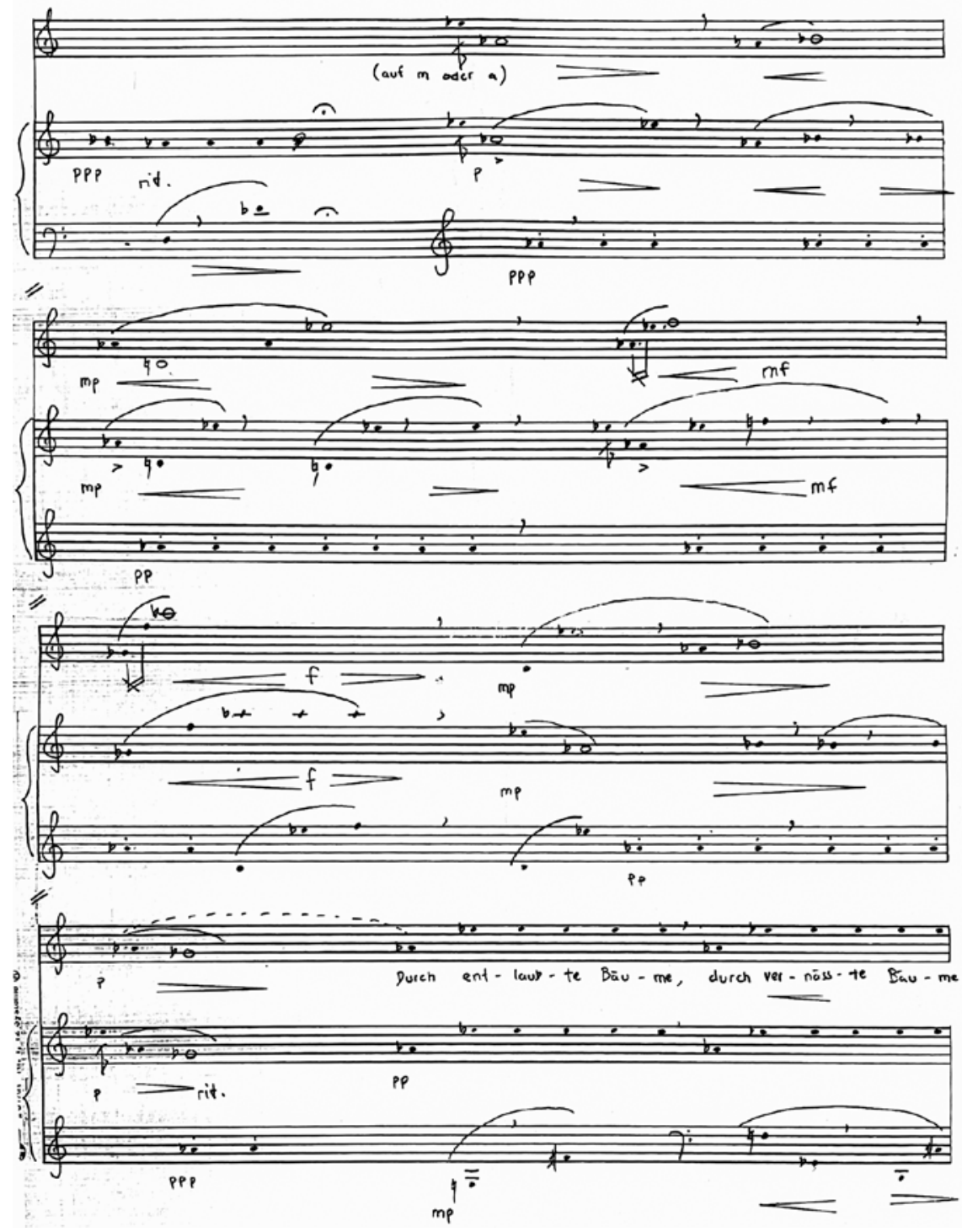

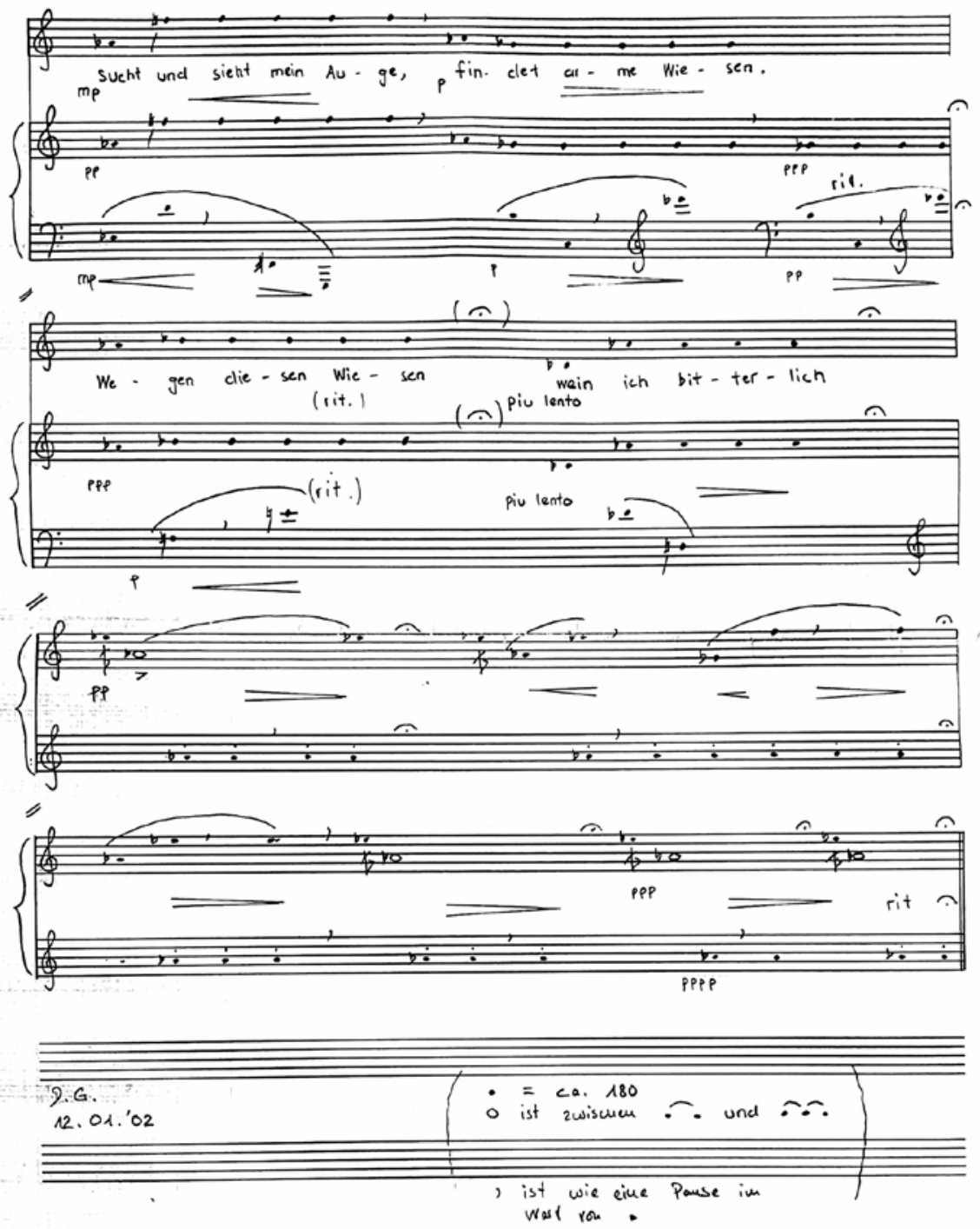


\subsection{4 >Abelsche Form<: Kit Powell}

Für das Zürcher Projekt komponierte Kit Powell ( $\left.{ }^{*} 1937\right)$ den neunteiligen Zyklus Scheint denn die Sonne heut' nicht? nach frühen Gedichten Robert Walsers. Diese Lieder sind vom Tonhöhenmaterial her eng aufeinander bezogen: Aus 24 Tönen, bestehend aus einer Zwölftonreihe und deren Umkehrung, gewinnt Powell durch Segmentierungen das Tonhöhenmaterial für jedes der einzelnen Lieder. Diese Segmentierung betrifft die Singstimme, deren Tonvorrat pro Lied auf drei bis fünf Töne beschränkt ist. Kit Powell, der in Neuseeland ursprünglich Mathematik studierte, ordnet die Lieder in einem Formschema an, das er, in Anlehnung an die Verknüpfungstafeln abelscher Gruppen aus der Mathematik als »abelsche Form « bezeichnet. Die neun Lieder sind in ein 3x3-Quadrat eingefügt, an dessen Diagonale sich die Lieder spiegeln. »Selten habe ich einen Zyklus komponiert, in dem die Sätze so eng miteinander verbunden sind, wie in diesem. «117 Die >abelsche Form< hat dabei nicht etwas Schließendes, wie das bei Symmetrien meist der Fall ist, sondern erlaubt Powell die formale Disposition eines in sich logischen $>$ Spaziergangs $<$.

What I had also produced, however, was a new way of organising musical material. In contrast to traditional forms which finish with a recapitulation of the opening material, Abelian Form produces a sort of musical journey from A to Z with stations on the way which are heard twice (often in variation) - a musical trip with constant reminders of the past. With careful selection of the material one can create a gradual transition from the beginning to an end which, in view of the route taken, is not only new, but has a logic which makes arriving here completely convincing. ${ }^{118}$

Dass es zwischen Niels Henrik Abel (1802-1829) und Robert Walser auch biografische Parallelen gibt, war Powell nicht bewusst. ${ }^{119}$ Den jung an Tuberkulose verstorbenen, genialen norwegischen Mathematiker zog es früh in die Welt hinaus, er kritzelte Hefte voll, führte ein unkonventionelles Leben und litt unter häufigen Depressionen:

La nuit devenait jour, et le jour était nuit, et les pensées étaient jetées dans les cahiers de notes quand et comme elles venaient. Puis il y avait des périodes de dépression et de fatigue. Il pouvait rester des jours entiers seul, silencieux, maussade, et complètement inactif. Si on lui demandait ce qu'il avait, il répondait: »Je suis sombre. ${ }^{120}$

117 E-Mail von Kit Powell an Roman Brotbeck vom 10.09.2020.

118 Powell: Abelian Form. Hier ist auch das Quadrat angegeben, nach dem Scheint denn die Sonne heut' nicht? komponiert ist.

119 E-Mail von Kit Powell an Roman Brotbeck vom 16.og.2020.

120 Mittag-Leffler: Niels Henrik Abel, S. 17. 
Die rigorosen Vorordnungen, die sich Powell mit der sabelschen Form< auferlegte, erinnern an die >contraintes< des 1960 von den mathematisch interessierten Schriftstellern François Le Lionnais und Raymond Queneau gegründeten Literatenkreises Oulipo, ${ }^{121}$ in dem mit Einschränkungen und Zwängen die künstlerische Fantasie angeregt werden sollte. Oft wird in der Ausarbeitung der begrenzende Charakter der >contraintes< gar nicht mehr wahrgenommen. Auch bei Kit Powells Zyklus sind die Einschränkungen des Tonhöhenmaterials nicht als Zwang, sondern als Wechsel und >Wanderung zu spüren. Er versteht es, die Singstimme mittels Lagenwechseln erfindungsreich zu gestalten, und er bedient sich einer emotionalen und direkten Musiksprache; er wiederholt Textstellen, steigert sie im Ausdruck und benutzt in der Klavierbegleitung zahlreiche Cluster, sodass zum Beispiel beim letzten Lied Trug (SW 13, 28) mit rasenden Clusterläufen und hochdramatischer Deklamation eine durchaus opernhafte Ästhetik etabliert wird.

\subsubsection{Walser-Kritisches: Michael Heisch, Hans Wüthrich}

Bemerkenswert am Robert Walser-Liederbuch ist, dass »Walsers subkutane Misogynie $« 122$ von zwei Komponisten deutlich thematisiert werden. ${ }^{123}$ In den 6 Serifen nach Sätze (SW 19, 231f.) lässt Michael Heisch ( $\left.{ }^{*} 1963\right)$ die Sopranistin zum Schluss beim Spruch »Wie interessant sind verbrecherische Frauen « (vgl. dazu auch die Vertonung von Edu Haubensak in diesem Kapitel) verstummen: »Die Sängerin steht bewegungslos, jedoch konzentriert da. Diese Situation wirkt >szenisch<, als ob sie auf einen Einsatz wartet, der demnächst folgen soll.«124 Dafür erklingt von einem fürs Publikum unsichtbaren, im Innern des Flügels aufgestellten »CD-Walkman« Othellos Monolog aus der Schlafzimmerszene V/2 von Shakespeares Othello mit dem abartigen Motiv vieler Frauenmörder »Doch sterben muss sie, sonst betrügt sie andre«. Der Monolog wird von keinem Schauspieler eingesprochen, sondern vom Pianisten selber (als »beabsichtigte Irritation «125). Chimärisch wird der Verdi-Versatzstücke spielende Pianist zum Othello und die vergeblich auf ihren Einsatz wartende Sängerin zur Desdemona. Es ist auch der Pianist, der am Schluss nach Othellos Monolog und einem Handkantenschlag auf die Taste des Subkontra- $A$ Walsers mit »ruhige $[\mathrm{r}]$ Vortragsstimme «spricht: »Wie interessant sind verbrecherische Frauen.« Es kommt zu einer ambivalenten Überkreuzung der Aussagen: Der

\footnotetext{
121 Vgl. Oulipo: Contraintes.

122 E-Mail von Michael Heisch an Roman Brotbeck vom 03.08.2020.

123 Zur Diskussion von Walsers Frauenbild vgl. Evans: »Ich finde es schön, daß sie unglücklich ist« sowie Caduff: Die Lust des Lesers.

124 Heisch: [Anmerkung zu] Serife VI.

125 Ebd.
} 
implizite Autor, gesprochen vom Pianisten, findet »verbrecherische Frauen « interessant; Othello erklärt aus dem Innern des Klaviers heraus die unschuldige Desdemona zur Verbrecherin. Wäre mithin das Interessante verbrecherischer Frauen, dass sie unschuldig und fälschlicherweise eines Verbrechens verdächtigt sind?

Hans Wüthrich (1937-2019) hat für Walsers Satz »Schweigsam sich die Fraun verhalten« ebenfalls eine Form von `Stummschaltung« komponiert. Er nennt seine Vertonung nach dem Gedicht Arabien (SW 13, 248f.) walser arabien. Sie ist im Werk Wüthrichs eine Rarität, da er als promovierter Linguist und langjähriger Lehrbeauftragter für Phonetik an den Universitäten Zürich und Basel in jedem seiner Werke fast obsessiv mit Grammatiken und Sprachen arbeitete, aber fast nie literarische Werke vertonte.

In Arabien hat der Mann einen Mantel flatternd an. Mit romantischer Gebärde reitet er auf herrl'chem Pferde.

Aus dem glühendgoldnen Sand
steigt wie eines Kindes Tand
die erquickliche Oase
wie die Blume aus der Vase.

Tagelang muß man dort reisen, ehe man in einem leisen Hauch von Bildungszentrum steht und durch eine Straße geht.

Schweigsam sich die Fraun verhalten.

Mit nur spärlichen Gestalten, wenn mich nicht ein Irrtum trügt, jeder willig sich begnügt. (SW 13, 248f.)

Wüthrichs früherer Kompositionsschüler Alfred Zimmerlin schreibt zum Werk:

Und wie kein Zweiter hat Hans Wüthrich in seinem »walser arabien« die ganz subtile Theatralik umgesetzt, nahe an der Verdoppelung und dennoch so anders, dass das Moment des unerwartet Erhellenden sich ereignen konnte. ${ }^{126}$

Ich würde noch weitergehen und nicht nur von Verdoppelung, sondern von falschen Fährten oder bewusst >dilettantischem< Komponieren sprechen. In

126 Zimmerlin: Unerwartete Illumination, S. 44. 
der ersten Strophe illustriert Wüthrich nämlich wie ein Amateurkomponist Wort für Wort: mit einem Triller über »flatternd«, einem weiten Gesangsbogen bei »mit romantischer Gebärde« und Arpeggien und >großem< Schluss bei »auf herrlichem Pferde «.127 In der zweiten Strophe wird mit orientalisch anmutenden aufsteigenden Achttonskalen eine Schlangenbeschwörung evoziert, ${ }^{128}$ was zwar in Zusammenhang mit dem Kompositionstitel walser arabien Sinn ergibt, aber etwas abbildet, das im von Metaphern chiastisch überladenen Gedicht gerade nicht vorhanden ist: Dort wird die aus dem Sand steigende Oase überraschenderweise mit einer Blume verglichen, die nicht etwa in der Vase steht, sondern daraus aufsteigt. Wüthrich geht mit Walsers Text also ähnlich um, wie dieser mit dem literarischen Vokabular der Romantik. Es ist eine Vertonung, die das Geschäft des Vertonens ironisiert und in der Wüthrich selber auch reflektiert, weshalb er die Gattung der Literaturvertonung, die fast unausweichlich zu Verdoppelungen zwingt, gemieden hat.

Spätestens beim slapstickartigen Schluss wird die Kritik am Vertonungsgeschäft explizit: Nach dem »Hauch von Bildungszentrum « bricht das Werk einfach ab; das ist auch selbstironisch auf das Bildungszentrum der Musikhochschule Zürich gemünzt, in der Wüthrich bis zu seiner Pensionierung 2002 unterrichtet hat. Die Sängerin hält nur noch ein durchaus vieldeutiges Plakat mit der Aufschrift »Schweigsam sich die Fraun verhalten« in die Höhe. Letztlich bildet dies die Übersteigerung der naiv-nachvollziehenden Vertonungsweise: Die Sängerin imitiert nicht nur die Worte des Gedichts, sondern führt sie einfach aus.

\subsection{6 >Zertonungen«: Thomas David Müller}

Ähnlich kritisch wie Wüthrich setzt sich Thomas David Müller (“1953) mit der Literatur-Vertonung auseinander. Für das erste Lied seiner Drei Lieder nach Robert Walser wählt Müller das Gedicht Nutzen des Redens, in dem das Sprechen selbst thematisiert wird:

Worüber man sich mündlich gut unterhält, das sieht man auch schon mit den schau'nden Augen.

Das Sprechen will zu irgend etwas taugen, und das Gespräch ersetzt uns eine Welt. (SW 13, 128)

127 Abweichend zu Walsers Original mit »herrl'chem« vertont Wüthrich deutlich »herrlichem « auf einem absteigenden F-Dur-Akkord.

128 Im Unterschied zur diatonischen Skala (meist mit fünf Ganztönen und zwei Halbtönen) setzen sich Achttonskalen aus je vier Halb- und Ganztönen zusammen. Am einfachsten entstehen diese Achtton-Skalen, wenn man Halbton und Ganzton abwechselt. Wüthrich benützt während der zweiten Strophe neben dieser regelmäßigen Form auch unregelmäßige Varianten, wohl um das Exotische noch zu verstärken. 
Expressiv gesungen wird nur das Wort »Augen« in der Mitte des Liedes. Ansonsten dominiert das Sprechen, das bis ins Stottern aufgeteilt und Silbe für Silbe auskomponiert ist, sodass man wegen elidierten Konsonanten den Text laut sprechen muss, um zu verstehen, was zum Beispiel »MITEN SCH[:]-AU-N-DE-N « bedeutet. Am stärksten verfremdet wird die Stelle »Das Sprechen will zu«: »DA-S[:] S[:]-SCH[:]-P[a]-Ä-R Ä-CH[:]-ÄN WI-LL-TS TS TS TS TS TS TS TSU $\ll$.

Begleitet wird dies von im Innern des Flügels gezupften Tönen in der Subkontralage.

Im zweiten und dritten Lied ist der Zyklus auch eine Auseinandersetzung mit Schuberts Winterreise. Beim zweiten Lied Auf meine Sinne (SW 13, 45) übernimmt Müller - mit Viertelton-Sekunden verfremdet - das Melodiegerüst von Franz Schuberts schauerlichem Lied Das Wirtshaus (Winterreise, Nr. 21), das von Schubert als teils >heiterer Trauermarsch in F-Dur gesetzt ist. Darin wird die von Walser oft erzählte Geschichte vom Wanderer, der zum Schluss im Totenhaus seine Ruhe findet, aus anderer Perspektive erzählt: Im kühlen Wirtshaus des Friedhofs gibt es für den Wanderer keinen Platz mehr; weil alle Grabkammern besetzt sind, muss er weiterziehen. Mit diesem AhasverMotiv bekommt der »Wanderungen Gier « und das »Ich halte inne« in Walsers Gedicht eine ambivalente Gegenspannung.

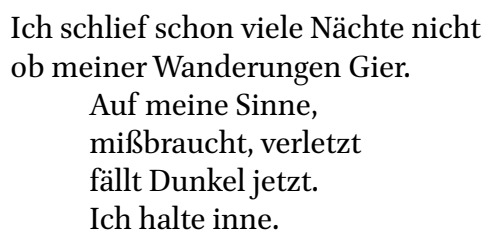

Das Klavier begleitet mit sirrenden und irreal wirkenden Flageolett-Tönen, die mit der rechten Hand im Innern des Flügels auf den Saiten erzeugt werden, während die linke Hand die entsprechenden Tasten drückt. In der Gesangsstimme sind die >Schubert-Töne< unterstrichen (vgl. Abb. 84). Als Irritation führt Müller zwei Frikative ein, die als gespenstisches Zischen den Wortsinn unterlaufen. »SCH« leitet Müller von »schlief« ab. Er isoliert den Anfangskonsonanten, sodass man beim Hören auch »Ich lief« verstehen kann. »F« könnte von Schuberts Tonart F-Dur abstammen oder vom letzten Buchstaben von »schlief«. Beide Frikative setzt Müller wie musikalische Vorschläge zur onomatopoetischen Verstärkung, aber auch zur Sinnvernebelung der Wörter ein, zum Beispiel »SCH[:]VER-FLETZT « in Takt 9 oder: »FÄLL $S C H[:] D U N-$ FKEL $S C H[:]$ ICH HAL-SCH[:]TE« in den Takten 12-14. 


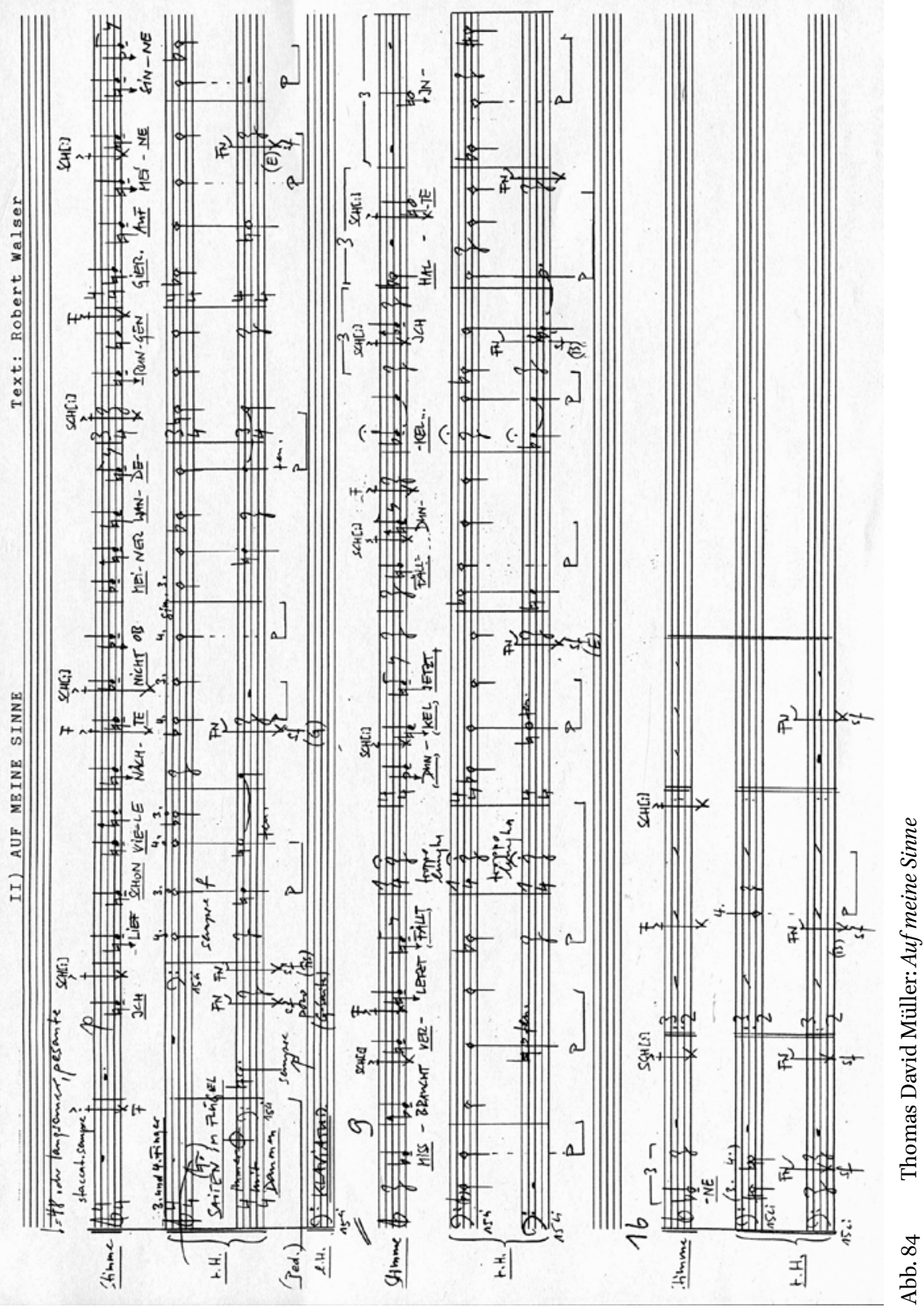


Das letzte Lied Morgenstern (SW 13, 10) bezieht sich auf Schuberts Lied Im Dorfe (Winterreise, Nr. 17); knurrende und bellende Hunde treiben den Wanderer durchs Dorf. Ein tremolierendes Motiv im Klavier vollzieht dieses Knurren und Bellen bei Schubert anschaulich nach. Mit dem Bezug zum grotesken Schubertlied gewichtet Müller nicht die stille Schneestimmung des Gedichts Morgenstern, sondern dessen letzte vier Silben: »in mir brennt's heiß«. Das Klavier spielt bei Müller fast nur aggressiv laute Tremoli in tiefer Lage, die wie Störungen wirken; die Sängerin führt 92 einzelne Aktionen durch, die in elf vertauschbare Abschnitte aufgeteilt sind. Das Stück ist beendet, wenn alle Abschnitte einmal gespielt wurden. Dieses Zeremoniell dauert doppelt so lange wie die beiden ersten Lieder von Müllers kleinem Zyklus. Und in den extremen vokalen Sprüngen und expressiven Spannungen wird man hier ans expressionistische Melodram von Schönberg erinnert.

Thomas Müller widmete die Lieder seinem Lehrer Jacques Wildberger, seinerseits Schüler von Wladimir Vogel, der sich mit diesem anlässlich der Uraufführung von Flucht überworfen hatte (vgl. Kap. 3.3). Die Möglichkeiten und Grenzen dessen, was Vertonung kann (von kommunistischen AgitpropSongs über kritische Hölderlin- bis zu sublimen Celan-Vertonungen), waren Wildbergers kompositorisches Lebensthema. Thomas Müllers Lieder sind wie ein Nachklang zu dieser Auseinandersetzung, die er mit seiner neuesten Entwicklung in eine unerwartete Richtung wendet (vgl. Müllers Beiseit in Kap. 10.16).

\subsection{Aleksander Gabryś: Da ich ein Knabe war (2003)}

Man könnte ihn als einen >Jimmy Hendrix des Kontrabasses< bezeichnen. Zuweilen meint man, das Instrument mit beinahe 100 Kilogramm Saitenspannung würde das Spiel von Aleksander Gabryś ( ${ }^{*} 1974$ ) nicht überstehen und bersten. Gabryś zählt zu jenen Interpretinnen und Interpreten der zeitgenössischen Musik, welche die lange hochgehaltene Rolle des neutralen Ausführenden verweigern, mit `Leib und Seele< spielen und ihre Persönlichkeit als Ganzes einbringen. Er wurde in Polen geboren, studierte in Kattowitz und Basel, wo er seit bald zwei Jahrzehnten schwerpunktmäßig lebt und insbesondere im zeitgenössischen Musikbereich tätig ist. ${ }^{29}$ Dass Gabryś auch komponiert, oft mit elektroakustischen Mitteln, zuweilen auch in Zusammenarbeit mit seinem

129 In Zusammenhang mit Robert Walser ist zu erwähnen, dass Helmut Oehring in seinem Gunten die Partie des Kraus Aleksander Gabryś auf den Leib geschrieben hat (vgl. Kap. 9.8). 
Vater und Lehrer Ryszard Gabryś, wird ob seiner spektakulären Performances manchmal vergessen.

2003 komponierte Gabryś für ein schweizerisch-polnisches Austauschprojekt ein Stück in memoriam Robert Walser für Sopran, Horn, Klarinette, Violine, Violoncello und Klavier, bei dem er das Motiv des Knabenhaften fokussierte, allerdings nicht mit einem Walser-Text, sondern mit dem Gedicht Da ich ein Knabe war ... von Friedrich Hölderlin. ${ }^{130}$ Er schreibt dazu:

Da ich ein Knabe war ... - »wir kennen dieses wunderbare Lied«, sagte Robert Walser [...] über das von mir ausgewählte Gedicht von Friedrich Hölderlin, und war von diesem Genie, dessen Schicksal er teilweise teilte, sichtlich gerührt. [...] Inspirierend war für mich nicht nur das Gedicht, dem ich die Anfangsund Endstrophen entnahm, sondern auch Robert Walsers schöne Impression »Hölderlin«. Ich habe mich hier bemüht etwas aus der daguerreotypischen Stimmung der Kindheit (»... ich spielt im Hain / Und mit mir spielten / Die Lüftchen des Himmels ... « $)^{131}$ und gleichzeitig wenigstens einen Schatten des Wanderns, einen flüchtigen Augenblick aus dem ungewöhnlichen, für beide Künstler faszinierenden und schweren Lebensweg zu erfassen. ${ }^{132}$

Das Werk beginnt mit einem Unheil ankündenden Vorspiel: im Innern des Klaviers gedämpfte Klänge, mikrotonale Verfärbungen und wilde Glissandi der Streicher. Anschließend setzt die Sopranistin flüsternd, keuchend, singend und pfeifend ein. Fast bei jedem Wort wechselt der Modus der Stimme. So jagt Gabryś bei der Stelle »die Lüftchen des Himmels spielten mit mir« auf das Wort »Himmels« die Singstimme auf den höchsten Ton der ganzen Partie $\left(b^{2}\right)$ und wechselt sogleich bei »spielten mit mir« in ein irres Schreien - »harlequino« fügt Gabryś an. ${ }^{133}$

Man kann sich des Eindrucks nicht erwehren: Da singt und schreit jemand Hölderlin in einer Isolationszelle oder in einem Albtraum. Nach dieser ersten Hölderlin-Strophe folgt ein von ostinaten Rhythmen geprägtes instrumentales Zwischenspiel.

130 Hölderlin: Gedichte, S. 21f. Zum Projekt vgl. Gartmann:Robert Walser imuzyka szwajcarska. Vgl. auch die CD Robert Walser in der Schweizer Musik.

131 Im Original: »Da spielt ich sicher und gut / Mit den Blumen des Hains, / Und die Lüftchen des Himmels / spielten mit mir.«

132 Aleksander Gabryś zit. nach Gartmann: Robert Walser in der Schweizer Musik, S. 9.

1332020 hat Gamaliel von Tavel mit Walser-Fantasie über Hölderlin für Alphorn, Knabenstimme, Bariton und Sprecher oder Sprecherin eine zu Gabryś in jeder Beziehung gegensätzliche Vertonung geschaffen. Von Tavel vertont das Gedicht Da ich ein Knabe war integral und wählt stilistisch ein strahlendes und weitgehend dissonanzenfreies Dur in einfacher Diktion und 4/4-Takt-Rhythmik. Diese mit dem Alphorn noch verstärkte Idyllik wird von der die Vertonung umrahmenden Lektüre des abgründigen, autobiografische Züge tragenden Textes Hölderlin (BA 15, 108-111) von Robert Walser konterkariert. 
Jene Strophen, in denen Hölderlin die Götter, Gestirne und den Äther in hohem Ton besingt, lässt Gabryś weg; er springt direkt auf die sechste Strophe mit einem >Walser'schen< Grundton: »Mich erzog der Wohllaut / Des säuselnden Hains / Und lieben lernt' ich / Unter den Blumen.« Hier wechselt der Charakter der Vertonung, denn Gabryś komponiert für die Singstimme weit ausgreifende Kantilenen mit vielen emotionalisierenden Portamenti, bei denen die Tonhöhen mit Schleifern verbunden werden. Das steigert sich fast zu einem vokalen Jauchzen, unterstützt von entsprechenden Parallelbewegungen in den Instrumenten, insbesondere in den beiden Streichern. Allerdings wird auch diese Überschwänglichkeit zerstört. Wie in vielen Gedichten von Robert Walser kippt der Schluss ins Gegenteil: Auf das Wort »Blumen« schreit die Sängerin erneut im Pfeifregister, stürzt dann lachend in die Tiefe, die Endsilbe »men« nur noch flüsternd (vgl. Abb. 85).

Bei Hölderlins letzter, nur aus einem Satz bestehender Strophe vermeidet Gabryś jede naheliegende Überhöhung. Mit einer schlichten aufsteigenden Skala wird nur das einfache Großwerden und die damit verbundene Entfernung vom Knabendasein vertont; zum Schluss verengt sich die Skala zum Viertelton und bleibt stehen. Auch das Großwerden »im Arme der Götter« hört einmal auf. Es folgt ein Nachspiel, das auf den `Stillstand « von Hölderlins und Walsers zweiten Lebenshälften anspielt: ${ }^{134}$

Irreguläres rhythmisches Anschlagen der tiefsten Klaviertaste bei gleichzeitigem Verschieben der linken Hand, welche die Saite bis zum Ende der Wicklung verkürzt: hier mehrmals, diesmal secco spielen, abgerissen, stumpf und abnehmend, diminuendo, in einer ad infinitum Stimmung. ${ }^{135}$

134 Die Repetitionen desselben Klaviertons erinnern an Giacinto Scelsi, der in den 1940erJahren während einer psychischen Krise in einer luxuriösen Lausanner Nervenklinik stundenlang auf einem Klavier denselben Ton auf unterschiedlichste Weise gespielt haben soll. Zur >tödlichen` Qualität der damaligen Schweizer Psychiatrie äußerte sich Scelsi später folgendermaßen: »Les meilleures cliniques sont en Suisse ... Mais c'est celles, aussi, où ... l'on meurt le plus. Parce que les gens n'y ont pas d'autres fins ... pas d'autres possibilités que ... celle de mourir ... Alors, ils meurent ... c'est connu.« Vgl. Von der Weid: Entretiens avec Giacinto Scelsi, S. 8.

135 Vgl. Gabryś: Da ich ein Knabe war, S. 6: »nieregularne rytmiczne uderzenia w najniższy klawisz przy równoczesnym przesuwaniu skracającej strunę lewej dłoni aż do końca owijki: tu kilkakrotne, grane tym razem secco, urywane, głuche i odchodzące diminuendo, w nastroju >ad infinitum « 


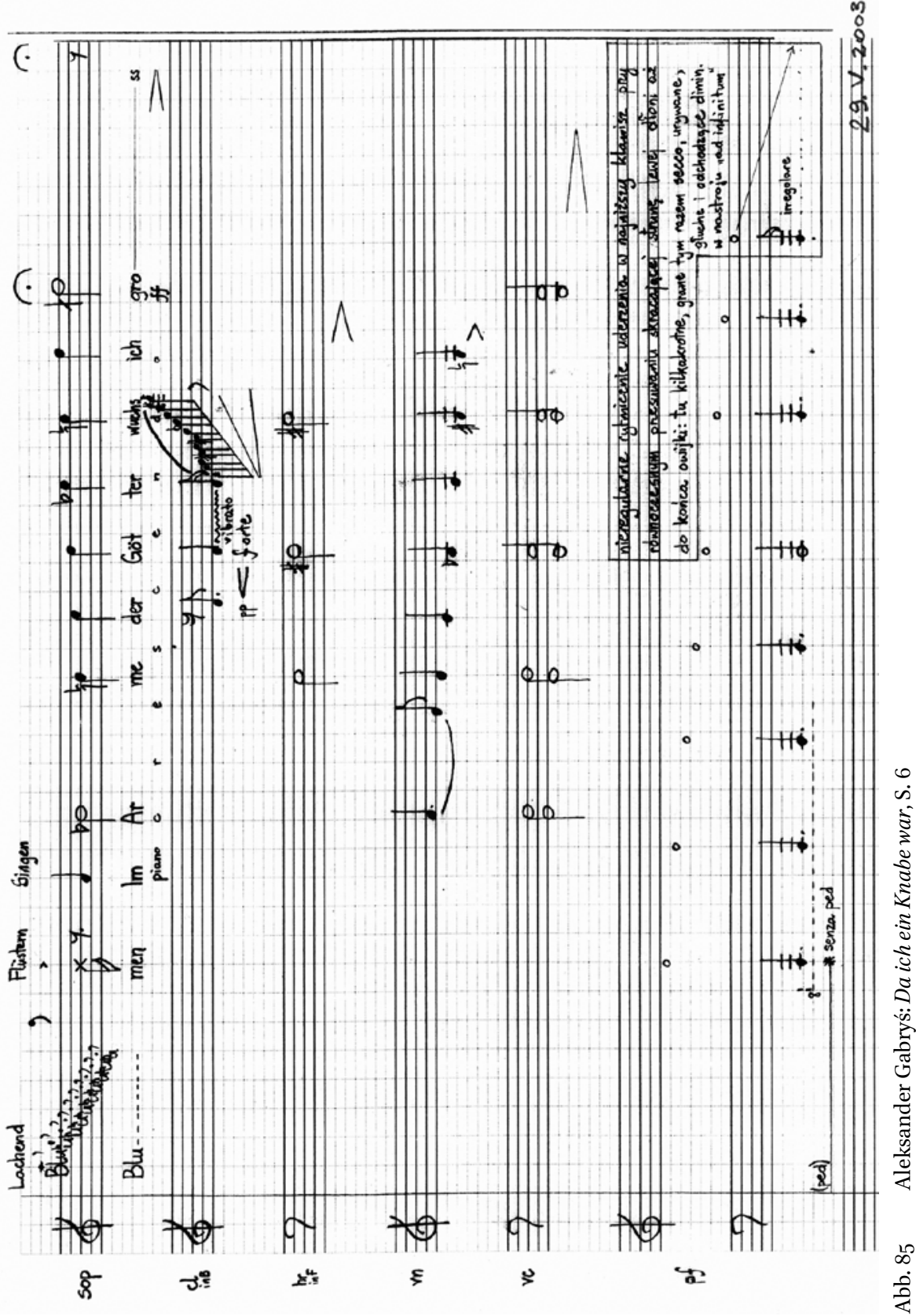


11.17 Eva-Maria Houben: mittagspause (2004), vor schlafengehen (2005), wiegen (2005), vier geschichten von robert walser (2005), langezeit (2005), walser lesen (2007) und ein schlummer (2013)

2004 bis 2007 waren für die Komponistin Eva-Maria Houben ( $\left.{ }^{*} 1955\right)$ eigentliche Walser-Jahre, denn sie schrieb gleich sechs Kompositionen zu Gedichten und kurzer Prosa des Dichters. Wie ein Kondensat ihrer Walser-Beschäftigung erscheint das 2013 komponierte ein schlummer für Flöte(n) und Orgel über Warum auch (SW 13, 9). In diesem frühen Gedicht wird die Haltung zu Welt und Gesellschaft benannt; zuerst das aktive lyrische Ich mit »ich stürze mich in den Kampf hinein; [...] bis das Volk befreit«, dann das in der dritten Person kommentierte lyrische Ich: »da überkam ihn ein Erwägen, ein Schlummer: ach, lass doch das.« Eva-Maria Houben schreibt dazu:

Warum auch ist ein für mich existentielles Gedicht. [...] Man macht nicht mehr (allzu) viel, aber doch etwas ... aber was??? Es ist diese Walsersche Haltung, die mich so unbeschreiblich anspricht, und die nicht nur Bescheidenheit und Zurücknahme ausdrückt, sondern (für mich) eine absolut selbstbewusste künstlerische Haltung ist, die auf unbegriffliche Weise auch politische Sprengkraft hat: »Ach, lass doch das (werden! ergänze ich hier)«. Eine Haltung, die es sich erlauben kann, auf Aktionismus und Ameisen-Tun zu verzichten. [...] Es ist auch eine Einlassung auf Geschehnis: das Musikalische daran. ${ }^{136}$

Eva-Maria Houben ist Komponistin, Organistin, Pianistin und Musikwissenschaftlerin. Von 1993 bis 2021 war sie Professorin am Institut für Musik und Musikwissenschaft der Technischen Universität Dortmund. Ihre Forschungsgebiete sind Musiktheorie und Neue Musik, wobei sich Eva-Maria Houben weniger auf die produktionsästhetisch orientierte Analyse von Werken als vielmehr auf das Hören konzentriert. Sie versammelte in Gastseminaren an der Universität Dortmund eine ganze Reihe von Komponistinnen und Komponisten, die in ihrem Schaffen ein neues Hören suchen oder fordern. ${ }^{137}$ In diesem Zusammenhang publizierte Houben auch über den Schweizer Walser-Vertoner Jürg Frey, ein Seelenverwandter auf der Suche nach Stille und Klangreduktion (vgl. Kap. 11.4) ${ }^{138} 2018$ legte Houben eine bahnbrechende Studie vor, in der sie die musikalische Praxis nicht unter dem Aspekt des Machens, sondern des Hörens und Zuhörens umfassend untersuchte. ${ }^{139} \mathrm{Im}$

136 E-Mail von Eva-Maria Houben an Roman Brotbeck vom o8.05.2021.

137 Vgl. Houben: Immer wieder anders.

138 Vgl. Houben: Möglichkeiten des Hörens.

139 Houben: Musikalische Praxis als Lebensform. 
Zentrum steht die Frage, wie die Ausführenden allein oder in unterschiedlichen Ensemble-Konstellationen einander und sich selbst hören und zuhören.

Auch die sieben Werke, die Eva-Maria Houben zu Robert Walser komponiert hat, könnte man als Studien des Hörens bezeichnen, in denen Solo-, Duound Ensemble-Situationen erprobt werden. Bei mittagspause (2004) ist das Ensemble noch instrumentiert, bei den späteren Ensemblestücken langezeit und walser lesen ist die Besetzung variabel.

Allen Werken ist gemeinsam, dass die Texte von Walser weder gesungen noch gesprochen werden, sondern nur in der Partitur abgedruckt sind. Die Texte würden das von Houben angestrebte musikalische Hören der Stille überdecken oder in den Hintergrund drängen.

Das Klavierwerk vor schlafengehen besteht aus elf Klangzeichen, die beharrlich wiederholt werden, zum Beispiel wird gleich zu Beginn 66 Mal die Quinte $f^{2}-c^{3}$ angeschlagen; dann folgt 22 Mal die tiefe Quinte $D-A$ und anschließend 34 Mal die mittlere Quinte $h$-fis ${ }^{l}$. Obwohl diese Information mit Wiederholungszeichen auf einer halben Zeile notierbar wäre, schreibt die Komponistin jedes Klangzeichen einzeln aus, sodass auf der ersten Seite nur regelmäßig angeordnete Quinten stehen und das Partiturbild an Minimal Art erinnert (vgl. Abb. 86). Dieser visuelle Aspekt eröffnet sich allerdings nur den Ausführenden. Die Zuhörenden sind den Quinten ausgeliefert und werden sich fragen, was das mit Vor Schlafengehen (SW 13, 23) von Walser zu tun haben könnte; anderen wird vielleicht die rasche Schwebung der temperierten Quinte in dieser Höhe auffallen und wieder andere werden wegzuhören versuchen. Wie auch immer: Das Hören und der Klang, vor allem die Intervallwahrnehmung wird aktiviert und thematisiert.

Deshalb wählt Houben auch dieQuinte, neben der Oktave das konsonanteste Intervall, das aber wegen der minimalen Schwebung in der temperierten Stimmung des Klaviers ein regelmäßiges feines >Wimmern aufweist, und zwar unterschiedlich schnell je nach Lage. Es ist die Kunst des Klavierstimmens, diese gegen oben schneller werdende Schwebung der Quinten exakt zu zählen, um sie richtig zu temperieren. Dieser unterschiedliche Klang der Quinten und später der großen Terzen in den verschiedenen Lagen des Klaviers ist eines der Themen der Komposition. Nur bei diesen sehr konsonanten Intervallen sind solche Schwebungen überhaupt wahrnehmbar.

Es ist kein Zufall, dass vor schlafengehen aus 365 solcher Klangereignisse besteht und einen `Jahreslauf^symbolisiert, der einen mit den Wiederholungen an Walsers Gänge denken lässt. Elf Elemente werden in unterschiedlicher Anzahl wiederholt; bei der Anzahl der Wiederholungen sind neben den Fibonacci-Zahlen 34 und 55 die Zahlen $11(66,22,55)$ und $12(48,36,9+3)$ strukturbildend: 

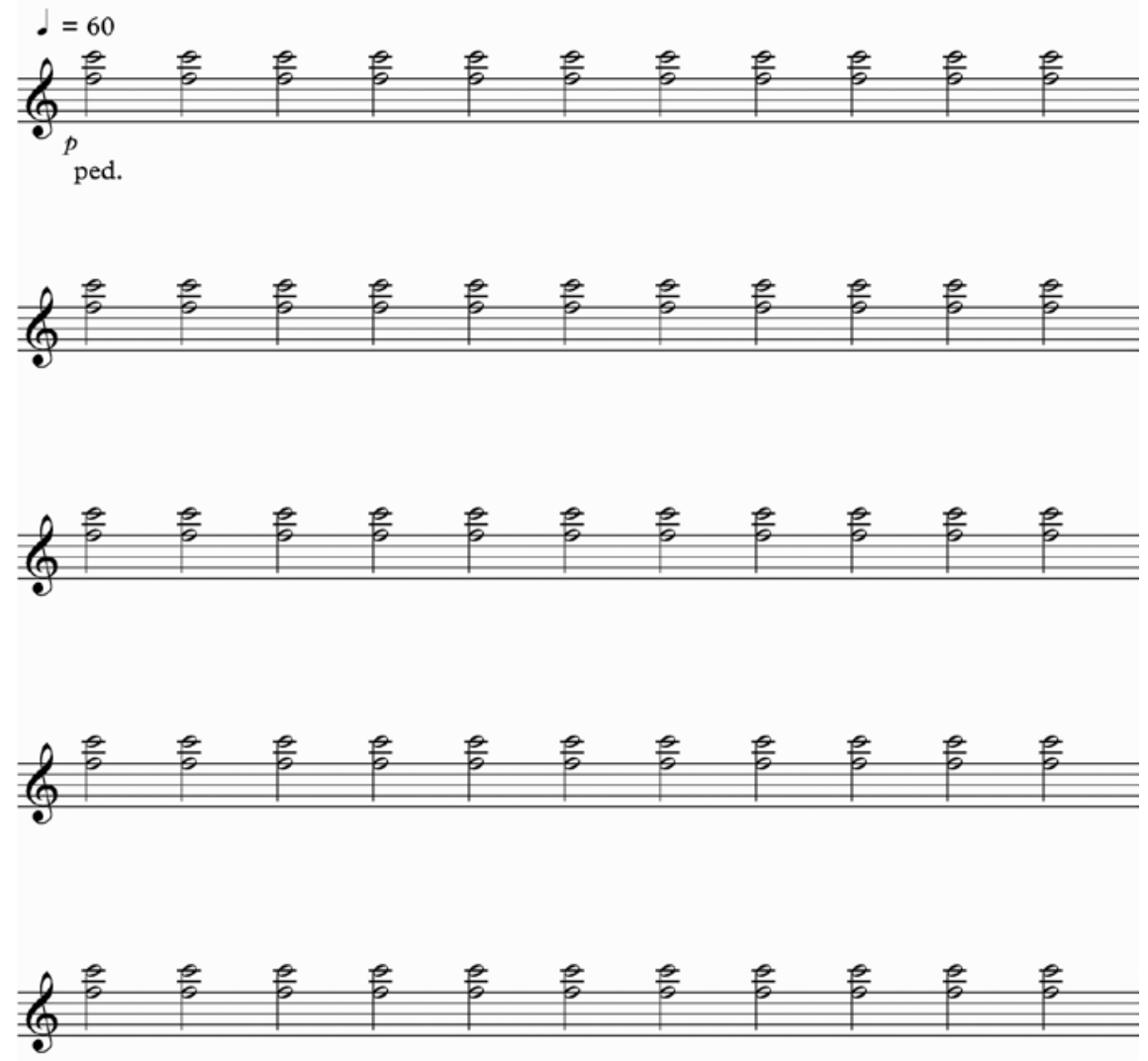

Abb. 86 Eva-Maria Houben: vor schlafengehen, S. 1

1. 66 Quinten hohe Lage (3/2),

2. 22 Quinten tiefe Lage (3/2),

3. 34 Quinten mittlere Lage (3/2),

4. 18 Duodezimen mittlere Lage (3/1),

5. $\quad 38$ Großdezimen in weiter Lage (10/1),

6. 48 Einzeltöne Kontralage $(C)$,

7. 36 Großterzen in Subkontralage (5/4),

8. 36 Großterzen in Subkontralage (5/4),

9. 9 Dreiklänge in weiter Lage mit kleiner Septime $\left(H_{1}-d^{1}-a^{I}\right)$,

10. 3 Dreiklänge in weiter Lage (Quintakkorde: $G_{7}-d^{I}-a^{I}$ )

11. 55 Einzeltöne in Subkontralage $\left(G_{\imath}\right)$

Besonders hingewiesen sei auf die Klangereignisse 3 bis 5 , denn dort wechselt Houben von der normalen Quinte (3/2) in die Duodezime, die noch konsonanter wirkt, weil durch die Oktavierung das Intervall in der Proportion 3/1 schwingt. 
Beim Klangereignis 5 geschieht etwas ähnliches mit der großen Terz $5 / 4$, die Houben in eine weite Lage setzt, sodass sich durch die Oktavierungen die Schwingung der Terz zur Proportion 10/1 vereinfacht und ähnlich konsonant schwingt wie die Quinte. Diesen Übungen in Konsonanzen wird bei Klangereignis 7 und 8 eine >dissonante< Welt gegenübergestellt, denn die großen Terzen klingen in der tiefsten Lage für das menschliche Ohr wie Dissonanzen.

Viermal wird in vor schlafengehen das strenge Hörexerzitium von einstimmigen Melodien unterbrochen, die laut der Aufführungshinweise »wie eine weit gedehnte, ganz langsame melodie ${ }^{140} \mathrm{zu}$ spielen sind. Diese Melodien wirken so gesanglich, dass man Walsers Gedicht unterlegen könnte. Mit einem Augenzwinkern hat Houben für die erste der Melodien ausgerechnet eine tonal wirkende Zwölftonreihe gewählt, wohl ein kleiner Seitenhieb auf die die Quinte verachtenden Dodekaphonisten.

Bei dieser Komposition können sich die Zuhörenden nicht zurücklehnen und sich von Walsers faszinierenden Texten überraschen lassen; man wird gleichsam selber in einen seine Gänge ausschreitenden >Walser verwandelt.

Während bei vor schlafengehen eine Partitur vorliegt, die in traditionellem Sinne gespielt werden muss, können die Ausführenden bei Houbens anderen Walser-Werken die Form und den Ablauf teilweise selbst wählen - die Aufführung fällt jedes Mal anders aus. In zweien dieser Werke erkundet die Komponistin die Möglichkeiten der Zweistimmigkeit. Dabei geht sie auf jene Grundformen der Zweistimmigkeit zurück, die sich schon im Mittelalter herausgebildet haben, als es noch keine messbare rhythmische Notation gab: parallele Bewegung der beiden Stimmen, wobei eine liegenbleibt, die andere sich frei entwickelt (Haltetonstil); die beiden Stimmen wechseln sich ab und bilden so den Hoquetus. Houben übernimmt die im Mittelalter übliche rhythmisch freie Notation, bei der der musikalische Verlauf nur ungefähr aufgezeichnet ist.

Bei wiegen für Violoncello und Gitarre besteht die Partitur aus zweimal 14 Blättern mit sehr wenigen Noten drauf. In den Aufführungshinweisen heißt es: »Jeder der beiden spieler wählt einige seiten aus (beide gleich viele seiten). die reihenfolge ist frei ${ }^{141}$ Während der Part des Violoncellos aus langen und sehr langen liegenden Klängen besteht, spielt die Gitarre oft langsame und weit gedehnte Melodien. Auch hier ist man wie bei vor schlafengehen verführt, einzelnen Melodien Walsers Gedicht Wiegen (SW 13, 12) zu unterlegen.

Bei vier geschichten von robert walser, einem Zyklus für Klarinette/Bassklarinette und Violoncello, komponierte Houben für jede Geschichte ein

140 Houben: vor schlafengehen, S. [4].

141 Houben: wiegen, S. [4]. 
Bicinium mit "55 Zeilen «, womit erneut eine Fibonacci-Zahl wirksam ist. Das erste Bicinium zu Auf der Terrasse (SW 16, 12f.) besteht aus gemeinsamen Einsätzen der Instrumente, die dann ausklingen; im zweiten Bicinium zu Liebe kleine Schwalbe (SW 16, 396f.) erklingen Melodien im Unisono bzw. OktavUnisono; das dritte zu Die Blumen (SW 16, 404f.) ist ein Hoquetus; das vierte zu Im Wald (SW 16, 13f.) ist in einer Halteton-Faktur komponiert.

Häufige Hinweise sind »langsam « und »leise«, am wichtigsten ist für EvaMaria Houben aber die Stille, aus der jedes Element hervorgeht und in die es wieder verklingt. $\mathrm{Zu}$ vier geschichten von robert walser schreibt sie in den Aufführungshinweisen: »irgendwo anfangen, zeile für zeile weiterspielen, irgendwo aufhören. [...] zeilen werden nicht wiederholt. nach jeder zeile bleibt es eine zeitlang still.«142

Das Werk langezeit (SW 13, 7f.) für variables Ensemble ist ähnlich aufgebaut wie wiegen. Hier können die Ausführenden in beliebiger Zahl und mit beliebigen Instrumenten (es kann auch auf einem offenen $o$ gesungen werden) aus 34 Stimmen auswählen. Und auch hier steht in den Aufführungshinweisen: »jeder klang ist von sehr langer dauer: [...] ein stilles verklingen (laissez vibrer).« «143

Bei der 2007 entstandenen Komposition walser lesen denkt man unweigerlich an Hans Zenders fünfteilige Werkgruppe Hölderlin lesen, die dieser 1979 begonnen hatte (vgl. Kapitel 13.5). Allerdings gibt es bei Eva-Maria Houben keine Sprechstimme, denn mit walser lesen ist das lesende Publikum gemeint: »die texte könnten vielleicht vor der aufführung für das publikum bereitgelegt werden. wer möchte, liest stumm für sich - vor, während oder nach der aufführung.«144

Houben wählte die eher langen Texte Schnee (SW 4, 146f.), Lampe, Papier und Handschuhe (BA 13, 32-34) und Schneien (BA 13, 37-39). Die Noten für Schnee und Schneien sind provokativ kurz: Sie bestehen aus einer C-DurTonleiter. Bei Schnee wählen die Spieler Einzeltöne aus dieser Tonleiter aus:

ein spieler spielt seinen ton, die weiteren spieler setzen nach und nach so ein, dass die einzeltöne sich etliche zeit überschneiden.

so spielen, dass kein klang hervortritt.

nach jedem zusammenklang bleibt es einige zeit still: zusammenklang - stille zusammenklang - stille - zusammenklang - stille - usw.

eine ganze weile spielen. ${ }^{145}$

142 Houben: vier geschichten von robert walser, S. [8].

143 Houben: langezeit, S. [4].

144 Houben: walser lesen, S. [3].

145 Houben: walser lesen, S. [8]. 
Bei Schneien wählen alle Spieler gemeinsam einen Ton dieser C-DurTonleiter aus und spielen ihn im (Oktav-)Unisono nach dem gleichen Prinzip. Konsequenter kann man das alles überdeckende und entdifferenzierende »es schneit« von Schneien kaum in Klang umsetzen. Das mittlere Stück besteht aus 44 Seiten mit Melodien ohne Vorzeichen (also auch aus dem Material der $>$ C-Dur-Tonleiter<), wovon die Ausführenden je ein Blatt auswählen; es erklingt eine Folge aus diatonischen Klängen von langer Dauer. Wenn der letzte Spieler seine Seite gespielt hat, ist das Stück zu Ende. Das Stück walser lesen wirkt damit ein bisschen so, als hätte John Cage (1912-1992) posthum auch noch ein Werk zu Robert Walser geschrieben. Jedenfalls bilden die Werke von EvaMaria Houben in der musikalischen Walser-Rezeption einen Spezialfall, weil auf die Texte gar nicht eingegangen wird, sondern das >Prinzip Walser $<$ von den Zuhörenden und ganz speziell auch von den Spielenden durchlebt werden muss.

\subsection{Hans-Martin Linde: Fünf Lieder für Sopran, Bass und Klavier (2010)}

Hans-Martin Linde ( ${ }^{*} 1930$ ) kennt man vor allem als Interpreten und Dirigenten. Er wurde in den 195oer-Jahren als Traverso- und Blockflötenvirtuose bekannt, der die Alte Musik im Allgemeinen und die Blockflöte im Speziellen aus dem Dunstkreis betulicher Hausmusik, wie sie besonders während des Nationalsozialismus gepflegt wurde, herauslöste; auch dank ihm wurde die Blockflöte zu einem wichtigen Konzertinstrument nicht nur in der Alten Musik. HansMartin Linde kam 1957 nach Basel und unterrichtete während Jahrzehnten Flöteninstrumente an der Schola Cantorum Basiliensis. Als Solist und Kammermusiker spielte er viele Schallplatten und CDs ein, darunter zahlreiche Aufnahmen mit dem Linde-Consort. Seit den 198oer-Jahren wurde seine Tätigkeit als Dirigent, insbesondere in Zusammenarbeit mit der Cappella Coloniensis des WDR, wichtiger.

Als Komponist konzentrierte sich Linde anfänglich vor allem auf die Blockflöte, seit den 199oer-Jahren schreibt er für alle Gattungen außer der Oper. Zwischen 2006 und 2010 komponierte Linde eine Reihe von Klavierliedern, darunter auch die Fünf Lieder für Sopran, Bass und Klavier, die Texte in drei Sprachen und von fünf verschiedenen Autoren versammeln. Walsers spätes Gedicht Wie ich ein Blatt fallen sah (SW 13, 97f.) wird in den Kontext von Franz Kafka (1883-1924), Fujiwara no Yoshitsune (1169-1206) und Andri Peer (19211985) gestellt. Die Texte handeln vom Unterwegssein, von der Flüchtigkeit des Lebens und vom Verblassen der Natur. 
Wie ich ein Blatt fallen sah thematisiert den Blick zurück. Im Schluss »Schaue öfter zurück, wenn es dir dran liegt, dich zu bewahren« lässt sich eine ironische Anspielung auf Orpheus sehen, der mit seinem Gesang Eurydike aus der Unterwelt befreien kann, sie aber wegen des Blicks zurück endgültig verliert. Wohl aufgrund dieses Bezugs wählte Linde die Duett-Form, die es ihm erlaubt, die im lyrischen Du formulierte Anspielung als Duo zu gestalten.

Im Folgenden wird normal Gesetztes vom Bass, kursiv Gesetztes vom Sopran und fett Gesetztes von beiden gesungen.

\author{
Hätte ich mich nicht nach \\ den zum Teil bereits nackten \\ Zweigen umgedreht, so würde mir \\ der Augenblick des langsam- \\ goldig zu Boden fallenden, \\ aus üppigem \\ Sommer stammenden Blattes \\ entgangen sein. Ich hätte etwas \\ Schönes nicht gesehen und etwas Liebes, \\ Beruhigendes und Entzückendes, \\ Seelenfestigendes nicht empfunden. Schaue öfter \\ zurück, wenn es dir \\ dran liegt, dich zu bewahren. \\ Mit Gradausschauen ist's nicht getan. \\ Die sahen nicht alles, die nicht rund um sich sah'n. (SW 13, 97f.)
}

Linde schreibt in einem gemäßigten Stil, der die musikalischen Traditionen, die Linde als Interpret pflegte, nicht verleugnet. Das Duett kann man als Rezitativ bezeichnen. Das Klavier begleitet nur mit wenigen Akkorden, oft ist der Gesang unbegleitet. Dem Sprachrhythmus wird eng gefolgt und quasi die in Verse gefügte Prosa von Walser vertont. Die musikalischen Phrasierungen führen also über die einigermaßen unkonventionelle Versstruktur von Walser hinaus und werden nur dann eher zufällig berücksichtigt, wenn sie mit der syntaktischen Struktur zusammenfallen (zum Beispiel Phrasierungspausen nach »fallenden« und »Entzückendes«).

Mit leichter Ironie gestaltet Linde Walsers Schluss. Er leitet die Stelle mit dem auf der falschen Silbe betonten »öfte[ee]r « und dem apart akzentuierten »zurück « des Soprans ein, wechselt dann in die Bassstimme und lässt die entscheidende Sequenz »dich zu bewahren« im Duo in Gegenbewegung singen, eine Stimme führt aufwärts, die andere abwärts (vgl. Abb. 87). In analoger Weise sind alle Duostellen vertont - außer dem letzten Halbvers, der in Oktaven, einem konventionellen Emphasemittel, im Forte herausposaunt wird: »die nicht [Pause] rund um sich sah'n.« Mit unspektakulären und subtilen Mitteln erfasst Hans-Martin Linde Walsers feinen Witz. 

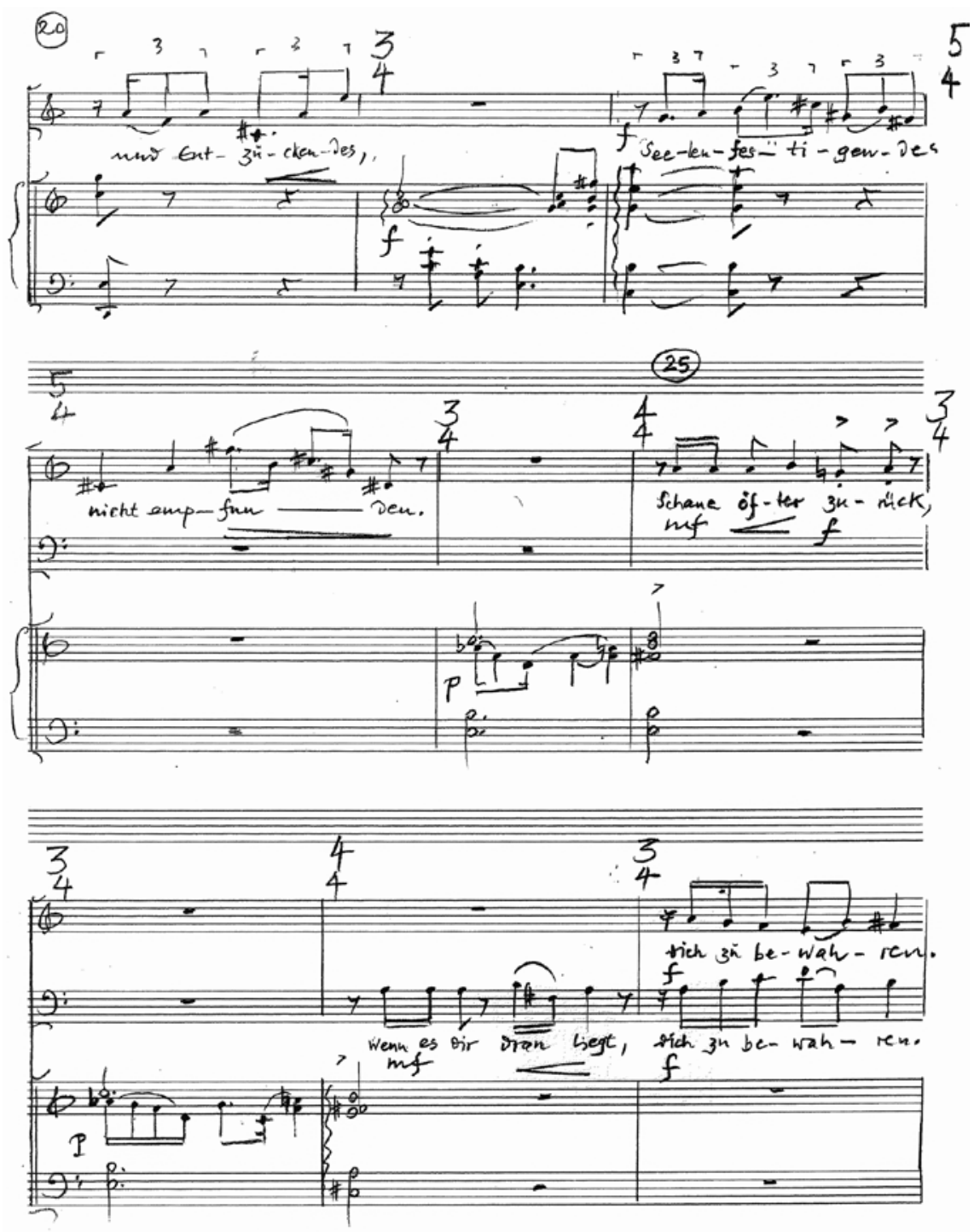

Abb. 87 Hans-Martin Linde: Wie ich ein Blatt fallen sah, S. 3 


\subsection{Gabrielle Brunner: Stunde (2011)}

Erst relativ spät begann die vielseitig tätige und auf zeitgenössische Musik spezialisierte Geigerin Gabrielle Brunner ( ${ }^{*} 1963$ ) nach einem Studium bei Daniel Glaus zu komponieren. 2011 konzipierte das Ensemble Proton Bern ein Programm, das Robert Walser gewidmet war. Dafür komponierte Gabrielle Brunner als Auftrag des Ensemble Proton das Werk Stunde, das man als einsätzige Kantate bezeichnen könnte. ${ }^{146}$ Die Komponistin beschränkt sich auf ein Ensemble von sechs Instrumenten, die paarweise angeordnet sind: Flöte und Oboe, Violine und Violoncello sowie Harfe und Klavier. Brunner verwendet in fünf Abschnitten drei Walser-Texte in teilweise extremer Fragmentierung:

- die ersten drei Worte von Der Spaziergang (Erstfassung) (BA 14, 9) für Mezzosopran, Bariton und Ensemble;

- den ersten Satz von DerSpaziergang (Erstfassung) für Bariton und Ensemble;

- Bangen (SW 13, 26), integral, für Mezzosopran und Ensemble;

- Stunde (SW 13, 27f.), Verse 1-4, für Mezzosopran, Bariton und Ensemble;

- die ersten vier Worte von Der Spaziergang (Erstfassung) für Bariton und Ensemble.

Den durchaus auffälligen Rahmen bilden die ersten Worte von Der Spaziergang (Erstfassung): »Ich teile mit« ist der Beginn und »Ich teile mit, daß« der Schluss (vgl. Abb. 88). ${ }^{147}$

Es ist sicher der abrupteste aller Schlüsse der Walser-Vertonungen: Eine chromatisch absteigende Umspielung der Violine mündet in der kleinen None $c i s^{3}-d^{4}$ im Fortissimo; gespiegelt dazu im Violoncello der Orgelpunkt mit den gleichen Tönen, aber als große Septime $d$-cis ${ }^{1}$. Der Höhepunkt besteht im gespuckten $t$ von »mit « und einem sogenannten Bartók-Pizzicato im Cello, bei dem die Saite senkrecht zum Griffbrett gespannt wird, um sie dann perkussiv aufs Griffbrett knallen zu lassen. Des Sängers letztes Wort »dass« ist zurückgenommen und wirkt verloren und unsicher. Wie oft bei Walser-Vertonungen befindet er sich allein in der Mitte des Klangraums. Die Flöte deutet eine

146 Uraufführung 17.09.2011, Dampfzentrale Bern, mit Liliane Glanzmann, Mezzosopran; Christian Hilz, Bariton; Ensemble Proton in seiner Erstbesetzung: Mirjam Lötscher, Flöte; Martin Bliggenstorfer, Oboe; Maximilian Haft, Violine; Thiemo Schutter, Violoncello; Vera Schnider, Harfe; Samuel Fried, Klavier. Musikalische Leitung: Matthias Kuhn. Neben Gabrielle Brunners Stunde wurde Christian Henkings Keine Zeit ist zeitig mit der Sehnsucht Zeit ur- sowie Xavier Dayers In hellem stillem Zimmer wiederaufgeführt.

147 Der Anfang »Ich teile mit« kommt nur in der Erstfassung von Der Spaziergang vor; aber der Entscheid für diese Version erfolgte nicht deshalb, sondern zufällig, weil die Komponistin nur diese Fassung bei sich zuhause stehen hatte. E-Mail von Gabrielle Brunner an Roman Brotbeck vom 20.08.2020. 


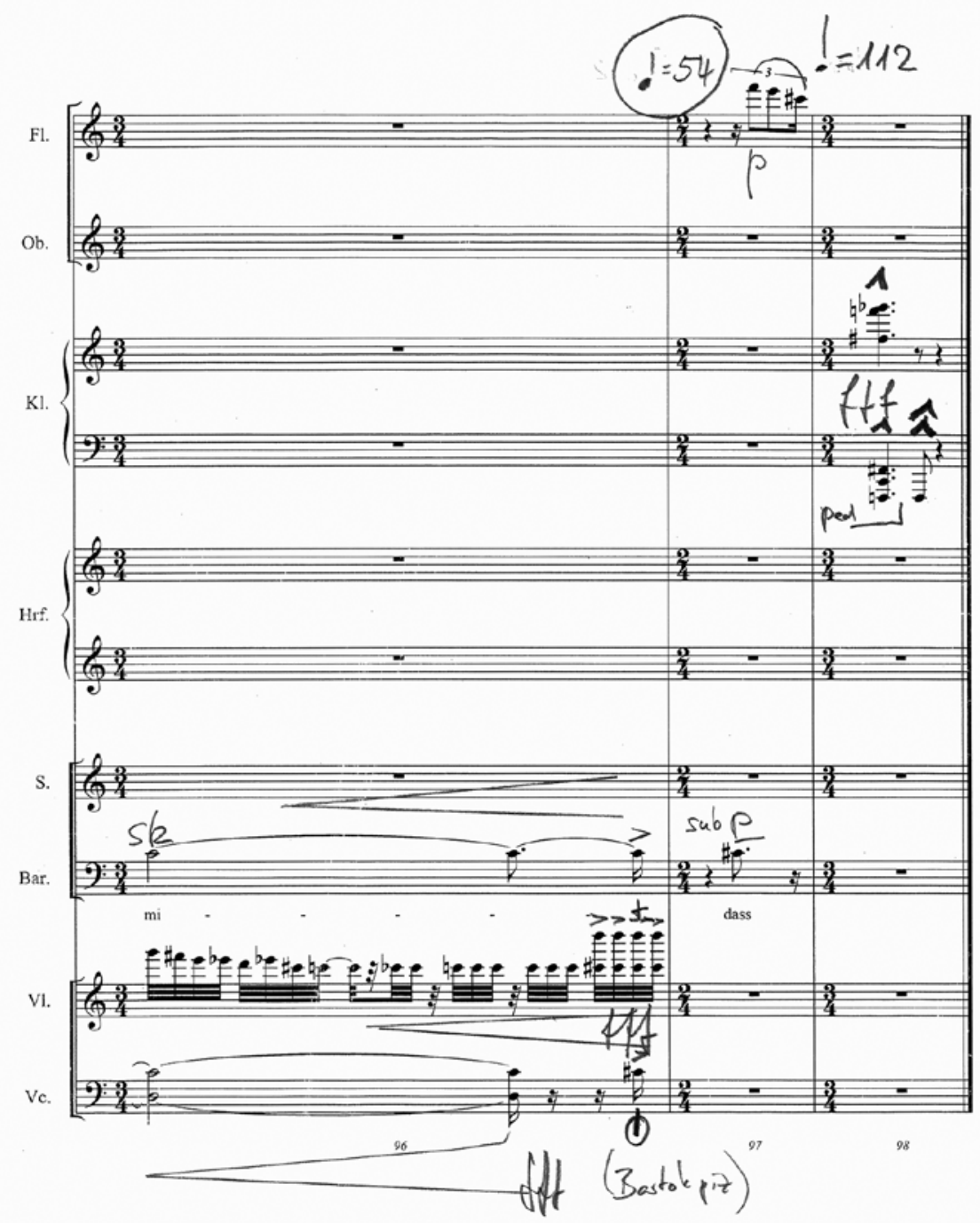

Abb. $88 \quad$ Gabrielle Brunner: Stunde, S. 41

Fortsetzung an, ein kurzer Gedanke, der zur erwarteten Aussage nach dem »dass « führen könnte. Auch der Taktwechsel im letzten Takt könnte etwas Neues ankünden, aber wie mit einer Guillotine wird die Musik abgeschnitten: Man könnte von einem >Bartók-Pizzicato des Klaviers sprechen. Es erklingt in Umkehrung die gleiche Konstellation wie in Takt 96 zwischen Violoncello und Violine: die kleine None $F_{7}$-Fis in der linken Hand und die große Septime $f i s^{2}-f^{3}$ in der rechten. Fast wie mit der Handkante gespielt muss der letzte Ton 
klingen. Es ist der lauteste und mit Doppelakzent am stärksten betonte Ton des ganzen Stücks.

Oft steht an den Schlüssen von Walser-Vertonungen der verstummende Sänger. Bei Gabrielle Brunner wird er im Moment, wo er zu einer Aussage ansetzt, von außen zum Schweigen gebracht - mit einem auskomponierten >die Türe ins Schloss knallen lassen<.

Die Art, wie Brunner diesen aggressiven Schluss nur mit einem Teil der Instrumente umsetzt, ist typisch für die ganze Kantate: Tuttis sind selten; meist wird mit den Registern Flöte/Oboe, Violine/Violoncello sowie Klavier gearbeitet. Die Harfe wird wie ein Continuo-Instrument behandelt und ist bei Bangen dominierend. Zweistimmigkeit ist von entscheidender Bedeutung; so sind die instrumentalen Zwischenspiele von Klavier bzw. Violine und Violoncello jeweils zweistimmige Sätze. Bei der eigentlichen Stunde, die dem Werk den Titel gibt, greifen die beiden Vokalstimmen frei ineinander.

Der Bariton - implizit eine Walser-Emanation - wird zu Beginn und am Schluss unsicher gezeigt. Beim ersten Satz von Der Spaziergang wird das erste »Ich teile mit« nur geflüstert, so als wagte der Sänger gar nicht zu beginnen. Die Partie der Sängerin ist in sich geschlossener, ihr Bangen bildet einen Ruhepunkt in diesem expressionistisch angelegten, von abrupten Unter- und wilden Ausbrüchen bestimmten Werk. Dessen Beginn gibt den >Grundton< des Werks: eine Art `Schreien<, denn die Streicher und Bläser spielen in höchster Lage in stürmischer Polyphonie und »sempre ff«.

\subsection{Christian Henking: Keine Zeit ist zeitig mit der Sehnsucht Zeit (2011)}

Er zählt zum Typus des `Stadtkomponisten<, wie es ihn früher häufig gab; ein Musiker, der seine musikalische Tätigkeit kompositorisch, pädagogisch, interpretatorisch und organisatorisch seiner Stadt widmet und dort viel bewirkt. Trotz dieser Konzentration auf den Wirkungsort Bern fehlt Christian Henking ( $\left.{ }^{*} 1961\right)$ alles Provinzielle, und er steht vernetzt mit der Welt in Kontakt. Er studierte am Konservatorium in Bern Musiktheorie (beim Berner Musiktheoretiker Theo Hirsbrunner) ${ }^{148}$ und Komposition bei den Gastprofessoren, die das Konservatorium nach dem Rücktritt von Sándor Veress 1981 engagierte: Cristóbal Halffter und Dimitri Terzakis. Es folgten Meisterkurse bei Edisson Denissow und Heinz Holliger. Der wohl wichtigste Kompositionslehrer wurde - einzig im Schriftverkehr - György Kurtág:

1481998 schrieb Theo Hirsbrunner über seinen ehemaligen Schüler und den Unterricht mit ihm einen Aufsatz. Vgl. Hirsbrunner: Tendenziell, nicht starr. 
Als junger Komponist habe ich ihm mal telephoniert und ihn gefragt, ob ich privat bei ihm Kompositionsunterricht nehmen könnte (Kurtág hatte vorgängig bei einem Kammermusikkurs ein Stück von mir einstudiert und wusste deshalb, wer ich war). Kurtág willigte ein, wollte aber nicht mühselig irgendwelche Treffs vereinbaren, sondern verlangte, dass ich ihm jeweils fertige Stücke schicken, er dann per Brief darauf eingehen würde. So geschah es dann. [...] Und mit diesen Briefen habe ich sehr viel gelernt. ${ }^{149}$

Schon kurz nach Abschluss seiner Ausbildung wurde Christian Henking Dozent für Musiktheorie und Komposition an der gleichen Hochschule (heute Hochschule der Künste Bern). Er dirigierte verschiedene Berner Chöre und die wichtigsten Aufführungen seiner Werke fanden in Bern statt, zum Beispiel die Uraufführung seiner Oper Leonce und Lena nach Georg Büchner (2004). Seit einigen Jahren ist Henking auch als Fotograf erfolgreich tätig. 2010 gehörte er als künstlerischer Berater zu den Gründungsmitgliedern des Ensemble Proton, des Berner Ensembles für zeitgenössische Musik. Für das Walser-Projekt von 2011 komponierte Henking im Auftrag des Musikfestivals Bern den Zyklus Keine Zeit ist zeitig mit der Sehnsucht Zeit (im Folgenden Keine Zeit genannt). ${ }^{150}$

Henking hat mit Keine Zeit einen eigentlichen Walser-Kosmos geschaffen. Aus 21 Texten collagierte er eine Art Libretto. Nur fünf Gedichte werden integral vertont, aber auch diese gehen ineinander über. Allerdings hat Henking einen rigiden Kompositionsplan entworfen: Das Werk besteht aus 20 Abschnitten, die manchmal von Zwischenspielen getrennt werden. Diese 20 Abschnitte sind in sechs symmetrisch angelegte Teile geordnet, die vier Topoi oder >Grundorte< von Walser anzeigen. Innerhalb dieser Grobstruktur ist jeder der 20 Abschnitte zudem anders instrumentiert; Tutti-Stellen gibt es nur zu Beginn und in den Zwischenspielen:

\begin{tabular}{|c|c|c|}
\hline $\mathrm{Zu}$ Hause [1] & $(1-2)$ & Lupophon, Kontraforte, Harfe \\
\hline Wanderung & $(3-5)$ & Flöte, Lupophon, Kontraforte, (Violine), Cello, Klavier \\
\hline Rast [1] & $(6-9)$ & $\begin{array}{l}\text { Flöte, Lupophon, Kontraforte, (Violine), Cello, Harfe, } \\
\text { Klavier }\end{array}$ \\
\hline Rast [2] & $(10-14)$ & Violine, Cello, Harfe $\mathrm{e}^{151}$ \\
\hline Aufbruch & $\left(15^{-16)}\right.$ & Lupophon, Violine, Cello, Klavier \\
\hline $\mathrm{Zu}$ Hause [2] & $(17-20)$ & Flöte, Kontraforte, Violine, Cello, Harfe, Klavier \\
\hline
\end{tabular}

149 E-Mail von Christian Henking an Roman Brotbeck vom 19.10.2020.

15 O Vgl. die Aufnahme des Werks: Henking: Keine Zeit ist zeitig mit der Sehnsucht Zeit (2012). Der Titel der Komposition entstammt Walsers Gedicht Zeit (SW 13, 31f.).

$15^{1}$ Beim Abschnitt 14 gibt es eine Ausnahme: Im Sinne eines Übergangs setzt die Harfe hier aus und das Lupophon dafür schon ein. 
Ähnlich wie Benjamin Schweitzer in seiner Kammeroper Jakob von Gunten differenziert Henking zusätzlich die Rolle und Funktion der Instrumente. Es gibt je Abschnitt »Hauptinstrumente « sowie »Ergänzungsinstrumente « und in sieben Abschnitten auch »Gegeninstrumente «.

Speziell an Keine Zeit sind die neuentwickelten tiefen Blasinstrumente Lupophon und Kontraforte, die 2010 auf den Markt gelangten und hier erstmals als Bass-Duo eingesetzt wurden; sie verleihen dem gesamten Werk einen tiefen und magischen Grundklang.

Das Lupophon ist nach seinem Erfinder Guntram Wolf (lupo = italienisch: Wolf) benannt; der Oboist des Ensemble Proton, Martin Bliggenstorfer hat diese 2010 neukonstruierte Bassoboe im Frühjahr 2011 in Amsterdam eingeweiht. ${ }^{152}$ Das Lupophon erreicht eine Tiefe bis $F$, liegt also eine große Terz tiefer als das Heckelphon und weist im Vergleich zu diesem eine höhere dynamische Kraft und klangliche Abrundung auf. Im gleichen Jahr brachte die Firma Guntram Wolf aus Kronach auch das 2001 zusammen mit Benedict Eppelheim aus München entwickelte Kontraforte auf den Markt, ein ParallelInstrument zum Kontrafagott, das sich durch eine enorme dynamische Spannweite und einen runden und sich mit anderen Instrumenten gut mischenden Klang auszeichnet. Das Näselnde und Sirrende des Kontrafagotts fehlt dem Kontraforte. In der Gründungsbesetzung des Ensemble Proton spielte der Fagottist Lucas Rössner das Kontraforte; er setzt sich seither stark für dieses Instrument ein. ${ }^{153}$

Christian Henking unterscheidet in den zwanzig Teilen nicht nur vier Topoi, sondern auch vier Konstellationen zwischen Mezzosopran und Bariton: Bariton allein (acht Abschnitte), Mezzosopran allein (vier Abschnitte), Duos von Mezzosopran und Bass (fünf Abschnitte) und als Besonderheit Duos, bei denen die Mezzosopranistin im Hintergrund und wie eine zweite Seele den Bariton ergänzt (drei Abschnitte). Hinzu kommt ein eigenes System von Taktarten, Tempoverläufen, Taktzahlen und Abschnittsbildungen.

Mit diesen zahlreichen Vorgaben und Eingrenzungen, die vor allem großformal wirksam sind, schafft sich Henking in gewisser Weise die $>$ Freiheit<, die es ihm erlaubt, Lokalstrukturen zu entwickeln und gleichsam in jedem Moment kompositorisch auf Walsers Texte zu reagieren. Schon im Libretto-Konzept ist angelegt, dass Henking nicht einzelne geschlossene Gedichte in ihrer von Walser konzipierten Form vertont, sondern vielmehr einen Assoziationsfluss anstrebt, bei dem sich Bezüge über die einzelnen Texte hinweg ergeben.

152 Vgl. Mühlemann: Langes Rohr mit dicker Nase, S. 32.
153 Vgl. Meier: Magische Tieftöner aus der Wolfswelt, S. 28 


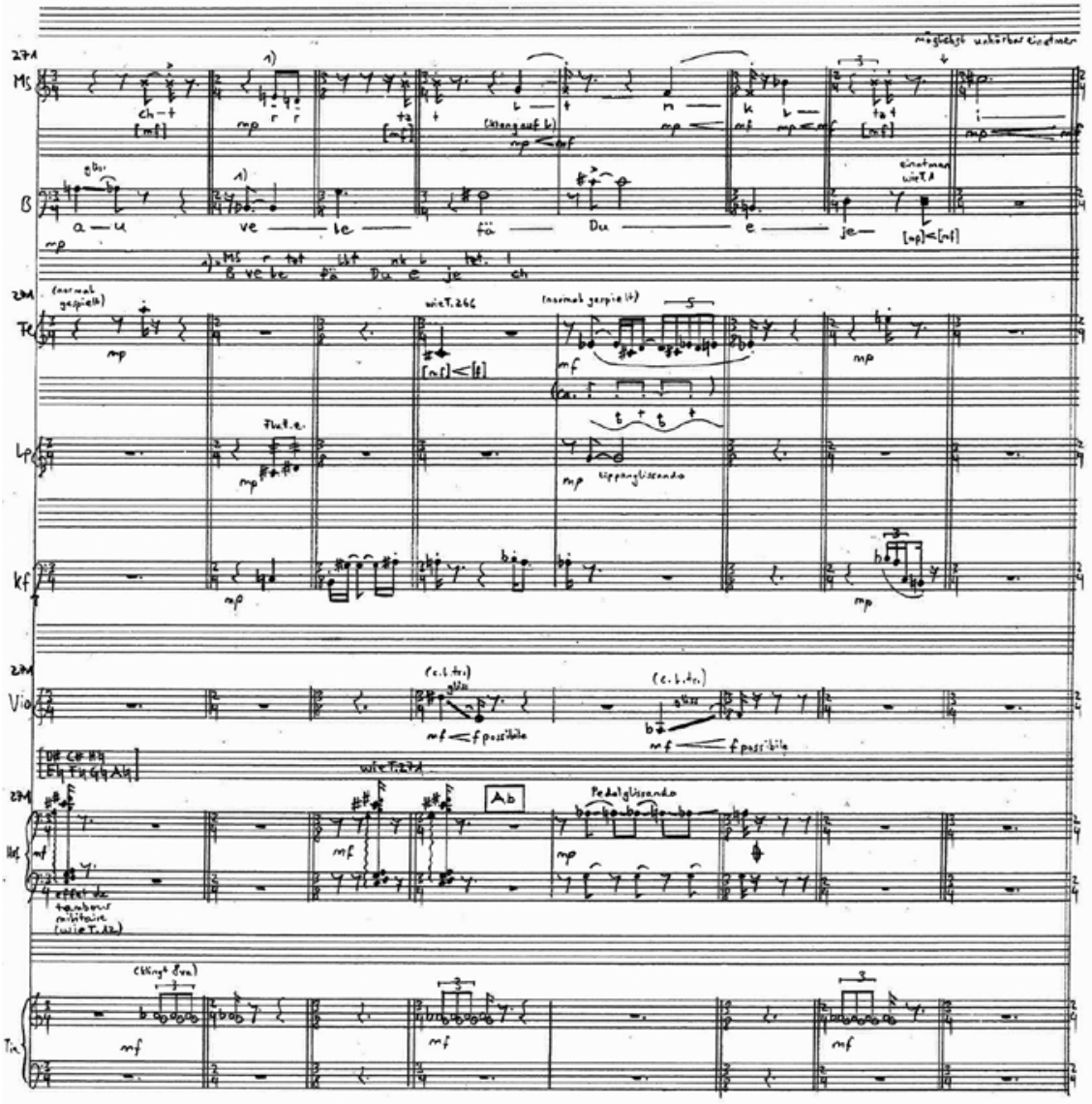

Abb. 89 Christian Henking: Keine Zeit ist zeitig mit der Sehnsucht Zeit, S. 5 of. 
(51)

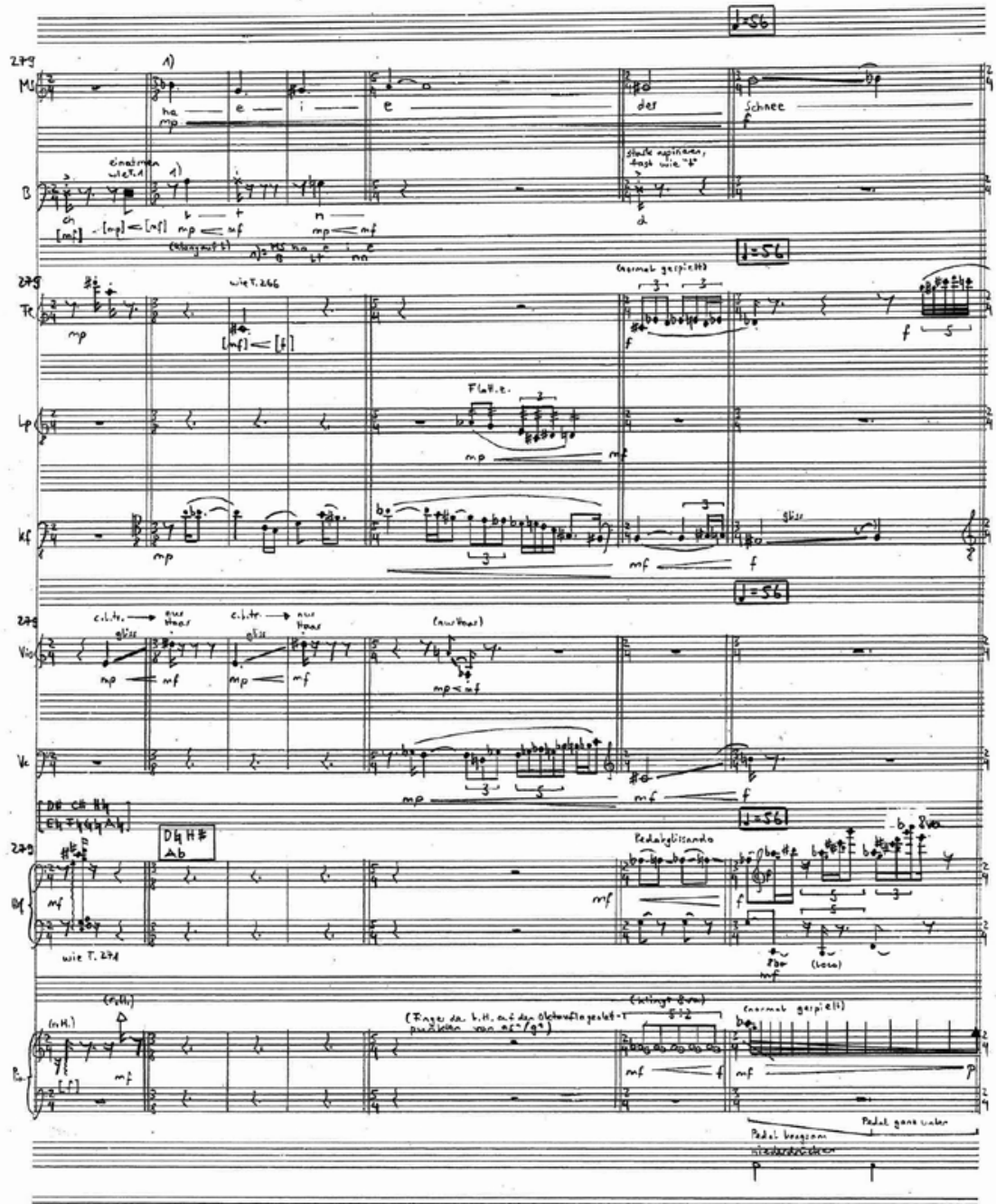


Das betrifft selbst jene Partie (Abschnitte 3-7), in der Henking hintereinander fünf Gedichte integral vertont. Die Partiturseiten 50 und 51 zeigen den Übergang von Auf meine Sinne (SW 13, 45) zu Der Schnee (SW 13, 147) (vgl. Abb. 89). ${ }^{154}$ Die beiden Gedichte stoßen direkt aneinander, sodass auch eine inhaltliche Verbindung entsteht, weil Der Schnee als eine Art Fortführung des Gedankens des Innehaltens am Schluss von Auf meine Sinne erscheint (kursiv gesetzter Text ist in Abbildung 89 enthalten), zitiert nach der Partitur:

Auf meine Sinne, / mißbraucht, verletzt / fällt Dunkel jetzt. / Ich halte inne /// der Schnee fällt nicht hinauf / sondern nimmt seinen Lauf / hinab und bleibt hier liegen, / noch nie ist er gestiegen.

Die Deklamation ist aufgetrennt: Die Männerstimme singt die Vokale, die Frauenstimme die Konsonanten, deren Tonhöhen fixiert sind, wenn es sich um stimmhafte Konsonanten handelt. Die Wörter »mißbraucht« und »verletzt« werden mit dieser Technik autoreflexiv >missbraucht $<$ und >verletzt $<$ vertont.

Überraschenderweise werden bei »ich«(T. 278) die Rollen vertauscht: Nun singt die Frau die Vokale und der Mann die Konsonanten. Den Umschlagpunkt bildet das hörbare und hier als Exklamation des Erstickens oder der Luftnot wirkende Einatmen des Baritons in Takt 277. ${ }^{155}$ Das Werk beginnt bereits mit einem solchen, dort aber gemeinsamen, Luftholen von Sängerin und Sänger. Solch stimmhaftes Einatmen ähnelt einem nach innen gezogenen »ich«, so auch hier bei Takt 277; die Sängerin kehrt es im folgenden Takt mit »i[ch]« nach außen. Bei der Mezzosopranistin steht an dieser Stelle »möglichst unhörbar einatmen«, um dem Rollenwechsel etwas Magisches zu geben. In den Takten 279 und 280 hören wir noch einmal ein solches >Ein- und Ausatmen< beim Wort »halte «: Der Bariton zieht ein asthmatisches »h« nach innen, die Mezzosopranistin singt es gleich anschließend nach außen.

Bruchlos führt die Sängerin dann (T. 284) in den nächsten Abschnitt Der Schnee.

Das hier dargelegte Ineinander der Stimmen lässt sich auf die organisch gestaltete Instrumentalbegleitung übertragen. Diese ist - ähnlich wie bei

154 Vorausgegangen und durch ein instrumentales Zwischenspiel (Tutti) deutlich getrennt ist Alles Nacht (SW 13, 37f.) für Mezzosopran allein. Auf die strengen Vorgaben in Walsers Gedicht (vgl. die Ausführungen zu Alles Nacht bei Daniel Andres) geht Henking nur ansatzweise ein, zum Beispiel werden die Repetitionswörter »Nacht« und »Tag« mit der Musik variiert und meist anders vertont. Er hält sich in der Deklamation an die syntaktische Struktur, die bei Walser eigentlich nur ein Hilfsgerüst ist, um die homonyme Erstarrung von »Tag« und »Nacht« zu realisieren.

155 Das Einatmen ist mit einem quadratischen Notenkopf notiert. In Takt 1 schreibt der Komponist dazu: »einatmen (ev. Luft leicht durch die Zähne ziehen)«. 
Schönbergs Pierrot lunaire - auf ständige Wortausdeutung und klangliche Verbindungen angelegt. Eine Überausdeutung der Worte entsteht dann, wenn gewisse Begriffe wörtlich genommen und aus dem Sinnkontext herausgelöst werden; es erinnert an Holligers Verfahren bei Schneewittchen.

\subsection{Christophe Schiess: Hibernation (2011/12) und »... hinaus in die Winternacht.«(2013/14)}

Das Werk Hibernation schrieb der in Biel geborene und seit 2010 wieder dort lebende Westschweizer Komponist Christophe Schiess (*1974) für das Ensemble Phoenix Basel. Es ist ein reines Instrumentalwerk für eine mit Bratsche erweiterte Pierrot-lunaire-Besetzung, allerdings mit der Kontrabassklarinette statt der Bassklarinette als Parallelinstrument. Zwar gibt es in der Partitur keinen Bezug zu Robert Walser, und selbst der Titel Hibernation (Winterschlaf), auf den im Programmheft der Uraufführung mit einem abgebildeten Murmeltier unmissverständlich hingewiesen wurde, lässt sich nicht auf Walser beziehen. Zwei Jahre später deklarierte Christophe Schiess Hibernation allerdings als ein mögliches Vorwerk $\mathrm{zu}$ »... hinaus in die Winternacht.« für Sopran und die gleiche Pierrot-lunaire-Besetzung, erweitert mit einer Harfe. ${ }^{156}$ Schon auf dem Titelblatt steht: »peut être immédiatement précédé du sextuor >Hibernation< (2011-2012)《. Dadurch wurde Hibernation nachträglich in einen expliziten Walser-Kontext gebracht. Tatsächlich passen die beiden Werke in ihrer Klangsinnlichkeit und vor allem in der extensiven Verwendung verschiedenster Mikrotöne gut zusammen. Man hört deutlich, dass Christophe Schiess bei zwei musikalischen Alchemisten studiert hat, einerseits beim Mikrotonspezialisten Georg Friedrich Haas, andererseits bei Roland Moser, dessen Kompositionen oft in komplexen Kontext-Geflechten mit zahlreichen Anspielungen an die Literatur-, Musik- und Kunstgeschichte stehen. Solche Anspielungen gibt es auch bei Christophe Schiess: Ein Motiv sind die Schritte im Schnee, die durch die Radierung, die Karl Walser für die Gedichtausgabe von 1909 schuf, zu einer Robert Walser-Ikone geworden sind, weil sie die Schritte auf den Polizeifotos anlässlich seines Todes ikonografisch vorwegnehmen.

Christophe Schiess spielt an diese Schritte in Hibernation mit einem zweimaligen Zitat aus Des pas sur la neige, das sechste Stück aus dem ersten Band

${ }_{15}$ Der auffällige Punkt im Titel verweist auf den Schluss des Romans Geschwister Tanner. 
der Préludes von Claude Debussy, an. ${ }^{157}$ »Triste et lent« ist die Spielanweisung, und zum schreitenden Motiv merkt Debussy an: »Ce rythme doit avoir la valeur sonore d'un fond de paysage triste et glacé«. 158

Die Noten dieser Komposition könnte Robert Walser in den Händen gehabt haben. Mindestens lässt eine Stelle in den Briefen an die junge Leserin Therese Breitbach, der Walser zwischen 1925 und 1932 zwanzig Briefe schrieb, ${ }^{159}$ diese Spekulation zu. Walser schreibt am 15. Januar 1926: »Vielen Dank, mein Fräulein, für die Übersendung der Schneekomposition, von der ich als Nichtmusiker selbstverständlich nichts verstehe.« (BA 2, 181)

Therese Breitbach und ihr frankophiler Bruder Joseph, die beide mit Robert Walser korrespondierten, könnten in den 192oer-Jahren, in denen Debussy und Ravel das französische Musikleben dominierten, dem melancholischen Prélude begegnet sein oder dieses sogar selbst gespielt haben. Weil die Gegenbriefe von Therese Breitbach fehlen, ist das allerdings nicht zu belegen. Walsers Bemerkung, dass er davon als »Nicht-Musiker selbstverständlich nichts verstehe«, ist ein wenig zu relativieren. Es gibt - auf eine Anfrage von Carl Seelig, der an einer Biografie zu Walser arbeitete - einen entsprechenden Hinweis von Fanny Walser:

Robert musste, wie alle Walser-Geschwister, in den Jugend-Jahren Klavierstunden nehmen. Von Componieren war gar nicht die Rede. Keine besondere Begabung zur ausübenden Musik. ${ }^{160}$

Robert Walser konnte also mindestens Noten lesen; Fanny Walsers Hinweis auf die mangelnde pianistische Begabung ihres Bruders gibt dessen Spotten aufs Klavierspiel auch eine autobiografische Komponente.

Während die Debussy-Zitate in Hibernation nur als Assonanzen wahrgenommen werden, wird in Winternacht eine ganze Partie mit Wilhelm Müllers Gedicht Erstarrung, dem vierten Lied aus Franz Schuberts Winterreise, gestaltet. Müllers Text beginnt ebenfalls mit Schritten im Schnee: »Ich such' im Schnee vergebens / Nach ihrer Tritte Spur «. Christophe Schiess übernimmt das Liedmaterial von Schubert in der Singstimme und der Klavierbegleitung fast wörtlich, und es wird beim Hören sofort als offensichtliches

157 E-Mail von Christophe Schiess an Roman Brotbeck vom 28.05.2016: »>des pas sur la neige< sont cités deux fois: aux mes. 22/23 (piano) (ce qui va générer le >réveil dès la page suivante), et aussi au plus profond du sommeil (l'accord au début de la mes. 81)«.

158 Debussy: Préludes, S. 22f.

159 Vgl. Stocker: Adressierungsambivalenzen.

16o Fanny Walser: Brief-Beilage an Carl Seelig (26.og.1958). Ich danke Gelgia Caviezel herzlich für diesen Hinweis. 
Zitat wahrgenommen. Allerdings berücksichtigt Schiess nur jene Verse, die keinen Hinweis auf die verlassene Liebe enthalten, vielmehr interessiert ihn das Blütenmotiv, das chiastisch den Schnee- und Winterbildern gegenübergestellt wird. »Wo find' ich eine Blüthe, / Wo find' ich grünes Gras? [...] Soll denn kein Angedenken / Ich nehmen mit von hier? / Wenn meine Schmerzen schweigen « ${ }^{161}$ Von Walser selbst wählte er Texte einerseits aus Winter, wo Blumen und Eis verbunden sind: »Unter dem Eise wuchsen Frühlingsblumen« (SW 16, 375), andererseits aus dem Roman Geschwister Tanner (SW 9, 101, 332), mit dessen Schluss er Winternacht beendet. Dieser >vereisten $<$ Walser/SchubertWelt stellt Schiess zwei >brennende< Kontrapunkte gegenüber, nämlich zwei Gedichte aus der ersten Gedichtsammlung Soledad des spanischen Lyrikers Antonio Machado (1875-1939), eines Zeitgenossen Walsers. Was Schiess beim Schubert-Zitat weggelassen hat, die Erinnerung an eine verlorene Liebe, ist in den Machado-Gedichten omnipräsent: Im Prolog von Winternacht wird einer einstigen Liebe in der Hitze der starren Sonne (»sol yerto «) gedacht, ${ }^{162}$ der Mittelteil besteht aus einer Vertonung des Gedichts Crepúsculo, das später von Machado in die Neuauflagen nicht mehr aufgenommen wurde ${ }^{163}$ und deshalb bei den Obras Completas unter die Poesías sueltas eingeordnet ist. Es ist die glühende Gegenwelt: Das weibliche lyrische Ich geht an einem heißen Sommernachmittag los, um hinter den blauen Bergen die bittere Myrrhe einer weit zurückliegenden Liebe zu verbrennen (»la mirra amarga de un amor lejano«). Zum Schluss wandert das lyrische Ich verstummt, umhüllt von Staub und Sonne (»Y muda caminaba, en polvo y sol envuelta «), während der Sommer seinen purpurnen Weihrauch verbrennt (»mientras quemaba / sus inciensos de púpura el verano«). ${ }^{164}$

Für die Machado-Teile wählt Christophe Schiess eine einfache und direkte Vertonungstechnik, bei der die Sängerin mehr rezitiert als singt und die Begleitung wie ein zurückhaltendes Continuo wirkt, mit Liegeklängen und Repetitionsfiguren. Crepúsculo ist wie ein Feuer gestaltet, das leise zu glühen beginnt, kurz auflodert und zu Asche verglimmt. ${ }^{165}$

Die Walser-Partien heben sich davon mit gläsernen, hohen und höchsten Klängen ab. Sie weisen eine reiche Palette an Mikrotönen auf, die akustische Spezialeffekte ermöglichen. Man könnte es als harmonisch-klangfarbliche $>$ Molekularkücheく bezeichnen, denn Schiess erzielt mit extremer Effizienz

\footnotetext{
161 Müller: Gedichte, S. 81f.

162 Machado: Soledades XXXIII. In: Obras completas, S. 34.

163 Vgl. Manso: Todos los fuegos del crepúsculo, S. 741.

164 Machado: Obras completas, S. 33of.

1652014 hat Chistophe Schiess Crepúsculo von Machado in Once estaciones ein zweites Mal in ähnlichem Gestus vertont.
} 
unglaubliche Wirkungen; so verändert er mit nur sieben um einen Viertelton vertieften Saiten der Harfe die Harmonik komplett. Mit vielen Intervall- und Proportionsrechnungen nun diese Aggregate im Detail zu erklären, würde den Eindruck eines physikalischen Klanglabors hinterlassen. Wichtiger sind die Entwicklungsbögen, die Schiess über die zusammen mit Hibernation 25 Minuten dauernde Komposition spannt. Das ist mitreißende Musik, auch dann, wenn sie stillsteht, wie am Schluss: Nach dem Schubert-Zitat friert die Stimme der Sängerin auf der Tonhöhe $h^{1}$ ein, während nun die erwähnten sieben Töne der Harfe die Musik in eine fremde Welt führen: »hinaus in die Winternacht.«

\title{
11.22 Yonghee Kim: Der Winter und Das Ruheplätzchen (2019)
}

Noch in Korea ist Yonghee Kim ( $\left.{ }^{*} 1982\right)$ in einer Buchhandlung zufälligerweise auf Walsers Jakob von Gunten gestoßen und war vom Roman fasziniert. Nach dem Bachelor-Studium in Komposition an der Korea National University of Arts in Seoul bei Byung-Eun Yoo, einem koreanischen Komponisten, der sich für die Verbindung von koreanischer Volks- und Kunstmusik mit den westlichen Musiksprachen interessiert, kam die Komponistin nach Europa, um an der Universität der Künste Berlin bei Walter Zimmermann ${ }^{166}$ das Kompositionsstudium fortzusetzen und 2015 mit einem Master abzuschließen. In Berlin, wo Kim heute lebt, setzte sie ihre Lektüre von Walser-Texten fort.

\begin{abstract}
Was mich an seinen Dichtungen fasziniert, ist die transparente und klare poetische Ausdrucksweise und die Stimmungen. Weder pedantisch noch belehrend, vielmehr wie ein Monolog, der in klaren und kindlich-unschuldig wirkenden Bildern seine innersten Gedanken enthüllt. Schlicht und transparent sind für mich die meisten seiner Dichtungen. ${ }^{167}$
\end{abstract}

In der 2019 entstandenen Komposition für Sopran und Streichquartett verwendet Yonghee Kim zwei Texte aus dem 2005 von Bernhard Echte edierten Bändchen Feuer mit bis dahin unbekannter Prosa und Lyrik. Die beiden Texte bilden eine kompositorische Einheit, wobei das deutlich kürzere Das Ruheplätzchen (FEUER, 102) wie ein heiterer Epilog wirkt. »Mit den Streichern des

\footnotetext{
166 Walter Zimmermann hat mich dankenswerterweise auf die Komponistin Yonghee Kim aufmerksam gemacht.

167 E-Mail von Yonghee Kim an Roman Brotbeck vom 19.11.2020.
} 
Streichquartetts konnte ich vielfältige, subtile Klänge erzeugen, die mit der Stimmung von Walsers Gedichten korrespondieren.«168

Das Streichquartett muss bei Yonghee Kim - ähnlich wie in Ruedi Häusermanns drei Walser-Produktionen - keine polyphone Kontrapunktik realisieren, vielmehr schafft es bei Der Winter (FEUER, 104f.) eine Art >Super-Monodie<: Von Beginn an umspielen die Instrumente die Gesangsstimme, wobei sie sich im gleichen Tonraum bewegen (vgl. Abb. 9o). Der Triller auf »Winter« in Takt 2 wird von der ersten Violine mit einem Vibrato und ebenfalls auf $g^{1}$ imitiert; die zweite Violine spielt das $g$ mit dem Bogenholz, die Bratsche streicht es ordinario, aber um einen Viertelton vertieft, und das Violoncello realisiert denselben Ton als Flageolett auf der G-Seite - vier verschiedene Begleittöne, die sich zu Klangmixturen mischen. Nach diesem Prinzip des Umspielens, der geräuschhaften Verfärbung, mikrointervallischen Differenzierung und rhythmischen Verwischung der Gesangsstimme sind beide Stücke komponiert. Das ist nicht nur impressionistische Klangkomposition, sondern unterstützt den Text ganz direkt, zum Beispiel in Takt 4, wo die Rhythmik von Walsers Vers durch die Figurationen akzentuiert werden. Kim gibt diesen Umspielungsfiguren keine Richtung, indem sie sie mit Gegenbewegungen gleichsam im Gleichgewicht hält; die Singstimme bleibt das Zentrum.

Es gibt im Stück auch weite Intervallsprünge. Damit hebt Yonghee Kim Stilbrüche oder Ironisches hervor, und zwar genauso `naiv<, wie es Walser tut.

Walsers den Winter entzauberndes »das Schnupftuch wird häufiger gebraucht als sonst « vertont sie mit einer einfachen, kinderliedähnlichen aufund absteigenden Tonleiter: $e-f-g-a-g-f-e-d$. Allerdings oktaviert sie vier der Töne, was zu übertriebenen und falschen Betonungen führt, welche die schnäuzenden Folgen von Walsers Schnee-Idyll gewitzt verdeutlichen. Die fett gesetzten Silben sind oktaviert.

Schnupf- $\left[e^{I}\right]$ tuch $\left[f^{2}\right]$ wird $\left[g^{l}\right]$ häu- $\left[a^{2}\right]$ fi- $\left[g^{I}\right]$ ger $\left[f^{2}\right]$ ge- $\left[e^{l}\right]$ braucht $\left[d^{l}\right]$ als $\left[e^{2}\right]$ sonst $\left[d^{l}\right]$.

Während in den meisten Walser-Vertonungen die Instrumente als Gegenstimmen zum Gesang auftreten oder eine eigenständige Harmonik entwickeln, ist Kims origineller Ansatz jener eines entfächerten Unisono oder besser >Multisono<, bei dem vier Beteiligte der Gesangsstimme zudienen, sie differenzieren, bestätigen, sie mitziehen im Sinne einer vervielfachten Ich-Fiktion.

168 Ebd. 


\section{DerWinter}

für Sopran und Streichquartett nach dem Gedicht "Der Winter" von Robert Walser
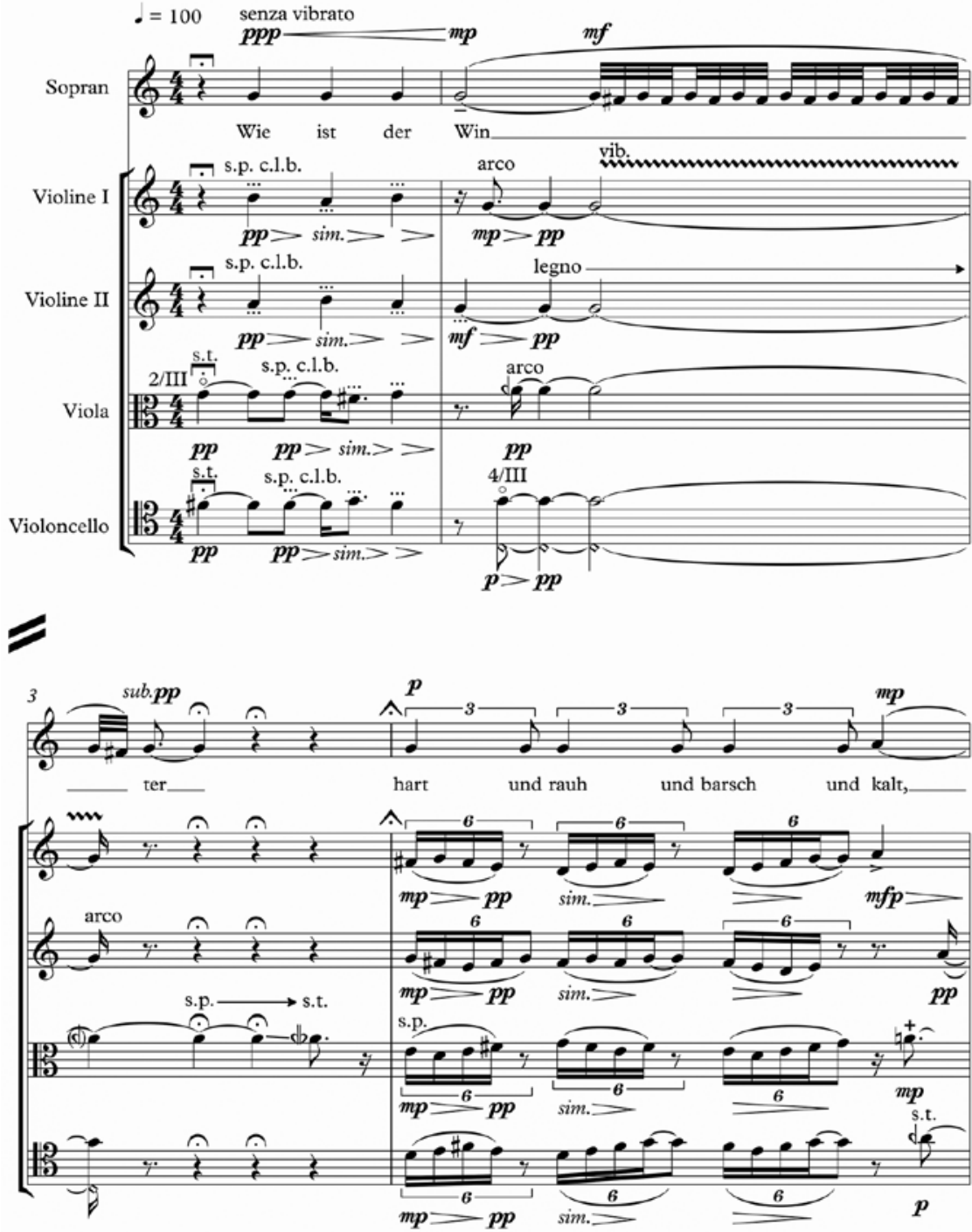

Abb. $90 \quad$ Yonghee Kim: Der Winter, S. 1 
Das Ruheplätzchen ist ähnlich angelegt, hier aber dominiert das aparthumorvolle und leichte Fach, was durch die zahlreichen Miniaturisierungen und eine nervös-ziselierte Rhythmik verdeutlicht wird.

Der Winter und Das Ruheplätzchen von Yonghee Kim unterstreichen die Internationalität, die Walser heute erfährt. Neben Ezko Kikoutchi (vgl. Kap. 8.6.4) und Eunshin Jung (vgl. Kap. 12.7) ist Kim die dritte Walser-Komponistin aus einem ostasiatischen Land, die den Schweizer Dichter in neue Kontexte stellt. 